San Jose State University

SJSU ScholarWorks

Master's Theses

Master's Theses and Graduate Research

Summer 2010

\title{
Interspecific Variation In Morphology And Swimming \\ Performance Within Surfperches (Embiotocidae) From California
}

Benjamin Michael Perlman

San Jose State University

Follow this and additional works at: https://scholarworks.sjsu.edu/etd_theses

\section{Recommended Citation}

Perlman, Benjamin Michael, "Interspecific Variation In Morphology And Swimming Performance Within Surfperches (Embiotocidae) From California" (2010). Master's Theses. 3825.

DOI: https://doi.org/10.31979/etd.enek-gdd6

https://scholarworks.sjsu.edu/etd_theses/3825

This Thesis is brought to you for free and open access by the Master's Theses and Graduate Research at SJSU ScholarWorks. It has been accepted for inclusion in Master's Theses by an authorized administrator of SJSU ScholarWorks. For more information, please contact scholarworks@sjsu.edu. 


\title{
INTERSPECIFIC VARIATION IN MORPHOLOGY AND SWIMMING PERFORMANCE WITHIN SURFPERCHES (EMBIOTOCIDAE) FROM \\ CALIFORNIA
}

\author{
A Thesis \\ Presented to \\ The Faculty of Moss Landing Marine Laboratories \\ and the Department of Marine Sciences \\ San José State University \\ In Partial Fulfillment \\ of the Requirements for the Degree \\ Master of Science
}

by

Benjamin Michael Perlman

August 2010 
(C) 2010

Benjamin Michael Perlman

ALL RIGHTS RESERVED 
The Designated Thesis Committee Approves the Thesis Titled INTERSPECIFIC VARIATION IN MORPHOLOGY AND SWIMMING PERFORMANCE WITHIN SURFPERCHES (EMBIOTOCIDAE) FROM CALIFORNIA
by
Benjamin Michael Perlman
APPROVED FOR THE DEPARTMENT OF MARINE SCIENCES
SAN JOSÉ STATE UNIVERSITY
August 2010
Dr. Gregor M. Cailliet, Emeritus
Department of Marine Sciences (Fresno State)
Dr. Michael H. Graham
Department of Marine Sciences
Dr. Lara A. Ferry-Graham
Department of Marine Sciences 


\begin{abstract}
INTERSPECIFIC VARIATION IN MORPHOLOGY AND SWIMMING PERFORMANCE WITHIN SURFPERCHES (EMBIOTOCIDAE) FROM CALIFORNIA
\end{abstract}

By Benjamin Michael Perlman

Surfperches are marine fishes that occupy nearshore habitats along the California coast. Morphology was analyzed to determine if there were differences among 19 preserved species. Principal components analysis (PCA) was used to reduce the dimensionality of the data. Morphological differences occurred among the 19 species. ANOVA revealed a habitat effect on PC2, which described the angle of attachment of the pectoral fin. Pearson correlation revealed that genetic relatedness decreased with increasing morphological differences on PC1, which described aspect ratio and body ratio. Based on PC2, four species were selected to conduct experiments on their swimming performance. $\mathrm{U}_{\text {crit }}$ and fin beat frequency were measured in a flume to assess speed; flexibility was assessed via the body bending coefficient and the C-start escape response. Species differences were observed in all swimming performance variables, yet there were no tradeoffs in swimming fast versus maneuverability. Morphology seems to describe only part of the story. 


\section{ACKNOWLEDGEMENTS}

I would like to thank my advisor Dr. Lara Ferry-Graham for her guidance and intellectual support throughout my tenure at Moss Landing Marine Labs. I would also like to thank the rest of my thesis committee, Dr. Gregor Cailliet and Dr. Michael Graham, for their professional assistance regarding field and laboratory work, along with many conversations about statistics, life, or anything else. I especially want to acknowledge the Ecomorphology lab, Ichthyology lab, and BEERPIGs for their tremendous support with field and lab work, listening to practice talks, and always being a great sounding board. Dave Catania at the California Academy of Sciences assisted me with obtaining preserved specimens from the Ichthyology collections and Dr. Giacomo Bernardi shared his phylogenetic data with me. Joe Welsh and Manny Ezcurra from the Monterey Bay Aquarium assisted with field help and husbandry issues for surfperches. Christina Slager from Aquarium of the Bay donated a pile surfperch for the swimming performance experiments. Larry Young of SJSU helped me with the IACUC reports. This study was supported by funds from the Signe Lundstrom Memorial Scholarship, Packard Research and Travel Award, C.F. and L.V. Burmahln Scholarship, and NSF Grant CAA-0641286 to Dr. Lara Ferry-Graham. I would also like to acknowledge the many students who assisted me in the field collecting fishes and in the laboratory. Thanks to my friends and family who supported me throughout my time here at MLML. I dedicate this thesis to all of you! 


\section{PREFACE}

The journal articles were written and formatted according to the publication guidelines for the Journal of Morphology. 


\section{TABLE OF CONTENTS}

Page

List of Tables $\quad$................................. ix

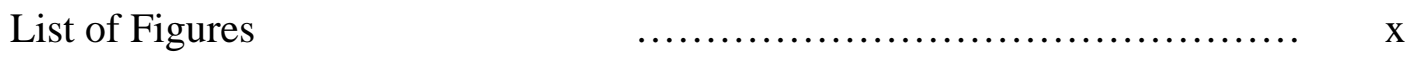

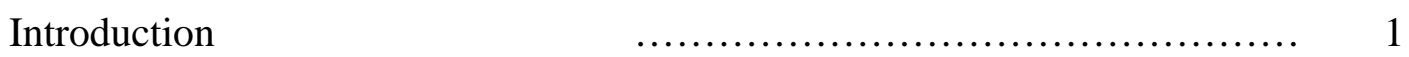

Chapter 1: Interspecific variation in fin and body morphology within surfperches (Embiotocidae) from California
Abstract
Introduction
Materials and Methods
Results
Discussion
Acknowledgements
Literature Cited
25

Chapter 2: Swimming performance, as indicated by $\mathrm{U}_{\text {crit }}$ and stage 1 of the

C-start escape response, in surfperches (Embiotocidae)

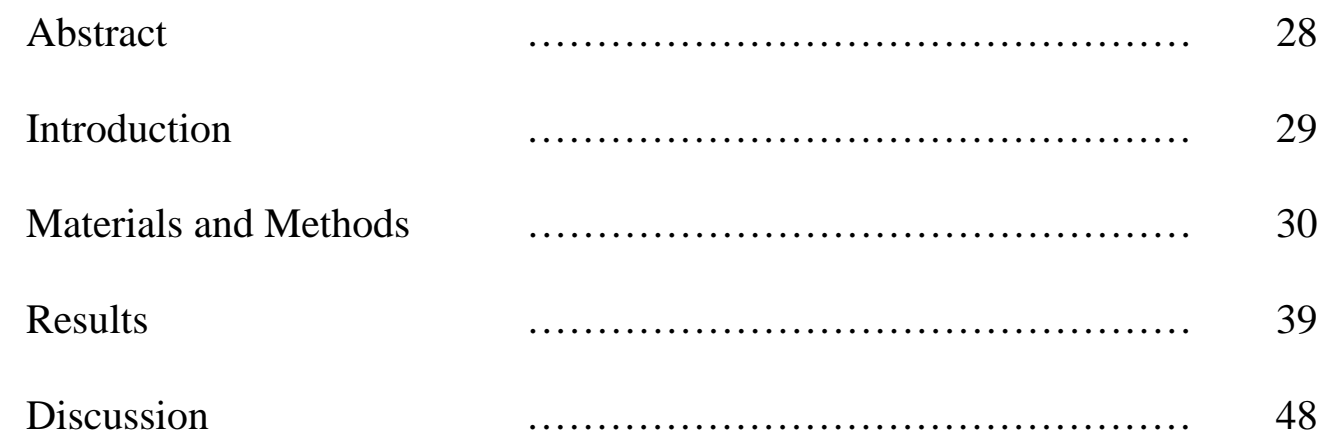


Chapter 3: The C-start escape response in four species of surfperches (Embiotocidae) from central California

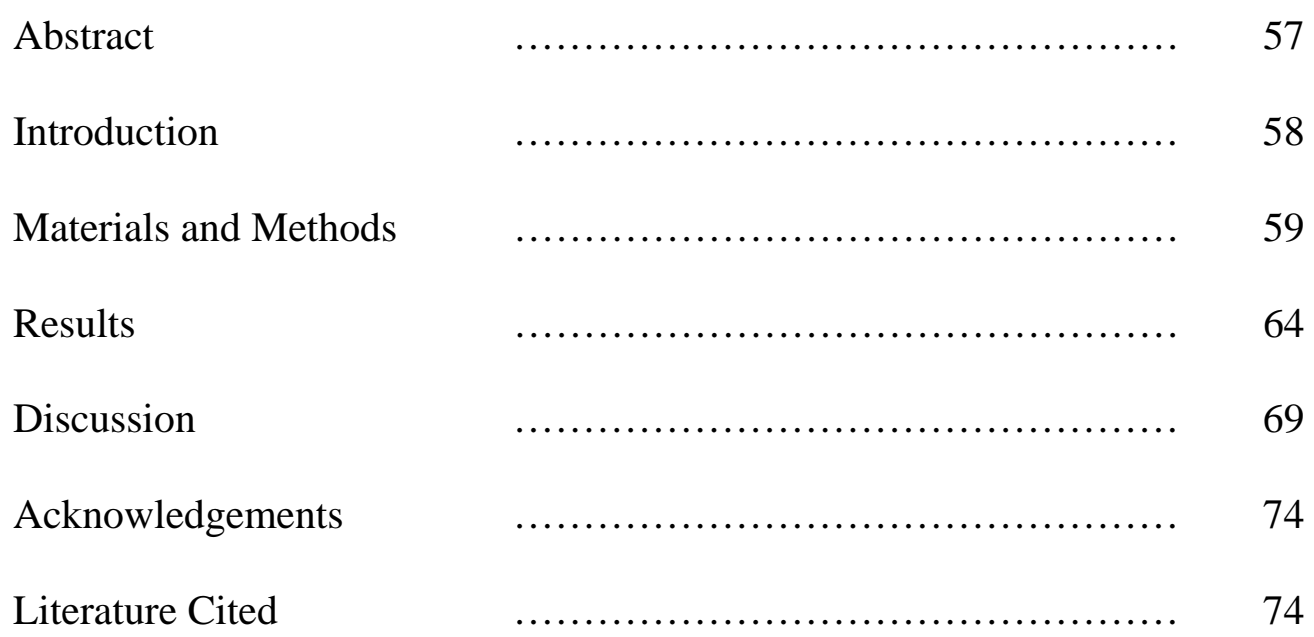

Conclusion $\quad$.................................. 77

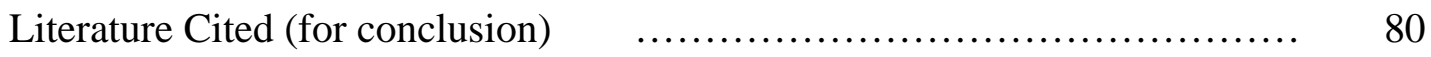
Appendices
A. Chapter 1
B. Chapter 2
83
C. Chapter 3
85 


\section{LIST OF TABLES}

Table 1.1 Common habitat associations for California embiotocid species. $\quad 9$

Table 1.2 Means \pm SD of four morphometric variables from 19 species of $\quad 11$ preserved surfperches from the California Academy of Sciences.

Table 1.3 Loadings of the principal components (PC).

Table 1.4 Results of PC1 LSD post hoc test with species as the main effect. 15

Table 1.5 Results of PC2 LSD post hoc test with species as the main effect. 17

Table 1.6 Results of PC2 LSD post hoc test with habitat as the main effect. 20

Table 2.1 Pearson correlation matrix of swimming performance variables. 39

Table 3.1 Species and morphological variables.

Table 3.2 Mean \pm SE raw data for all variables during the C-start escape $\quad 67$ response.

Table $3.3 \quad$ PCA results.

Table $3.4 \quad$ C-start escape response comparisons among different adult fishes. 73

Table A.1 Preserved specimens from the collections in the Department of 81 Ichthyology, California Academy of Sciences, San Francisco, California. 


\section{LIST OF FIGURES}

Figure 1.1 Four morphometric variables measured on each surfperch specimen using Image $\mathrm{J}$ software.

Figure 1.2A Means \pm standard error (SE) for species effects with PC1 along the $\mathrm{x}$-axis and PC2 along the $\mathrm{y}$-axis.

Figure 1.2B Interpreted axes following Figure 1.2A.

Figure 1.3 Means \pm SE of the average factor scores of PC1 versus the average 20 factor scores of PC2, based on habitat.

Figure 1.4 Genetic distance versus morphological difference for PC1. 21

Figure 1.5 Genetic distance versus morphological difference for PC2. 22

Figure 2.1 Phylogenetic tree of the family Embiotocidae. 32

Figure 2.2 Pectoral fin beat frequency of a black surfperch (Embiotoca jacksoni). 35

Figure 2.3 Measurement of body bending coefficient $(1-(\mathrm{CL} / \mathrm{TL}))$

Figure 2.4 Standardized critical swimming speed $\left(\mathrm{U}_{\text {crit }}\right)$ of four species of $\quad 40$ surfperches versus total body length $(\mathrm{cm})$.

Figure 2.5 Absolute data of critical swimming speed ( $\left.U_{\text {crit }}\right)$ of four different 41 species of surfperches.

Figure 2.6 Standardized $U_{\text {crit }}$ versus pectoral fin angle. $\quad 42$

Figure 2.7 Absolute $U_{\text {crit }}$ versus pectoral fin angle. 42

Figure 2.8 Standardized $U_{\text {crit }}$ versus pectoral fin aspect ratio. 43

Figure 2.9 Absolute $U_{\text {crit }}$ versus pectoral fin aspect ratio.

Figure 2.10 Fin beat frequency at different stages of velocity increments. 45

Figure 2.11 Body bending coefficient versus mean total length $(\mathrm{cm})$. 46

Figure 2.12 Body bending coefficient versus pectoral fin angle. $\quad 47$

Figure 2.13 Body bending coefficient versus pectoral fin aspect ratio. 47 
Figure 3.1 Series of a startle and escape response of a barred surfperch (Amphistichus argenteus).

Figure 3.2 C-start escape response, as modified from Eaton and Emberley (1991).

Figure 3.3A Means \pm SE for C-start escape response effects with PC1 along the $\mathrm{X}$-axis and PC3 along the y-axis.

Figure 3.3B Interpreted axes following Figure 3.3A. 68

Figure 3.4 Mean \pm SE C-start escape response (sec) versus body length $(\mathrm{cm}) . \quad 69$

Figure B.1 Temperature fluctuations in holding tanks. 83

Figure B.2 Temperature fluctuations in the flume. 83

Figure B.3 Fluctuation of dissolved oxygen (mg/L) in the holding tanks. 84

Figure B.4 Fluctuation of dissolved oxygen (mg/L) in the flume. 84

Figure C.1 Mean \pm SE stage 1 duration (sec) versus body length (cm). 85

Figure C.2 Mean \pm SE stage 1 duration (sec) versus pectoral fin angle $\quad 85$ (degrees).

Figure C.3 Mean \pm SE stage 1 duration (sec) versus pectoral fin aspect ratio. 86

Figure C.4 Mean \pm SE stage 1 angle (degrees) versus body length (cm). 86

Figure C.5 Mean \pm SE stage 1 angle (degrees) versus pectoral fin angle 87 (degrees).

Figure C.6 Mean \pm SE stage 1 angle (degrees) versus pectoral fin aspect ratio. 87

Figure C.7 Mean \pm SE stage 2 duration (sec) versus body length (cm). 88

Figure C.8 Mean \pm SE stage 2 duration (sec) versus pectoral fin angle (degrees). 88

Figure C.9 Mean \pm SE stage 2 angle (degrees) versus body length (cm). 89

Figure C.10 Mean \pm SE stage 2 angle (degrees) versus pectoral fin angle $\quad 90$ (degrees). 
Figure C.11 Mean \pm SE C-start escape response (sec) versus pectoral fin angle (degrees).

Figure C.12 Mean \pm SE Escape trajectory angle (degrees) versus body length $(\mathrm{cm})$.

Figure C.13 Mean \pm SE Escape trajectory angle (degrees) versus pectoral fin angle (degrees).

Figure C.14 Mean \pm SE peak angular velocity (deg/s) versus body length $(\mathrm{cm})$.

Figure C.15 Mean \pm SE peak angular velocity (deg/s) versus pectoral fin 93 angle (degrees). 


\section{INTRODUCTION}

Surfperches are a diverse family of marine fishes. These nearshore fishes are viviparous, giving birth to live young (Agassiz, 1853). With the absence of larval dispersal, surfperches display a variety of morphological and physiological features to avoid interspecific competition (Tarp, 1952; DeMartini, 1969). Occupying habitats that include the surf zone, bays and estuaries, and kelp forests, surfperches have succeeded in entering almost every niche of coastal habitat in temperate marine ecosystems of the eastern Pacific (Allen et al., 2006).

With a range of hydrodynamic conditions in each habitat, fin morphology is extremely diverse among the surfperches. They primarily use their pectoral fins for locomotion, which is known as labriform swimming (Breder, 1926). Surfperches that maneuver around a rock, kelp, or another object in a structurally complex habitat at slow speeds have a particular fin morphology. Oar-shaped pectoral fin morphologies are extremely useful for maneuvering, whereas pectoral fins with a long, tapered morphology are useful for slicing through the water with fast velocities such as in the surf zone (Wainwright et al., 2002).

By exploring the morphology of fin and body structures among the members of the family of surfperches, we will be able to better understand how some of these morphological characteristics may group within particular genera of surfperches. Grouping surfperches into their most common habitats may also reveal one type of fin and body morphology to be associated with a certain habitat. One objective of this study is to determine which morphological characteristics vary among species within the 
family, and if those characteristics group with specific habitat associations and phylogeny.

Another objective is to test whether or not differences in morphology of surfperches translate to differences in their physiological abilities. Conducting swimming performance experiments on live specimens will allow us to determine how a particular form fits the function of surfperches. This is more commonly referred to as the ecomorphological paradigm (Liem, 1991). Testing whether or not a potential tradeoff in swimming speed versus maneuverability exists among four species of surfperches will allow us to determine if this paradigm holds true. For example, surfperches that achieve the fastest speeds would theoretically be less maneuverable than surfperches that have the greatest body bending.

Understanding the swimming abilities, as indicated by the critical swimming speed ( $\left.\mathrm{U}_{\text {crit }}\right)$ and the C-start escape response, of surfperches will allow us to determine where tradeoffs in performance occur. These potential tradeoffs may be the reason why some surfperches do not have the capability to fill in certain ecological niches. 


\section{CHAPTER 1: INTERSPECIFIC VARIATION IN FIN AND BODY MORPHOLOGY WITHIN SURFPERCHES (EMBIOTOCIDAE) FROM CALIFORNIA}

\section{ABSTRACT}

Embiotocids are a group of near-shore fishes that overlap considerably in their distributions. As a result, they are thought to partition themselves into relatively welldefined habitats. All embiotocids are labriform swimmers. The question here is whether aspects of their swimming ability, inferred by fin and body morphology, are related to the primary habitat of 19 embiotocid species, determined from a synopsis of multiple habitat use studies. Phylogenetic relatedness was also investigated to determine if morphological differences were correlated with genetic distance. The following variables were measured from flat fins of preserved specimens: angle of the fin base with the long axis of the body, fin length, fin surface area, and aspect ratio of the pectoral and caudal fins $\left(L^{2} / S A\right)$. PCA was conducted to investigate relationships among these variables in terms of habitat, and a Pearson correlation was conducted to determine phylogenetic relationships. For all species, PC1 described the aspect ratio and body ratio, and PC2 described an inverse relationship between pectoral fin aspect ratio. ANOVA performed on these PCs with species as a fixed factor indicated that there were significant differences in fin aspect ratios and angles among species. With habitat as the fixed factor, ANOVA revealed only PC2 to be statistically significant; PC2 exclusively described the pectoral fin angle. Pearson correlation revealed that with increasing morphological differences, as described by PC1, species decreased their genetic 
relatedness. Swimming performance studies were later conducted to quantify aspects of swimming ability among species.

KEY WORDS: embiotocids; labriform; morphology; aspect ratio; body ratio; fin angle

\section{INTRODUCTION}

Surfperches (Embiotocidae) occupy a variety of nearshore habitats that experience a range of oceanographic conditions (Allen et al., 2006). They have extreme overlap in habitat ranges because surfperches are viviparous, meaning that they give birth to fully-developed live young (Agassiz, 1853; Eigenmann, 1894; Tarp, 1952). Thus, surfperches occupy their natal habitat through adulthood with minimal dispersal.

Surfperch habitats include kelp forests, rocky reefs, the rocky intertidal, the surf zone and offshore demersal (DeMartini, 1969; Allen et al., 2006). Presumably to avoid interspecific competition, surfperches undergo intense habitat partitioning (Tarp, 1952; DeMartini, 1969; Hixon, 1980; Holbrook et al., 1985; Ebeling and Laur, 1986; Liem, 1986; Holbrook and Schmitt, 1992; Holbrook et al., 1997; Bernardi, 2005). For example, it would not be unusual to find black surfperches (Embiotoca jacksoni) near the holdfasts in a kelp forest and kelp surfperches (Brachyistius frenatus) in the canopy portions of the same habitat (Tarp, 1952; Allen et al., 2006). Similarly, one typically expects to find species such as barred surfperches (Amphistichus argenteus) in the surf zone and pink surfperches (Zalembius rosaceus) in deeper, calmer waters such as offshore demersal habitats (Tarp, 1952; Allen et al., 2006).

Habitats such as bays and estuaries, the canopy and holdfasts of kelp forests, and the surf zone differ greatly in terms of the forces experienced at each (Allen et al., 2006). 
Calm conditions may be present on one day and then high-energy, wave-swept conditions may be present on the next. Differences in morphology among surfperches may explain how and why surfperches are able to occupy different habitats with changing hydrodynamic regimes. This is more commonly known as the "Ecomorphological Paradigm” (Liem, 1991). The paradigm states that an organism’s morphology should reflect its habit and habitat.

This paradigm led to the hypothesis that embiotocids vary in aspects of their fin and body morphology because they occupy different habitats. The first expectation would be to observe variation in fin and body morphology among species. If so, one would expect that those differences in fin and body morphology would translate to surfperches occupying different habitats. Also, one would expect that surfperches with a different fin and body morphology would have different phylogenetic relationships because they are phenotypically and therefore genetically isolated from one another.

\section{MATERIALS AND METHODS}

Nineteen species of California surfperches were measured from the preserved collection at the California Academy of Sciences in fall 2007 (specimens listed in Appendix A). Three specimens per species were measured for a total of 57 specimens. Each specimen was photographed, with the fish laying flat on a tray and the left side exposed. All fins were fully splayed to make sure that the surface area of the median and paired fins were displayed and completely intact.

Four morphometric variables were analyzed using Image J software (Figure 1). The aspect ratio (AR) of the pectoral fin and caudal fin (length ${ }^{2} /$ surface area) was $^{2}$ 
measured as an indicator of thrust generation and propulsion, where a pectoral fin with a greater aspect ratio is capable of moving greater volumes of water past its body (Wainwright et al., 2002). For example, the high AR pectoral fin of a tuna allows it to cruise through the pelagic oceans. At the opposite extreme, a bluegill sunfish has a low AR pectoral fin, being equipped to maneuver around structures. Body ratio (height/standard length) was measured to indicate body shape, where a high ratio indicates a deep, ovate shape and a low ratio indicates a more elongate, fusiform body shape. Assuming laminar flow over a fish with a deep-bodied shape, the separation point of the boundary layer will cause turbulence to occur over much of the body, causing drag (Vogel, 1994). The separation point of the boundary layer will be pushed farther back along the body of a more streamlined fish, thus reducing the turbulence and drag forces for a fish to reach faster speeds through the water (Vogel, 1994). The angle of attachment of the pectoral fin, relative to the long axis of the body, was measured because it reflects the ratio of lift to drag in thrust generation for the production of forward locomotion. Lower angles are indicative of greater lift generation and, theoretically, more efficient thrust propulsion (Vogel, 1994; Triantafyllou et al., 2000; Walker and Westneat, 2000; Wainwright et al., 2002; Walker and Westneat, 2002; Lauder and Drucker, 2004). 


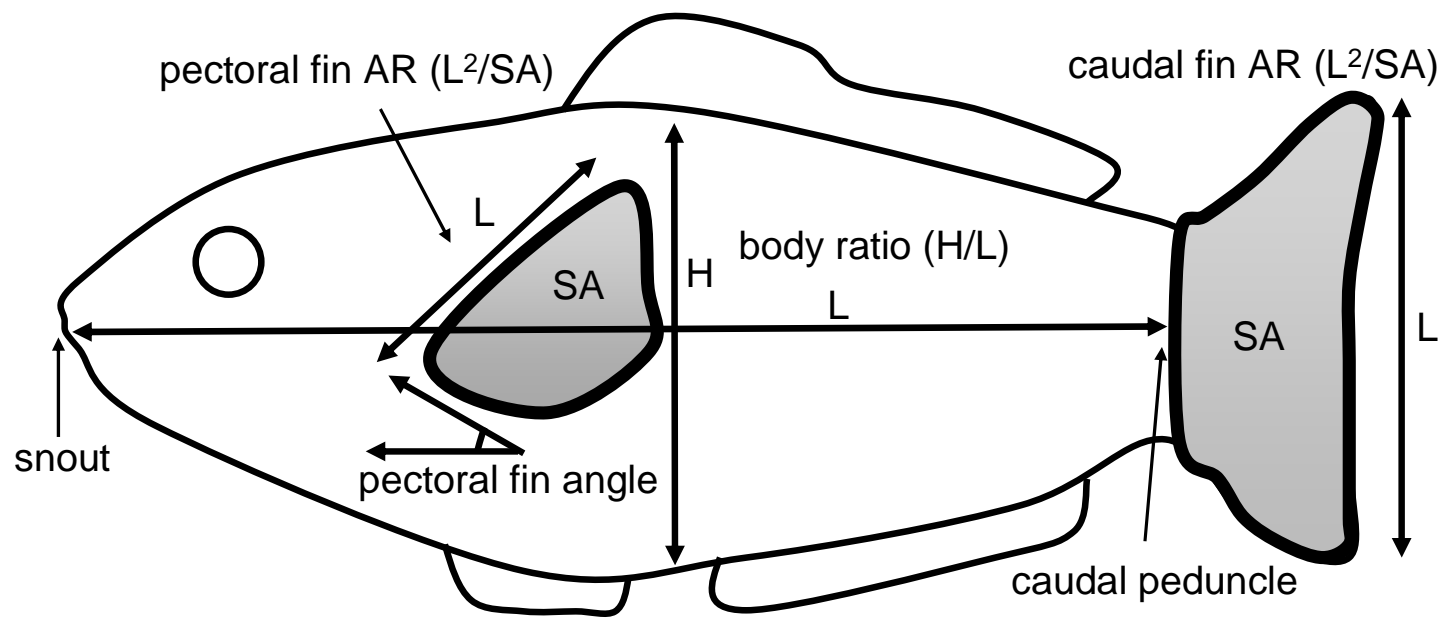

Figure 1.1. Four morphometric variables measured on each surfperch specimen using Image $J$ software. The aspect ratio (AR) was measured by the squared length (L) divided by the surface area (SA) for the pectoral and caudal fins (fins outlined in bold and shaded in gray). Body ratio was the height of the body $(\mathrm{H})$ divided by the length $(\mathrm{L})$, in this case, the standard length, being the tip of the snout to the caudal peduncle. The angle of the pectoral fin was measured at the insertion point on the body relative to the long axis of the body.

A Principal Components Analysis (PCA) was conducted on the four

morphometric variables to reduce the dimensionality of the dataset. These variables were assumed to be highly correlated with one another; therefore PCA transformed the data to decorrelate the variables, thus providing more accurate estimates of the natural variability in the dataset.

\section{Species effect}

To determine whether these aspects of fin and body morphology differed among the 19 embiotocids, an analysis of variance (ANOVA) was conducted using the resultant principal components (PCs) as the dependent variables. LSD post hoc tests were used to determine which species were different. 


\section{Habitat effect}

To test for a habitat effect, each of the 19 species was placed into six discrete habitat categories based on literature from 77 studies that ranged from 1966 to 2002 (Allen et al., 2006). The habitats were as follows: offshore demersal $(\mathrm{n}=2)$, bays and

estuaries ( $(n=2)$, kelp forest $(n=2)$, rocky reef $(n=3)$, shallow rock and sand $(n=5)$, and the surf zone ( $\mathrm{n}=5$; Table 1.1). ANOVA was conducted using the average factor scores of the species placed in each habitat grouping, followed by an LSD post hoc test to determine where any significant differences occurred. 
Table 1.1. Common habitat associations for California embiotocid species. Embiotocids were categorized into six discrete habitats based on 77 studies from 1966 to 2002 (Allen et al., 2006).

\begin{tabular}{|c|c|c|}
\hline Habitat & Species & Water motion \\
\hline offshore demersal & Zalembius rosaceus & calm \\
\hline offshore demersal & Hysterocarpus traski * & calm \\
\hline bay and estuary & Amphistichus rhodoterus & calm/moderate \\
\hline bay and estuary & Cymatogaster aggregata & calm/moderate \\
\hline kelp forest & Brachyistius frenatus & moderate \\
\hline kelp forest & Embiotoca lateralis & moderate \\
\hline rocky reef & Hyperprosopon ellipticum & moderate/turbulent \\
\hline rocky reef & Hypsurus caryi & moderate/turbulent \\
\hline rocky reef & Micrometrus aurora & moderate/turbulent \\
\hline shallow rock/sand & Damalichthys vacca & moderate/turbulent \\
\hline shallow rock/sand & Rhacochilus toxotes & moderate/turbulent \\
\hline shallow rock/sand & Phanerodon atripes & moderate/turbulent \\
\hline shallow rock/sand & Phanerodon furcatus & moderate/turbulent \\
\hline shallow rock/sand & Embiotoca jacksoni & moderate/turbulent \\
\hline surf zone & Amphistichus argenteus & turbulent/wave-swept \\
\hline surf zone & Amphistichus koelzi & turbulent/wave-swept \\
\hline surf zone & Hyperprosopon anale & turbulent/wave-swept \\
\hline surf zone & Hyperprosopon argenteum & turbulent/wave-swept \\
\hline surf zone & Micrometrus minimus & turbulent/wave-swept \\
\hline
\end{tabular}

* Hysterocarpus traski lives in freshwater habitats, but was grouped into the offshore demersal habitat due to similar calm conditions. 


\section{Genetic effect}

A molecular phylogeny exists for the embiotocids and is based on mitochondrial cytochrome $b$ and the $16 \mathrm{~S}$ ribosomal gene region (Bernardi and Bucciarelli, 1999). To test for any genetic effects, a Pearson correlation was conducted between the pairwise species PC differences, which were the morphological differences, and the pairwise genetic distances generated in the construction of Bernardi and Bucciarelli’s (1999) phylogenetic tree (provided by G. Bernardi). A significant correlation between morphological difference and genetic distance was interpreted as having explanatory value.

\section{RESULTS}

\section{Species effect}

The four morphometric variables that were measured varied widely among the 19 species (Table 1.2). The mean angle of insertion of the pectoral fin ranged from $26^{\circ}$ to $51^{\circ}$ at the extreme ranges in this family. The highest mean value of the pectoral fin AR (4.27) was almost double the lowest mean value (2.34); the highest mean value of the caudal fin AR (1.36) was three-fold higher than the lowest mean value (0.44). The mean value of the body ratio ranged from 0.36 to 0.50 , roughly a $50 \%$ increase. 
Table 1.2. Means \pm SD of four morphometric variables from 19 species of preserved surfperches from the California Academy of Sciences. Species are ranked by the pectoral fin angle $\left(^{\circ}\right)$ from lowest to highest. Values in bold are the lowest and highest values for each morphometric variable.

\begin{tabular}{|c|c|c|c|c|}
\hline Species & Pec. fin angle of attachment $\left(^{\circ}\right)$ & Pec. fin aspect ratio (AR) & Caudal fin AR & Body ratio (height/standard length) \\
\hline Hyperprosopon anale & $26 \pm 1$ & $4.19 \pm 1.03$ & $0.71 \pm 0.14$ & $0.36 \pm 0.02$ \\
\hline Amphistichus argenteus & $35.33 \pm 0.58$ & $3.16 \pm 0.37$ & $0.86 \pm 0.25$ & $0.41 \pm 0.01$ \\
\hline Amphistichus rhodoterus & $39.67 \pm 0.58$ & $2.34 \pm 0.35$ & $0.83 \pm 0.08$ & $0.45 \pm 0.07$ \\
\hline Brachyistius frenatus & $40.33 \pm 0.58$ & $2.72 \pm 0.55$ & $0.71 \pm 0.10$ & $0.41 \pm 0.02$ \\
\hline Amphistichus koelzi & $40.33 \pm 2.08$ & $2.92 \pm 0.22$ & $1.10 \pm 0.16$ & $0.49 \pm 0.02$ \\
\hline Micrometrus aurora & $40.67 \pm 1.15$ & $4.07 \pm 0.06$ & $0.90 \pm 0.48$ & $0.37 \pm 0.01$ \\
\hline Hyperprosopon ellipticum & $42 \pm 2.65$ & $3.87 \pm 0.65$ & $0.70 \pm 0.35$ & $0.42 \pm 0.08$ \\
\hline Hypsurus caryi & $42.33 \pm 1.15$ & $2.97 \pm 0.44$ & $1.05 \pm 0.30$ & $0.41 \pm 0.02$ \\
\hline Hyperprosopon argenteum & $43 \pm 2.65$ & $3.12 \pm 0.19$ & $1.36 \pm 0.22$ & $0.43 \pm 0.02$ \\
\hline Phanerodon furcatus & $43.67 \pm 3.06$ & $3.74 \pm 0.91$ & $0.59 \pm 0.15$ & $0.42 \pm 0.01$ \\
\hline Micrometrus minimus & $44.67 \pm 2.08$ & $3.08 \pm 0.21$ & $1.21 \pm 0.61$ & $0.49 \pm 0.02$ \\
\hline Phanerodon atripes & $45 \pm 2.65$ & $4.27 \pm 0.48$ & $0.44 \pm 0.02$ & $0.39 \pm 0.07$ \\
\hline Embiotoca jacksoni & $45.67 \pm 1.53$ & $4.08 \pm 0.60$ & $0.93 \pm 0.54$ & $0.50 \pm 0.02$ \\
\hline Cymatogaster aggregata & $46 \pm 2$ & $2.63 \pm 0.46$ & $1.06 \pm 0.34$ & $0.37 \pm 0.03$ \\
\hline Embiotoca lateralis & $46.67 \pm 1.53$ & $2.90 \pm 0.22$ & $1.33 \pm 0.36$ & $0.47 \pm 0.00$ \\
\hline Rhacochilus toxotes & $48 \pm 2$ & $3.47 \pm 0.57$ & $0.69 \pm 0.16$ & $0.40 \pm 0.03$ \\
\hline Hysterocarpus traski & $49.33 \pm 3.06$ & $3.15 \pm 0.32$ & $1.25 \pm 0.38$ & $0.47 \pm 0.06$ \\
\hline Damalichthys vacca & $51.33 \pm 0.58$ & $4.24 \pm 0.61$ & $0.93 \pm 0.38$ & $0.43 \pm 0.01$ \\
\hline Zalembius rosaceus & $51.33 \pm 1.53$ & $3.14 \pm 0.13$ & $0.66 \pm 0.23$ & $0.43 \pm 0.05$ \\
\hline
\end{tabular}


In the principal components analysis, all four morphometric variables loaded on PCs 1 and 2, which accounted for nearly $70 \%$ of the variability (Table 1.3). Thusly, PCs 3 and 4 were not included in the data analysis. PC1 described a negative loading of pectoral fin AR and positive loadings of caudal fin AR and body ratio. ANOVA performed on PC1 revealed that there was a species effect $(\mathrm{df}=18, \mathrm{~F}=4.623$, $\mathrm{p}<0.0001)$. Surfperches that had a higher pectoral fin AR had a lower caudal fin AR and a more elongate and streamlined body shape, as revealed by LSD post hoc tests (Figures 1.2A, 1.2B; Table 1.4).

PC2 exclusively described the positive loading of the angle of insertion of the pectoral fin. ANOVA performed on $\mathrm{PC} 2$ revealed that the angle of insertion of the pectoral fin differed among the 19 species of surfperches (Figures 1.2A, 1.2B; Table 1.5; $\mathrm{df}=18, \mathrm{~F}=6.073, \mathrm{p}<0.0001)$. The LSD post hoc test revealed that surfperches with a lower pectoral fin angle differed from surfperch species that had a lower pectoral fin AR and a rounder body shape (Table 1.5). Given a significant species effect for both PC variables, we went on to investigate possible causes for the differences.

Table 1.3. Loadings of the principal components (PC). Numbers in bold are the values of the morphometric variables that loaded most heavily for each PC. Absolute values of the loading number that were under 0.500 were considered not to be an important contributor in describing a particular PC.

\begin{tabular}{|c|c|c|}
\hline Principal components & 1 & 2 \\
\hline $\begin{array}{c}\text { Variation explained } \\
\text { (initial eigenvalues) }\end{array}$ & $41.634 \%$ & $26.035 \%$ \\
\hline pectoral fin AR & $\mathbf{- 0 . 6 6 0}$ & 0.460 \\
\hline caudal fin AR & $\mathbf{0 . 7 2 8}$ & -0.338 \\
\hline body ratio & $\mathbf{0 . 7 2 0}$ & 0.296 \\
\hline pectoral fin angle & 0.425 & $\mathbf{0 . 7 9 3}$ \\
\hline
\end{tabular}




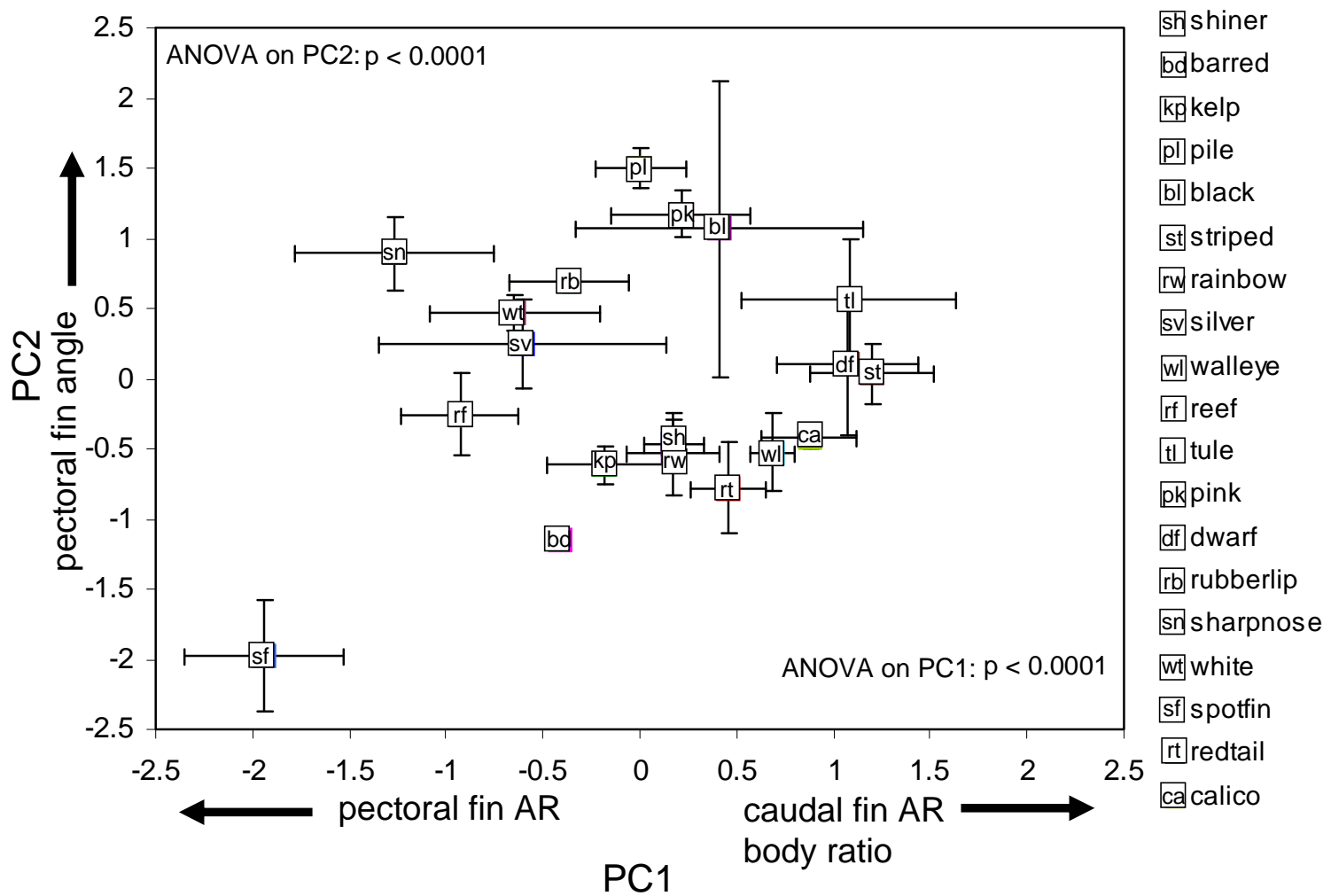

Figure 1.2A. Means \pm standard error (SE) for species effects with PC1 along the $x$ axis and PC2 along the $y$-axis. There were differences in the four morphometric variables measured among the surfperches. The 19 points are the means for each species $(n=3$ specimens per species). Arrows denote increasing values of the morphometric variables. 


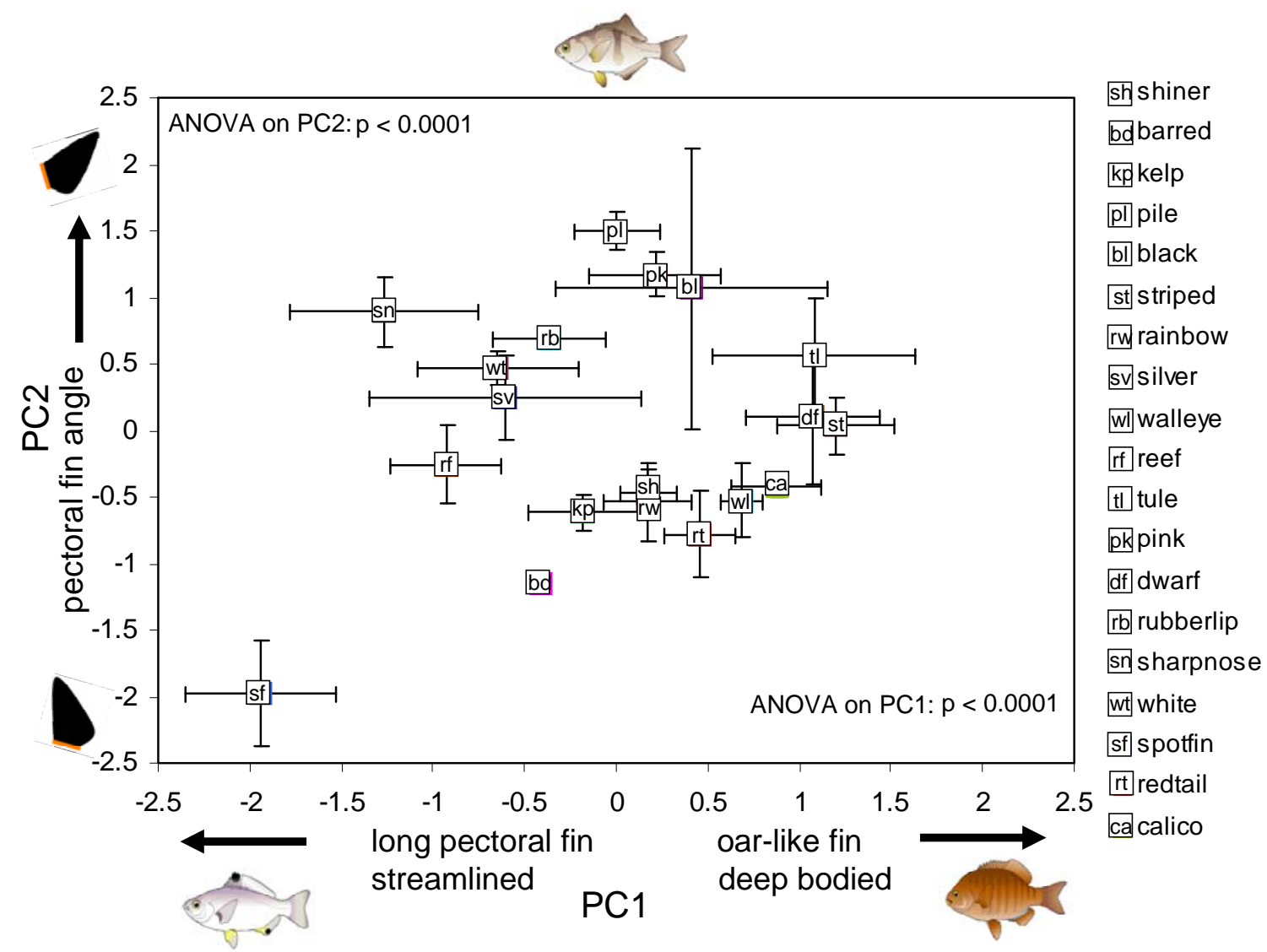

Figure 1.2B. Interpreted axes following Figure 1.2A. Along the $x$-axis, fishes that grouped toward the right had oar-like fins and were deep-bodied, such as a black surfperch. Fishes that grouped toward the left had a higher AR pectoral fin and a more streamlined body, such as a spotfin surfperch. Along the $y$-axis, fishes that grouped toward the bottom had a flapper morphology, whereas fishes that grouped toward the top had a rower morphology. 
Table 1.4. Results of PC1 LSD post hoc test with species as the main effect. Numbers in bold represent species that were significantly different from one another $(\alpha=0.05)$.

\begin{tabular}{|c|c|c|c|c|c|c|c|c|c|c|}
\hline Species & calico & barred & redtail & kelp & shiner & pile & black & striped & spotfin & walleye \\
\hline calico & 1 & - & - & - & - & - & - & - & - & - \\
\hline barred & 0.026 & 1 & - & - & - & - & - & - & - & - \\
\hline redtail & 0.456 & 0.126 & 1 & - & - & - & - & - & - & - \\
\hline kelp & 0.065 & 0.677 & 0.259 & 1 & - & - & - & - & - & - \\
\hline shiner & 0.215 & 0.297 & 0.615 & 0.527 & 1 & - & - & - & - & - \\
\hline pile & 0.124 & 0.461 & 0.417 & 0.747 & 0.756 & 1 & - & - & - & - \\
\hline black & 0.404 & 0.149 & 0.928 & 0.299 & 0.68 & 0.47 & 1 & - & - & - \\
\hline striped & 0.566 & 0.006 & 0.19 & 0.018 & 0.074 & 0.038 & 0.163 & 1 & - & - \\
\hline spotfin & $\mathbf{0}$ & 0.009 & $\mathbf{0}$ & 0.003 & $\mathbf{0}$ & 0.001 & $\mathbf{0}$ & $\mathbf{0}$ & 1 & - \\
\hline walleye & 0.733 & 0.056 & 0.684 & 0.128 & 0.365 & 0.226 & 0.62 & 0.362 & $\mathbf{0}$ & 1 \\
\hline rainbow & 0.214 & 0.298 & 0.613 & 0.529 & 0.997 & 0.758 & 0.678 & 0.073 & $\mathbf{0}$ & 0.364 \\
\hline silver & 0.011 & 0.732 & 0.064 & 0.449 & 0.169 & 0.283 & 0.077 & 0.002 & 0.021 & 0.026 \\
\hline tule & 0.714 & 0.011 & 0.268 & 0.029 & 0.111 & 0.059 & 0.232 & 0.835 & $\mathbf{0}$ & 0.48 \\
\hline reef & 0.002 & 0.355 & 0.017 & 0.183 & 0.053 & 0.101 & 0.021 & $\mathbf{0}$ & 0.077 & 0.006 \\
\hline dwarf & 0.723 & 0.011 & 0.273 & 0.03 & 0.114 & 0.061 & 0.237 & 0.826 & $\mathbf{0}$ & 0.487 \\
\hline sharpnose & $\mathbf{0}$ & 0.132 & 0.004 & 0.057 & 0.013 & 0.028 & 0.005 & $\mathbf{0}$ & 0.233 & 0.001 \\
\hline white & 0.009 & 0.674 & 0.054 & 0.404 & 0.147 & 0.25 & 0.065 & 0.002 & 0.025 & 0.022 \\
\hline rubberlip & 0.031 & 0.941 & 0.145 & 0.732 & 0.332 & 0.507 & 0.17 & 0.008 & 0.007 & 0.065 \\
\hline pink & 0.239 & 0.269 & 0.66 & 0.487 & 0.95 & 0.709 & 0.726 & 0.084 & $\mathbf{0}$ & 0.399 \\
\hline
\end{tabular}

Continued on the next page... 
Table 1.4. (Continued).

\begin{tabular}{|c|c|c|c|c|c|c|c|c|c|}
\hline Species & rainbow & silver & tule & reef & dwarf & sharpnose & white & rubberlip & pink \\
\hline rainbow & 1 & - & - & - & - & - & - & - & - \\
\hline silver & 0.17 & 1 & - & - & - & - & - & - & - \\
\hline tule & 0.111 & $\mathbf{0 . 0 0 4}$ & 1 & - & - & - & - & - & - \\
\hline reef & $\mathbf{0 . 0 5 4}$ & 0.558 & $\mathbf{0 . 0 0 1}$ & 1 & - & - & - & - & - \\
\hline dwarf & 0.113 & $\mathbf{0 . 0 0 4}$ & 0.99 & $\mathbf{0 . 0 0 1}$ & 1 & - & - & - & - \\
\hline sharpnose & $\mathbf{0 . 0 1 3}$ & 0.239 & $\mathbf{0}$ & 0.549 & $\mathbf{0}$ & 1 & - & - & - \\
\hline white & 0.148 & 0.937 & $\mathbf{0 . 0 0 4}$ & 0.612 & $\mathbf{0 . 0 0 4}$ & 0.271 & 1 & - & - \\
\hline rubberlip & 0.334 & 0.677 & $\mathbf{0 . 0 1 3}$ & 0.318 & $\mathbf{0 . 0 1 3}$ & 0.114 & 0.621 & 1 & - \\
\hline pink & 0.947 & 0.151 & 0.125 & $\mathbf{0 . 0 4 7}$ & 0.128 & $\mathbf{0 . 0 1 1}$ & 0.131 & 0.302 & 1 \\
\hline
\end{tabular}


Table 1.5. Results of PC2 LSD post hoc test with species as the main effect. Numbers in bold represent species that were significantly different from one another $(\alpha=0.05)$.

\begin{tabular}{|c|c|c|c|c|c|c|c|c|c|c|}
\hline Species & calico & barred & redtail & kelp & shiner & pile & black & striped & spotfin & walleye \\
\hline calico & 1 & - & - & - & - & - & - & - & - & - \\
\hline barred & 0.157 & 1 & - & - & - & - & - & - & - & - \\
\hline redtail & 0.472 & 0.478 & 1 & - & - & - & - & - & - & - \\
\hline kelp & 0.692 & 0.303 & 0.745 & 1 & - & - & - & - & - & - \\
\hline shiner & 0.914 & 0.19 & 0.541 & 0.774 & 1 & - & - & - & - & - \\
\hline pile & 0.001 & $\mathbf{0}$ & $\mathbf{0}$ & $\mathbf{0}$ & $\mathbf{0}$ & 1 & - & - & - & - \\
\hline black & 0.006 & $\overline{\mathbf{0}}$ & 0.001 & 0.002 & 0.004 & 0.394 & 1 & - & - & - \\
\hline striped & 0.376 & 0.025 & 0.113 & 0.203 & 0.321 & 0.006 & 0.048 & 1 & - & - \\
\hline spotfin & 0.004 & 0.109 & 0.024 & 0.011 & 0.005 & $\mathbf{0}$ & $\mathbf{0}$ & $\mathbf{0}$ & 1 & - \\
\hline walleye & 0.822 & 0.231 & 0.62 & 0.864 & 0.908 & $\mathbf{0}$ & 0.003 & 0.269 & 0.007 & 1 \\
\hline rainbow & 0.81 & 0.237 & 0.631 & 0.877 & 0.895 & $\mathbf{0}$ & 0.003 & 0.262 & 0.007 & 0.987 \\
\hline silver & 0.197 & 0.009 & 0.048 & 0.095 & 0.163 & 0.017 & 0.112 & 0.678 & $\mathbf{0}$ & 0.132 \\
\hline tule & 0.059 & 0.002 & 0.011 & 0.024 & 0.047 & 0.071 & 0.325 & 0.3 & $\mathbf{0}$ & 0.036 \\
\hline reef & 0.758 & 0.087 & 0.306 & 0.482 & 0.677 & 0.001 & 0.012 & 0.562 & 0.002 & 0.595 \\
\hline dwarf & 0.314 & 0.018 & 0.089 & 0.164 & 0.266 & 0.008 & 0.062 & 0.902 & $\mathbf{0}$ & 0.221 \\
\hline sharpnose & 0.013 & $\overline{\mathbf{0}}$ & 0.002 & 0.005 & 0.01 & 0.234 & 0.731 & 0.097 & $\overline{\mathbf{0}}$ & 0.008 \\
\hline white & 0.086 & 0.003 & 0.017 & 0.037 & 0.069 & 0.048 & 0.245 & 0.391 & $\mathbf{0}$ & 0.054 \\
\hline rubberlip & 0.034 & 0.001 & 0.006 & 0.013 & 0.027 & 0.116 & 0.46 & 0.201 & 0 & 0.02 \\
\hline pink & 0.003 & $\mathbf{0}$ & $\mathbf{0}$ & 0.001 & 0.002 & 0.52 & 0.833 & 0.03 & $\mathbf{0}$ & 0.002 \\
\hline
\end{tabular}

Continued on the next page... 
Table 1.5. (Continued).

\begin{tabular}{|c|c|c|c|c|c|c|c|c|c|}
\hline Species & rainbow & silver & tule & reef & dwarf & sharpnose & white & rubberlip & pink \\
\hline rainbow & 1 & - & - & - & - & - & - & - & - \\
\hline silver & 0.128 & 1 & - & - & - & - & - & - & - \\
\hline tule & $\mathbf{0 . 0 3 5}$ & 0.531 & 1 & - & - & - & - & - & - \\
\hline reef & 0.583 & 0.322 & 0.11 & 1 & - & - & - & - & - \\
\hline dwarf & 0.215 & 0.769 & 0.36 & 0.483 & 1 & - & - & - & - \\
\hline sharpnose & $\mathbf{0 . 0 0 7}$ & 0.207 & 0.519 & $\mathbf{0 . 0 2 8}$ & 0.123 & 1 & - & - & - \\
\hline white & $\mathbf{0 . 0 5 2}$ & 0.656 & 0.855 & 0.155 & 0.462 & 0.409 & 1 & - & - \\
\hline rubberlip & $\mathbf{0 . 0 1 9}$ & 0.383 & 0.804 & 0.067 & 0.246 & 0.691 & 0.667 & 1 & - \\
\hline pink & $\mathbf{0 . 0 0 2}$ & 0.073 & 0.234 & $\mathbf{0 . 0 0 7}$ & $\mathbf{0 . 0 3 9}$ & 0.579 & 0.172 & 0.343 & 1 \\
\hline
\end{tabular}




\section{Habitat effect}

When PC1 scores were pooled and averaged by habitat, ANOVA failed to detect any differences (Figure 1.3; $\mathrm{df}=5, \mathrm{~F}=0.756, \mathrm{p}=0.597$ ). When PC2 scores were pooled and averaged by habitat, however, ANOVA revealed that there was a habitat effect (Figure 1.3; $\mathrm{df}=5, \mathrm{~F}=6.673, \mathrm{p}=0.003$ ). The LSD post hoc test revealed that the offshore demersal and shallow rock and sand habitats were significantly different from the other four habitats (Table 1.6). However, hydrodynamically, this does not make much sense. The offshore demersal habitat tends to experience calm ocean conditions, whereas the shallow rock and sand habitat experiences higher-energy conditions, on average (Allen et al., 2006). Similarly, the bay and estuary habitat, which often experiences calm water conditions, was not revealed to be different from the wave-swept surf zone habitat (Table 1.6). 


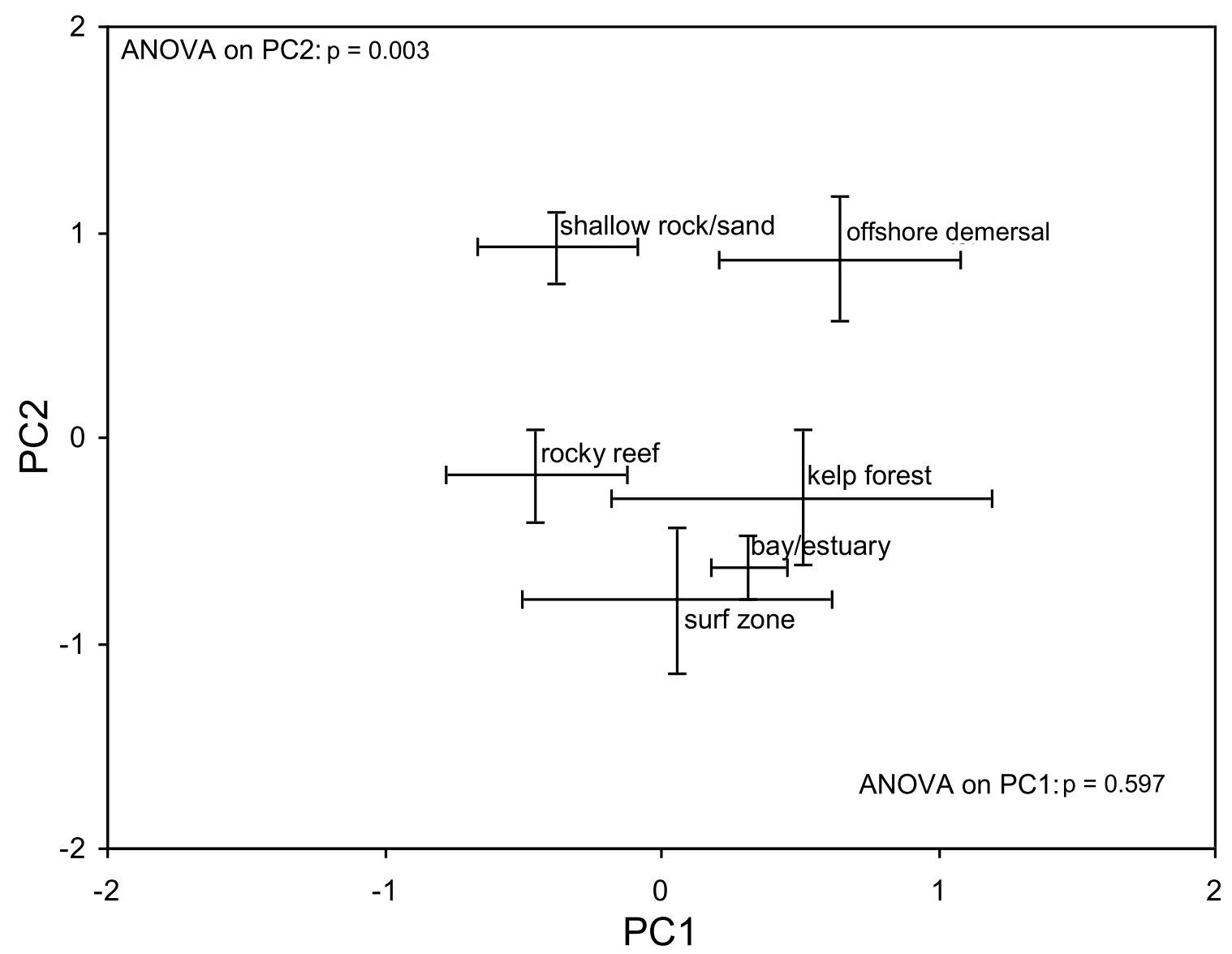

Figure 1.3. Means $\pm \mathrm{SE}$ of the average factor scores of $\mathrm{PC} 1$ versus the average factor scores of $\mathrm{PC2}$, based on habitat. Species were categorized into six discrete habitats. Each point is the single mean value for the species grouped into that habitat.

Table 1.6. Results of PC2 LSD post hoc test with habitat as the main effect. Numbers in bold represent fishes with varying angles of insertion of the pectoral fin that live in different habitats $(\alpha=0.05)$.

\begin{tabular}{|c|c|c|c|c|c|c|}
\hline Habitats & bay/estuary & kelp forest & offshore demersal & rocky reef & shallow rock/sand & surf zone \\
\hline bay/estuary & 1.0 & & & & & \\
\hline kelp forest & .550 & 1.0 & & & & \\
\hline offshore demersal & $\mathbf{. 0 1 7}$ & $\mathbf{. 0 5 4}$ & 1.0 & & & \\
\hline rocky reef & .391 & .834 & .055 & 1.0 & & \\
\hline shallow rock/sand & $\mathbf{. 0 0 5}$ & $\mathbf{. 0 2 0}$ & .906 & $\mathbf{. 0 1 6}$ & 1.0 & \\
\hline surf zone & .723 & .293 & $\mathbf{. 0 0 3}$ & .152 & $\mathbf{. 0 0 0}$ & 1.0 \\
\hline
\end{tabular}


Interestingly, the habitat gradient on PC1 made ecological sense even though ANOVA did not detect a difference (Figure 1.3). Along the PC1 axis, energy conditions in the six discrete habitats increased from right to left.

\section{Genetic effect}

Pearson correlation revealed that the genetic relatedness of surfperches decreased with increasing differences in the absolute factor scores of PC1 (Figure 1.4; $r=0.332$, $\mathrm{p}<0.0001)$. In other words, surfperches that were similar in their pectoral fin AR, caudal fin $\mathrm{AR}$, and body ratio were more closely related genetically to one another than surfperches differing in these three morphometric variables. Conversely, no relationship was detected between variation in PC2 and genetic distance (Figure 1.5; Pearson correlation: $\mathrm{r}=0.022, \mathrm{p}=0.816)$.

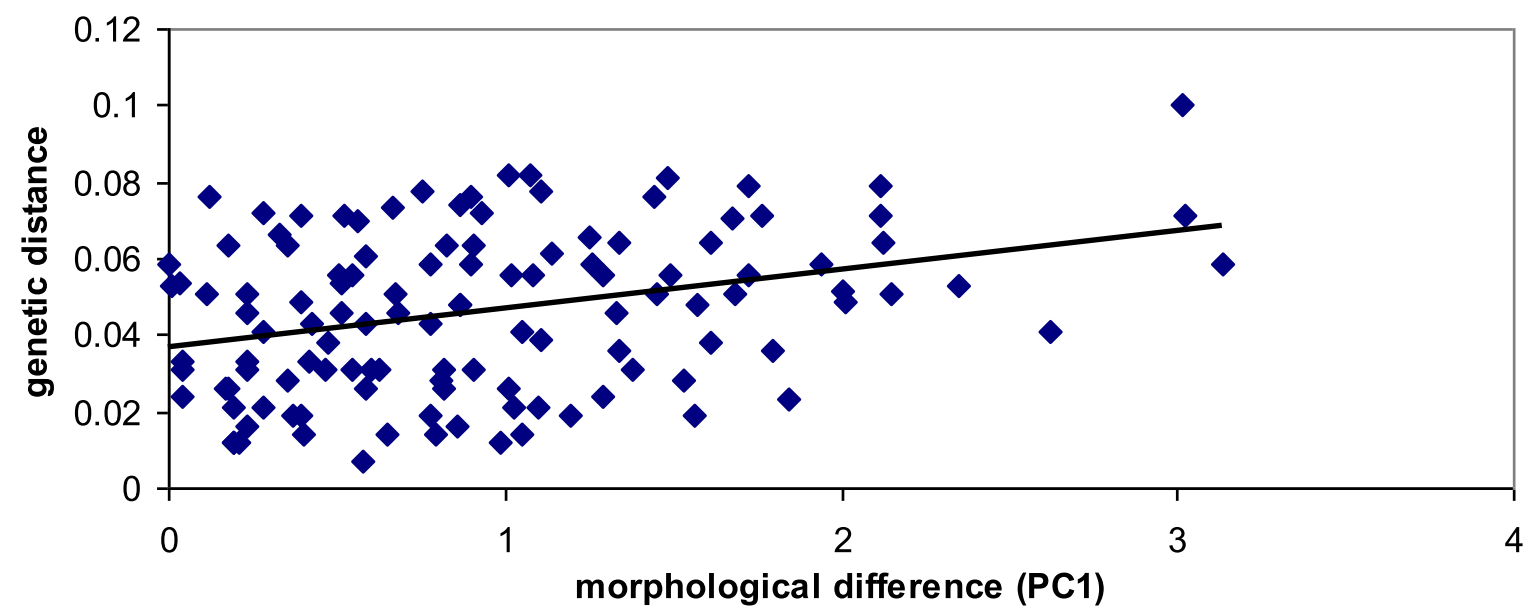

Figure 1.4. Genetic distance versus morphological difference for PC1. There was a positive relationship between genetic distance and morphological difference (Pearson correlation: $r=0.332 ; p<0.0001)$. 


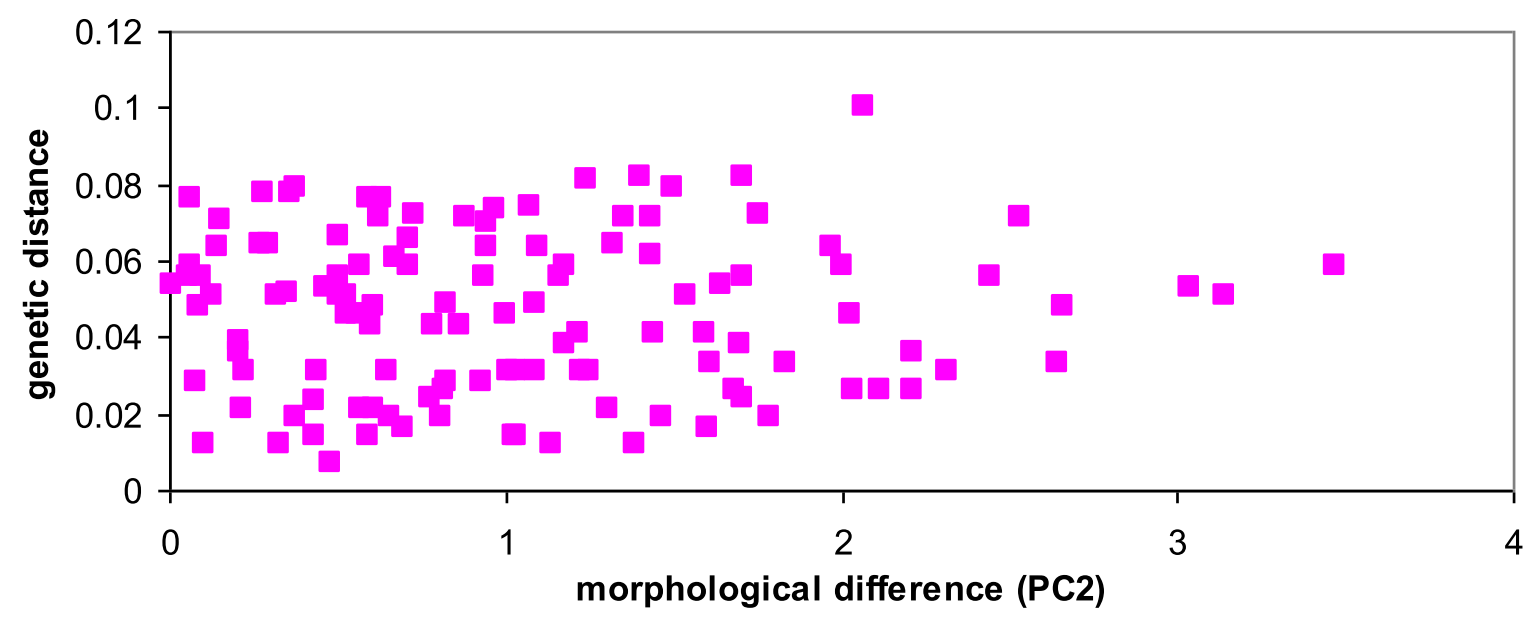

Figure 1.5. Genetic distance versus morphological difference for PC2. There was no relationship between genetic distance and morphological variables being different (Pearson correlation: $r=0.022 ; p=0.816$ ).

\section{DISCUSSION}

Placing two-dimensional measurements of morphometric variables into an ecological context can reveal an amazing amount of information about the functional roles of an organism. In this study, habitat explained only part of fin and body morphology and an additional amount appeared to be explained by genetics. The varying angle of insertion of the pectoral fin was the only statistically significant variable that differed among the surfperches from different habitats; however, the habitat gradient along PC2 does not make much biological sense. Habitats that were very similar to one another based on average ocean conditions most often experienced at each, such as offshore demersal and bays and estuaries, were revealed by the LSD post hoc test to be different. Also, the wave-swept, high energy surf zone was revealed not to be statistically different from the calm bay and estuary habitat (Table 1.6). This suggests 
that aspect ratios of the pectoral fins and caudal fins, along with body ratio, as described by PC1, are explained by genetics instead of habitat.

Even though PC1 was not statistically significant with habitat as the main effect, PC1 made biological sense regarding how the habitats were displayed along that axis. There was a gradient along the PC1 axis that went from habitats with high-energy conditions to habitats most commonly associated with calmer energy conditions (Figure 1.3). PCA revealed that the aspect ratio of the pectoral fin increased with a lower angle of insertion of the pectoral fin, which fits accordingly where one would expect a fish with a higher pectoral fin AR to reach a faster swimming speed and to be associated with habitats that experience high energy, wave-swept conditions (Wainwright et al., 2002; Fulton et al., 2005). Additionally, the spotfin surfperch had the lowest fin angle and one of the highest pectoral fin ARs; spotfins live in the surf zone and other habitats that experience wave-swept conditions.

In other studies of labriform fishes, the aspect ratio of the pectoral fin was the most important morphometric variable when it came to inferring a particular fish living in a certain environment (Wainwright et al., 2002; Fulton et al., 2005). In this study, the aspect ratio of the pectoral fin did not explain the habitat association of surfperches. Having a long, tapered morphology of the pectoral fin versus a blunted oar-like morphology affects the swimming performance of many labriform reef fishes (Fulton et al., 2005). In the family of surfperches, the pectoral fin AR does not seem to be an important and ecologically relevant morphometric variable to infer which habitats they might occupy. 
With a more detailed categorization of habitats, we may observe the AR of the pectoral fin to be the reason why some species are limited to certain habitats. Because the habitat types did not fall out along an ecologically relevant hydrodynamic gradient for PC2, speculation is necessary regarding the statistical significance of pectoral fin angle. The angle of insertion of the pectoral fin is indicative of different swimming modes from a flapping mode at $0^{\circ}$, to a rowing mode at $90^{\circ}$ (Walker and Westneat, 2000). Surfperches in this study had a much narrower range, from $26^{\circ}$ to $51^{\circ}$ (Table 1.2 ). Because the pectoral fin angle is directly related to the mechanical efficiency in thrust generation, the swimming speed achieved by surfperches may be greater in species that have a lower angle of insertion of their pectoral fin versus surfperches with a higher fin angle. Potential differences in swimming performance may be the limiting factor in why certain species cannot occupy a particular habitat.

As for the potential genetic effect on differences in fin and body morphology, similar phenotypes of pectoral fin and caudal fin ARs and body ratios were revealed to be less genetically distant than those morphological characteristics that were more phenotypically different (Figure 1.4). It makes intuitive sense that the evolution of multiple species that are genetically similar would possess similar fin and body morphologies. Surfperches that shared these genetic similarities seemed to occupy habitats with similar conditions, following the habitat gradient of PC1 (Figure 1.3). As related species evolved different morphologies, that is possibly why they were able to move into different habitats. 
A preserved specimen can reveal only so much about its functional ecophysiology. The pectoral fins were treated as plate-like structures, yet we know that fins can deform their shape at different flow velocities and change their functional angle of attack (personal observation). Therefore, I will be investigating the swimming performance of four species of surfperches that have different fin and body morphologies. It will be important to see if the results of this study translate to the expected physiological capabilities of surfperches that occupy different habitats and have different fin morphologies. Performance will be measured by the critical swimming speed ( $\left.\mathrm{U}_{\text {crit }}\right)$ and the C-start escape response.

\section{ACKNOWLEDGEMENTS}

I am very grateful to Dr. Lara Ferry-Graham for her assistance throughout this project. I also want to thank Dave Catania of the California Academy of Sciences who allowed me access to the many preserved specimens. All work was conducted with the approval of the SJSU IACUC under protocol \# 918.

\section{LITERATURE CITED}

Agassiz L. 1853. On Extraordinary Fishes from California, constituting a New Family. Silliman's Journal of Science 16(2):12.

Allen LG, Pondella D, Horn M. 2006. The Ecology of Marine Fishes: California and Adjacent Waters. Berkeley: University of California Press. 660 p.

Bellwood DR, Wainwright PC. 2001. Locomotion in labrid fishes: implications for habitat use and cross-shelf biogeography on the Great Barrier Reef. Coral Reefs 20:139-150.

Bernardi G. 2005. Phylogeography and demography of sympatric sister surfperch species, Embiotoca jacksoni and E. lateralis along the California coast: historical versus ecological factors. Evolution 59(2):386-394. 
Bernardi G, Bucciarelli G. 1999. Molecular phylogeny and speciation of the surfperches (Embiotocidae, Perciformes). Molecular Phylogenetics and Evolution 13(1):77-81.

Breder CM. 1926. The locomotion of fishes. Zoologica 50:159-297.

Combes SA, Daniel TL. 2001. Shape, flapping and flexion: wing and fin design for forward flight. Journal of Experimental Biology 204:2073-2085.

DeMartini EE. 1969. A correlative study of the ecology and comparative feeding mechanism morphology of the Embiotocidae as evidence of the family's adaptive radiation into available ecological niches. Wasmann J Biol 27:177-247.

Drucker EG, Jensen JS. 1996a. Pectoral fin locomotion in the striped surfperch. I. Kinematic effects of swimming speed and body size. J Exp Biol 199:2235-2242.

Ebeling AW, Laur DR. 1986. Foraging in surfperches: resource partitioning or individualistic responses? Environmental Biology of Fishes 16:123-133.

Eigenmann CH. 1894. On the viviparous fishes of the Pacific coast of North America. Bulletin of the U.S. Fish Commission 12:381-478.

Fulton CJ, Bellwood DR, Wainwright PC. 2005. Wave energy and swimming performance shape coral reef fish assemblages. Proceedings of the Royal Society 272:827-832.

Hixon MA. 1980. Competitive interactions between California reef fishes of the genus Embiotoca. Ecology 61(4):918-931.

Holbrook SJ, Schmitt RJ. 1992. Causes and consequences of dietary specialization in surfperches: patch choice and intraspecific competition. Ecology 73(2):402-412.

Holbrook SJ, Schmitt RJ, Coyer JA. 1985. Age-related dietary patterns of sympatric adult surfperch. Copeia 1985(4):986-994.

Holbrook SJ, Schmitt RJ, Stephens JS, Jr. 1997. Changes in an assemblage of temperate reef fishes associated with a climate shift. Ecological Applications 7(4):1299-1310.

Liem K. 1986. The Pharyngeal Jaw Apparatus of the Embiotocidae (Teleostei): A Functional and Evolutionary Perspective. Copeia 1986(2):311-323.

Liem KF. 1991. Functional morphology. In: MHA Keenleyside, editor. Cichlid fishes: behavior, ecology and evolution. New York: Chapman and Hall. p 129-150. 
Tarp FH. 1952. A revision of the family Embiotocidae (the surfperches). Calif Div Fish Game Fish Bull 88.

Thorsen DH, Westneat MW. 2005. Diversity of pectoral fin structure and function in fishes with labriform propulsion. Journal of Morphology 263:133-150.

Vogel S. 1994. Life in Moving Fluids: The Physical Biology of Flow, 2nd edition. Princeton: Princeton University Press.

Wainwright PC, Bellwood DR, Westneat MW. 2002. Ecomorphology of locomotion in labrid fishes. Environ Biol Fish 65:47-62.

Walker JA, Westneat MW. 1997. Labriform propulsion in fishes: kinematics of flapping aquatic flight in the bird wrasse Gomphosus varius (Labridae). Journal of Experimental Biology 200:1549-1569.

Walker JA, Westneat MW. 2000. Mechanical performance of aquatic rowing and flying. Proc R Soc London B 267:1875-1881.

Walker JA, Westneat M. 2002. Performance limits of labriform propulsion and correlates with fin shape and motion. Journal of Experimental Biology 205:177-187.

Webb PW. 1973. Kinematics of pectoral fin propulsion in Cymatogaster aggregata. Journal of Experimental Biology 59:697-710. 


\section{CHAPTER 2: SWIMMING PERFORMANCE, AS INDICATED BY U URIT AND STAGE 1 OF THE C-START ESCAPE RESPONSE, IN SURFPERCHES (EMBIOTOCIDAE)}

\section{ABSTRACT}

Surfperches are enigmatic labriform swimmers. Angle of insertion of the pectoral fin varies among species and theoretically allows for differing amounts of thrust to be generated, putatively affecting swimming performance. We predicted that speed and maneuverability trade-off in this clade of nearshore fishes. Specifically, I hypothesized that surfperches with lower fin angles would achieve a faster critical swimming speed $\left(\mathrm{U}_{\text {crit }}\right)$, but were less maneuverable, as indicated by the body bending coefficient $(\mathrm{BC})$

during Stage 1 of the C-start escape response. To address this hypothesis, I collected four surfperch species each with different pectoral fin angles (range: 35 to $51^{\circ}$ ). $\mathrm{U}_{\text {crit }}$ was measured in a flume. After acclimation, flow was set to 0.5 body lengths per second $(\mathrm{BL} / \mathrm{s})$ for 30 minutes, then increased by $0.25 \mathrm{BL} / \mathrm{s}$ every five minutes until $\mathrm{U}_{\text {crit }}$ was reached, as indicated by the onset of burst-and-glide behavior. I recorded maximum fin beat frequency and $U_{\text {crit. }}$ In separate experiments, I elicited C-starts from individual fish, recording the escape response with a high-speed digital camera at $250 \mathrm{fps}$. I measured the BC during Stage 1. ANOVA revealed differences among species in that surfperches with lower fin angles achieved a faster $U_{\text {crit }}$ and a higher maximum fin beat frequency. For the $\mathrm{BC}$, we conducted a fixed one-way ANOVA on the values of the Stage 1 angle, followed by LSD post hoc tests. ANOVA revealed that barred surfperches had the greatest BC. Contrary to my prediction, species with lower fin angles reached both faster $\mathrm{U}_{\text {crit }}$ and greater body bending than species with higher fin angles. 
KEY WORDS: embiotocids; labriform; ecomorphological paradigm; critical swimming speed; body bending coefficient

\section{INTRODUCTION}

Surfperches are labriform swimmers, primarily using their pectoral fins for forward locomotion (Breder, 1926). Angle of insertion of the pectoral fin, relative to the long axis of the body, varies among species and theoretically allows for differing amounts of thrust to be generated, thus affecting swimming performance (see Chapter 1 of this study). More specifically, lower angles of insertion of the pectoral fin have been revealed to generate greater lift and reduced drag during a fin beat (Wainwright et al., 2002). Conversely, surfperches with a high angle of insertion of the pectoral fin should generate greater amounts of drag on the recovery stroke of a fin beat, thus generating a slower swimming speed. Differences in this fin morphology may lead to differences in swimming performance, thusly affecting which habitats they might not be capable of occupying.

Fishes occupy just about every aquatic habitat around the world. Hydrodynamic conditions vary greatly on a spatial and temporal scale, thus influencing the species assemblages in a particular habitat (Fulton et al., 2005). Some fishes are built for speed, such as a tuna or mackerel, cruising constantly in the pelagic oceans. At the other extreme is a boxfish, living among corals with the ability to tightly maneuver around them. Surfperches are generalists, not the best performers for swimming fast or for tight body bending (Webb, 1984). Even so, surfperches occupy almost every nearshore habitat along the eastern Pacific coast that experience a range of flow conditions (Tarp, 1952; DeMartini, 1969). 
Seasonal events such as storms along the coast generate large waves and fastflowing currents. These conditions are where the maximum swimming performance of a particular fish will be tested. Operating under the ecomorphological paradigm, in which a certain body form should provide the necessary function to occupy a particular habitat, a potential tradeoff should exist in swimming performance (Liem, 1991). Surfperches that reach the fastest critical swimming speed $\left(\mathrm{U}_{\text {crit }}\right)$ were predicted to be the least maneuverable. Conversely, surfperches that are capable of the greatest body bending were predicted to swim the slowest. Differences in swimming performance, if any occur, might be the reasons that some species of surfperches are not capable of occupying highenergy, wave-swept habitats.

To carry out these experiments among the four selected species of surfperches, fast swimming performance will be indicated by the critical swimming speed ( $\left.U_{\text {crit }}\right)$. Maneuverability will be indicated by the body bending coefficient, which is measured during Stage 1 of the $\mathrm{C}$-start escape response. It was hypothesized that the four selected embiotocids, which vary in their fin and body morphologies as noted in Chapter 1, would each achieve a different $U_{\text {crit. }}$. Also, that fishes with a faster $U_{\text {crit }}$ would transition from pectoral to caudal fin-based propulsion $\left(\mathrm{U}_{\mathrm{p}-\mathrm{c}}\right)$ at a faster speed than fishes with a slower $\mathrm{U}_{\text {crit. }}$ Finally, the maximum fin beat frequency would differ among species during the $\mathrm{U}_{\text {crit }}$ tests.

\section{MATERIALS AND METHODS}

Four surfperch species were selected based on morphological differences, their phylogenetic placement within the family Embiotocidae, and availability (Figure 2.1). 
Angle of insertion and aspect ratio of the pectoral fin were the morphological variables used (Figure 1.1; Table 1.1). In the subfamily Amphistichinae, the barred surfperches (Amphistichus argenteus), had angles of attachment of the pectoral fin ranging from 35 to 36 degrees, being the lowest mean pectoral fin angle of attachment among the four selected species, and the second lowest values for the entire family (Table 1.2). Mean aspect ratio of the pectoral fin was $3.16 \pm 0.21 \mathrm{SE}$. In the subfamily Embiotocinae, shiner surfperches (Cymatogaster aggregata), had an intermediate fin angle of attachment (mean of $46^{\circ} \pm 1.15 \mathrm{SE}$ ) with a mean aspect ratio of $2.63 \pm 0.27$ SE. Black surfperches (Embiotoca jacksoni), also had a mean angle of attachment of the pectoral fin that was an intermediate value in the family $\left(45.67^{\circ} \pm 0.88\right)$ and a mean aspect ratio of $4.08 \pm 0.60$. At the opposite extreme, pile surfperches (Damalichthys vacca) had a mean angle of attachment of the pectoral fin ranging from 51 to 52 degrees. The pile surfperches had the highest mean angle of attachment among the four species selected for this research, along with having the highest mean angle of attachment for the entire family. Their mean aspect ratio of the pectoral fin was $4.24 \pm 0.35 \mathrm{SE}$, being the highest among the four selected species for my thesis, and the second highest value for the entire family. 


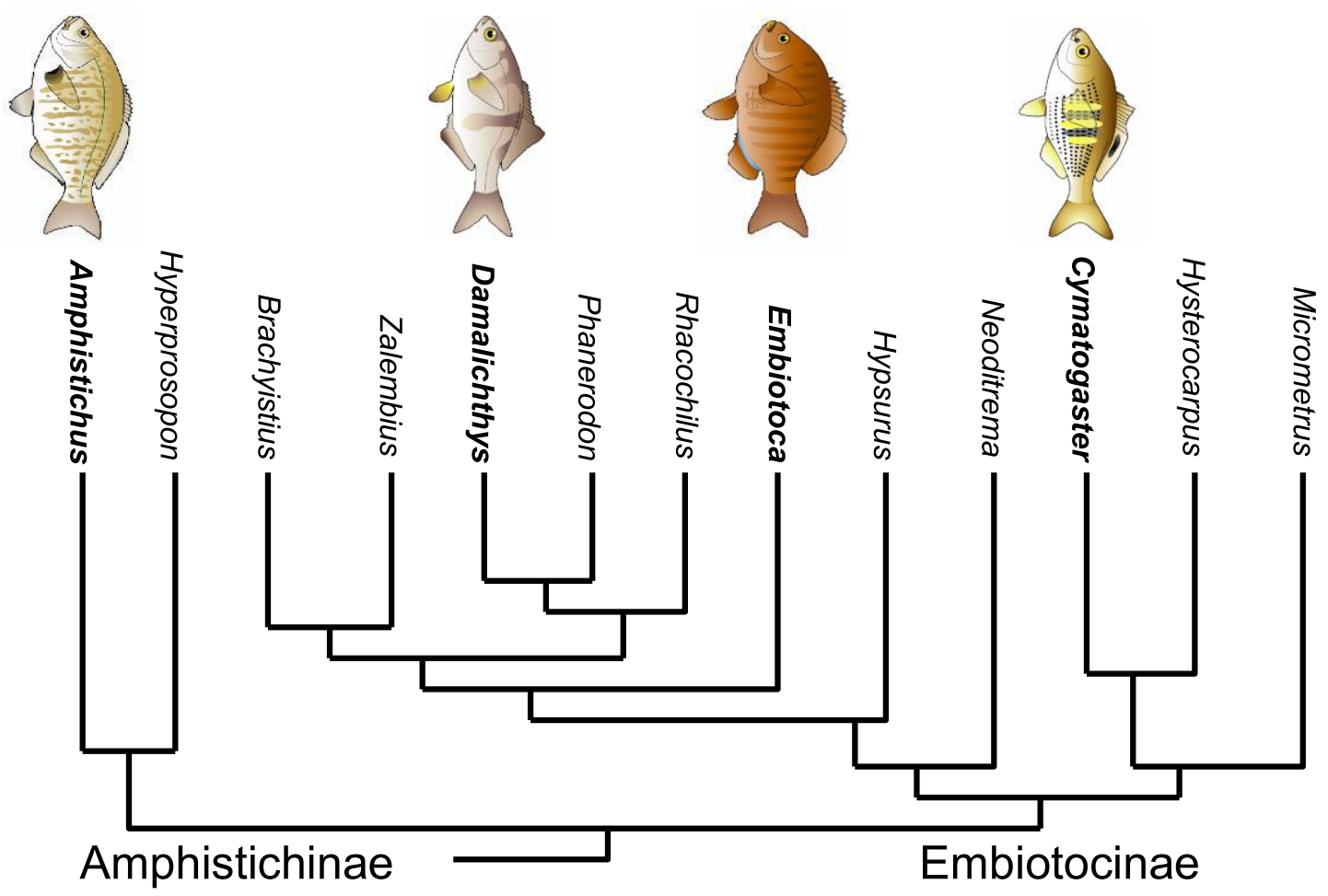

Figure 2.1. Phylogenetic tree of the family Embiotocidae. The four selected species in my thesis represent a wide range of the diversity, including both subfamilies Amphistichinae and Embiotocinae (genera of selected species in bold). Images from Allen et al. (2006) and tree modified from Bernardi and Bucciarelli (1999).

Five individuals per species were used (for a total of 20 individuals) in these experiments; this sample size was similar to other fish swimming kinematic studies (Gibb et al., 1994; Drucker and Jensen, 1996a; Mussi et al., 2002). Shiners were caught by using a beach seine at Vierra's beach in Elkhorn Slough, Monterey Bay in May 2009. Blacks were caught via an otter trawl in San Francisco Bay and by using a beach seine at Stillwater Cove, Carmel Bay in December 2008. Barred surfperches were caught using a beach seine at Del Monte beach in Monterey Bay in October 2008. Pile surfperch were caught via hook-and-line off the US Coast Guard dock next to the Monterey breakwater in November 2009. One pile was donated from the Monterey Bay Aquarium (Monterey, 
CA) and one from Aquarium of the Bay (San Francisco, CA) in August 2009. Upon capture, individuals were transferred to aquaria with a flow-through seawater system at Moss Landing Marine Laboratories and given a minimum of one week to acclimate. Fishes were monitored on a daily basis following IACUC (Institutional Animal Care and Use Committee) protocol and fed krill (Euphausia pacifica), northern anchovies (Engraulis mordax), and turban snails (Chlorostoma spp.) twice per week.

\section{Swimming performance}

Fishes tire more rapidly when swimming against persistent, greater velocity currents (Bainbridge, 1958b; 1960). The maximum aerobic swimming speed a fish can attain is the critical swimming speed, $\mathrm{U}_{\text {crit }}$ (Brett, 1964; Webb et al., 1984). To avoid being swept away, fishes that can no longer maintain their position in the water column when swimming only with pectoral fins use their caudal fin for additional forward thrust (Drucker and Jensen, 1996a; 1996b). The speed at which caudal fins are used for additional thrust is known as the pectoral-caudal fin gait transition, $\mathrm{U}_{\mathrm{p}-\mathrm{c}}$ (Brett and Sutherland, 1965; Webb, 1973; Drucker and Jensen, 1996b). Labriform fishes with increased maneuverability (more flexible body plan) reach the $\mathrm{U}_{\mathrm{p}-\mathrm{c}}$ sooner than labriform fishes with a more rigid body structure (Drucker and Jensen, 1996b; Korsmeyer et al., 2002; Mussi et al., 2002; Kendall et al., 2007).

There might be a tradeoff between maneuverability and fast aerobic-type swimming in labriform fishes. A fish with a more rigid fin and body structure may be able to generate more thrust and forward propulsion, whereas a more flexible fish may not be able to generate enough thrust via the pectoral fin to continue swimming 
aerobically at fast speeds. Using the caudal fin for additional thrust and steady swimming might help a fish to maintain its position in the water column. The critical swimming speed for each species was used to indicate their physiological limitations (Darwinian fitness), as this test is ecologically relevant to the flow conditions that surfperches experience throughout their lives in certain habitats (Brett, 1964; Brett and Sutherland, 1965; Reidy et al., 2000).

Each fish was starved for 24 hours before each trial to standardize metabolism (Brett, 1964). Each specimen was then placed into a laminar water tunnel (Engineering Laboratory Design, Inc.) that recirculates water with a flow loop arranged in a vertical configuration. Dimensions of the working section are $30 \mathrm{~cm}$ wide by $30 \mathrm{~cm}$ high by 100 $\mathrm{cm}$ long. Each fish was given one half hour to acclimate to a flow rate of half a body length per second $\left(0.5 \mathrm{BL} \mathrm{sec}^{-1}\right)$. Body length in this study was measured from the snout to the end of the caudal fin (total length; Miller and Lea, 1972). The standard formula of Brett (1964) was used to determine the critical swimming speed of each fish:

$$
\mathbf{U}_{\text {crit }}=\mathbf{U}_{\mathbf{i}}+\left(\left(\mathbf{T}_{\mathrm{i}} / \mathbf{T}_{\mathrm{ii}}\right) * \mathbf{U}_{\mathrm{ii}}\right)
$$

$\mathbf{U}_{\text {crit }}=$ critical swimming speed (distance/time)

$\mathbf{U}_{\mathbf{i}}=$ greatest velocity maintained for a full interval (minutes) at one particular velocity setting

$\mathbf{T}_{\mathbf{i}}=$ time of fatigue at the greatest current velocity (minutes)

$\mathbf{T}_{\mathrm{ii}}=$ interval duration (minutes)

$\mathbf{U}_{\text {ii }}=$ velocity $\left(\mathrm{cm} \mathrm{sec}^{-1}\right)$

Velocity $\left(\mathrm{U}_{\mathrm{ii}}\right)$ started at $0.5 \mathrm{BL} \mathrm{sec}^{-1}$ and was increased by $0.25 \mathrm{BL} \mathrm{sec}^{-1}$ every five minutes $\left(\mathrm{T}_{\mathrm{ii}}\right)$. Scaling velocity in body lengths per second allows for comparing fishes of different lengths. $U_{\mathrm{p}-\mathrm{c}}$ was noted. With the onset of burst and glide behavior of each fish, the experiment was terminated and $\mathrm{U}_{\mathrm{i}}, \mathrm{U}_{\mathrm{ii}}$, and $\mathrm{T}_{\mathrm{i}}$ were recorded, and velocity reduced to 
zero flow. Rome et al. (1990a) found that recruitment of white muscle fibers occurred when 'burst and coast' behavior was first observed during fast swimming speeds.

At each velocity increment, the pectoral fin beat frequency $(f)$ of each fish was recorded. One complete cycle of the pectoral fin beat begins with the power stroke abducting away from the body to the recovery stroke, adducting back to its resting position (Drucker and Jensen, 1996a; Figure 2.1). Pectoral fin beat cycles are speciesspecific in relation to critical swimming speed (Drucker and Jensen, 1996a; Mussi et al., 2002). Some species of surfperches reach the greatest pectoral fin beat frequency at the pectoral-caudal fin gait transition (Mussi et al., 2002).

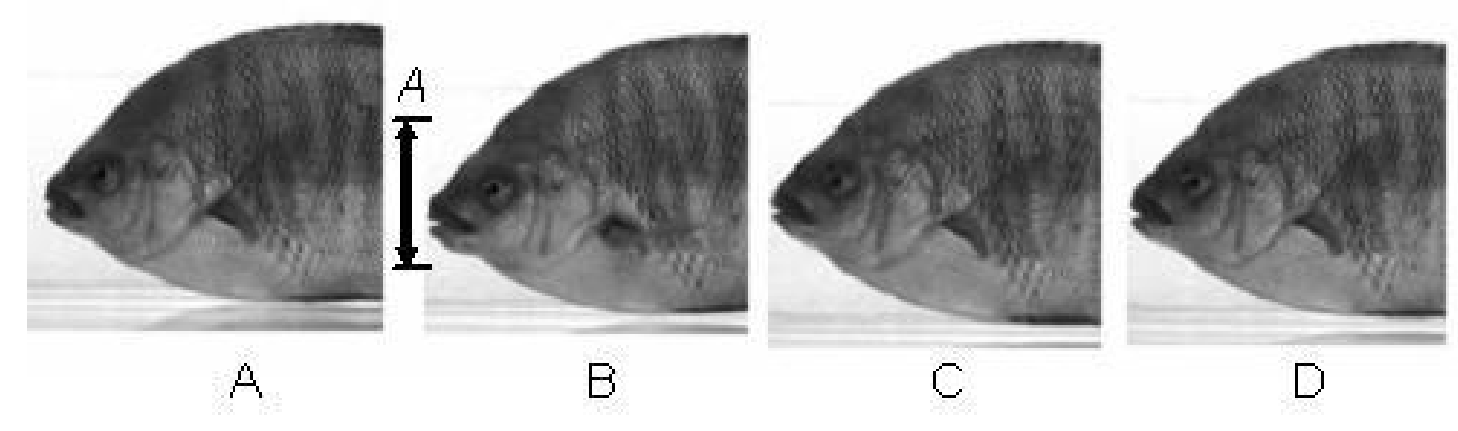

Figure 2.2. Pectoral fin beat frequency of a black surfperch (Embiotoca jacksoni). The four images were recorded from one complete fin beat cycle filmed with a high speed video camera at 250 frames per second. Thrust is generated in the power stroke (A-B) when the fin abducts away from the body and in the recovery stroke (B-D) when the fin adducts toward the body. Amplitude $(A)$ is the height of the pectoral fin when resting against the body (A) to the point when the pectoral fin is fully extended away from the body (B).

The number of fin beats in a 20 second time frame was recorded, beginning and ending the count with the fin resting against the body. Counts were recorded one minute into each velocity step so the individual fish was able to get into a steady fin beat frequency, as opposed to recording the frequency immediately at the time of transition to 
the next velocity increment, where the fish bursts and tends to swim in an erratic behavior up to about fifteen seconds (personal observation). By recording the fin beat frequency of each fish at each velocity increment until $U_{\text {crit }}$ was reached, it was possible to determine frequency changes with speed.

For the statistical analyses, a Pearson correlation matrix for the four variables $\left[\mathrm{U}_{\text {crit }}, \mathrm{U}_{\mathrm{p}-\mathrm{c}}\right.$, maximum $f$, and the change in $f$ (slope)] was conducted. If statistically significant ( $\alpha=0.05$ ), then a Principal Components Analysis (PCA) was conducted to transform the correlations and decorrelate the variables. This removed the shared components and reduced the dimensionality of the data. Subsequent analyses used the PCs as dependent variables. ANOVAs were then conducted on the PCs to test for significant differences. If there was no correlation, the original variables were run in a fixed one-way ANOVA. Also, analysis of fin beat frequency $(f)$ versus water velocity (from water velocity at acclimation to $\mathrm{U}_{\text {crit }}$ ) in each of the four species was conducted using analysis of covariance (ANCOVA), with the velocity increment as the continuous variable. The four slopes were compared to one another (value of $f$ at each velocity increment) to test if there was a difference.

\section{Body bending performance}

Surfperches are generalists, being morphological intermediates between the body forms typical of highly-maneuverable and speed-adapted fishes (Webb, 1984). Fishes that undulate their bodies are theoretically better equipped to maneuver in a tight space, whereas fishes at the other extreme with streamlined, fusiform body shapes are more adept at cruising and achieving high-speeds (Webb 1984). Increased maneuverability 
enables fishes to make sharper turns compared to fishes with a more rigid body structure (Webb, 1983; Blake et al., 1995; Fish, 1999; Gerstner, 1999; Walker, 2000).

There are many methods to test for maneuverability of live fishes such as filming them while they randomly turn in a tank, startling them to cause a turn and escape response, or observing a burst and turn (Hale, 1996; Hale et al., 2002; Wu et al., 2007). One commonly used method is to startle a fish while in a resting position. Startles generally elicit a C-start, so named because the fish makes a "C" shape while turning to change direction and avoid the offending stimulus (Weihs, 1973). The C-start is thought to be a behavior reflective of maximum bending ability, as the escape is often a life-ordeath situation (Blake, 2004).

I hypothesized that the four selected embiotocid species, which differ in their fin and body morphologies as noted in Chapter 1 of my thesis, would differ in their body flexibility, as indicated by Stage 1 of their C-start escape response. To test this hypothesis, surfperches were startled to elicit a C-start escape response. Tanks were of the following dimensions: $45 \mathrm{~cm}$ long x $35 \mathrm{~cm}$ wide with a minimum water height at 30 $\mathrm{cm}$. A plastic grid matrix was placed at the bottom of the tank with grid cells at $1.5 \mathrm{~cm}$ long $\left(2.25 \mathrm{~cm}^{2}\right)$. One to two fish of the same species were placed into the arena and given 24 hours to acclimate. Feeding was held off for at least a 24 time period to standardize specific metabolism (Brett, 1964). To elicit the startle response, a stick was hit against the side of the tank. Videos were filmed with a high-speed digital sports camera at 250 frames per second to record the C-start events. A mirror was placed over 
the tank at a $45^{\circ}$ angle with the camera being set up laterally to record the dorsal view. Two 650-watt lights were used to illuminate each fish and video.

For the purposes of this chapter, I focused exclusively on the stage 1 angle of maximum body curvature. Chapter 3 includes a detailed investigation of the entire Cstart escape response. To account for any potential displacement with the center of mass of the fish's body during stage 1 of the C-start escape response, the body bending coefficient, according to Azizi and Landberg (2002), was used:

$$
\mathrm{BC}=1-(\mathrm{CL} / \mathrm{TL})
$$

\section{BC: body bending coefficient \\ CL: chord length (cm) \\ TL: total length $(\mathrm{cm})$}

This dimensionless coefficient of body curvature allowed for a realistic measurement of the flexibility of a fish during locomotion (Webb, 1978; Azizi and Landberg, 2002; Porter et al., 2009; Figure 2.2). For statistical analyses, I conducted a fixed one-way ANOVA on the values of the stage 1 angle (C-start component) for each fish $(n=5$ per species) to compare among the four selected embiotocids. LSD post hoc tests were conducted to determine where significant differences, if any, occurred. 

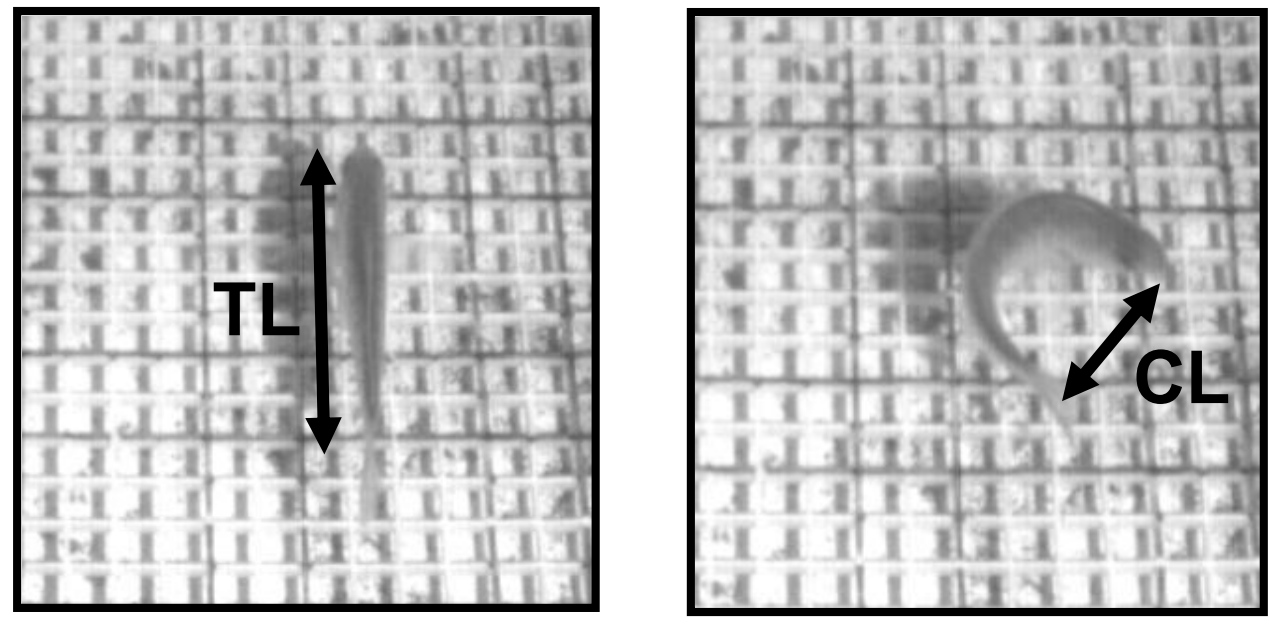

Figure 2.3. Measurement of body bending coefficient $(1-(C L / T L))$. Chord length (CL) is the distance from the tip of the snout to the tip of the caudal fin at the end of Stage 1 during the $\mathrm{C}$-start escape response. Total length (TL) of the fish is measured from the tip of the snout to the tip of the caudal fin when the fish is fully extended.

\section{RESULTS}

\section{Swimming performance}

A Pearson correlation on the four swimming performance variables $\left(\mathrm{U}_{\text {crit, }}, \mathrm{U}_{\mathrm{p}-\mathrm{c}}\right.$, maximum $f$, and slope) revealed that none were correlated with each other (Table 2.1).

Single-factor ANOVA was then conducted on each of the variables.

Table 2.1. Pearson correlation matrix of swimming performance variables. No statistically significant correlations $(\alpha=0.05)$ were found among these four variables. Therefore, a single-factor ANOVA was performed on each variable.

\begin{tabular}{|c|c|c|c|c|}
\hline Variables: & $U_{\text {crit }}(B L / s e c)$ & $U_{p-c}$ & maximum $f$ & slope $(\mathrm{m})$ \\
\hline$U_{\text {crit }}(B L / s e c)$ & 1 & - & - & - \\
\hline$U_{p-c}$ & 0.705 & 1 & - & - \\
\hline maximum $f$ & 0.804 & 0.483 & 1 & - \\
\hline slope $(\mathrm{m})$ & -0.501 & -0.058 & -0.494 & 1 \\
\hline
\end{tabular}


Standardized $\mathrm{U}_{\text {crit }}$ differed among the four species (ANOVA: $\mathrm{df}=3, \mathrm{~F}=30.386$, $\mathrm{p}<0.0001$ ). Barred and shiner surfperches swam the fastest among the four species, followed by black surfperches and then piles swimming the slowest. LSD post tests revealed that barred and shiner surfperches swam faster than blacks and piles, yet did not differ in $\mathrm{U}_{\text {crit }}$ with each another (Figure 2.4). Blacks and piles also did not differ from each other.

Absolute $\mathrm{U}_{\text {crit }}$ also differed among the four species (ANOVA: $\mathrm{df}=3, \mathrm{~F}=13.255$, $\mathrm{p}<0.0001$ ). Pile surfperch, which had the greatest body size, swam the fastest. LSD post hoc tests revealed that there were no differences in $\mathrm{U}_{\text {crit }}$ among the barred, shiner, and black surfperches, all of which had different body sizes (Figure 2.5).

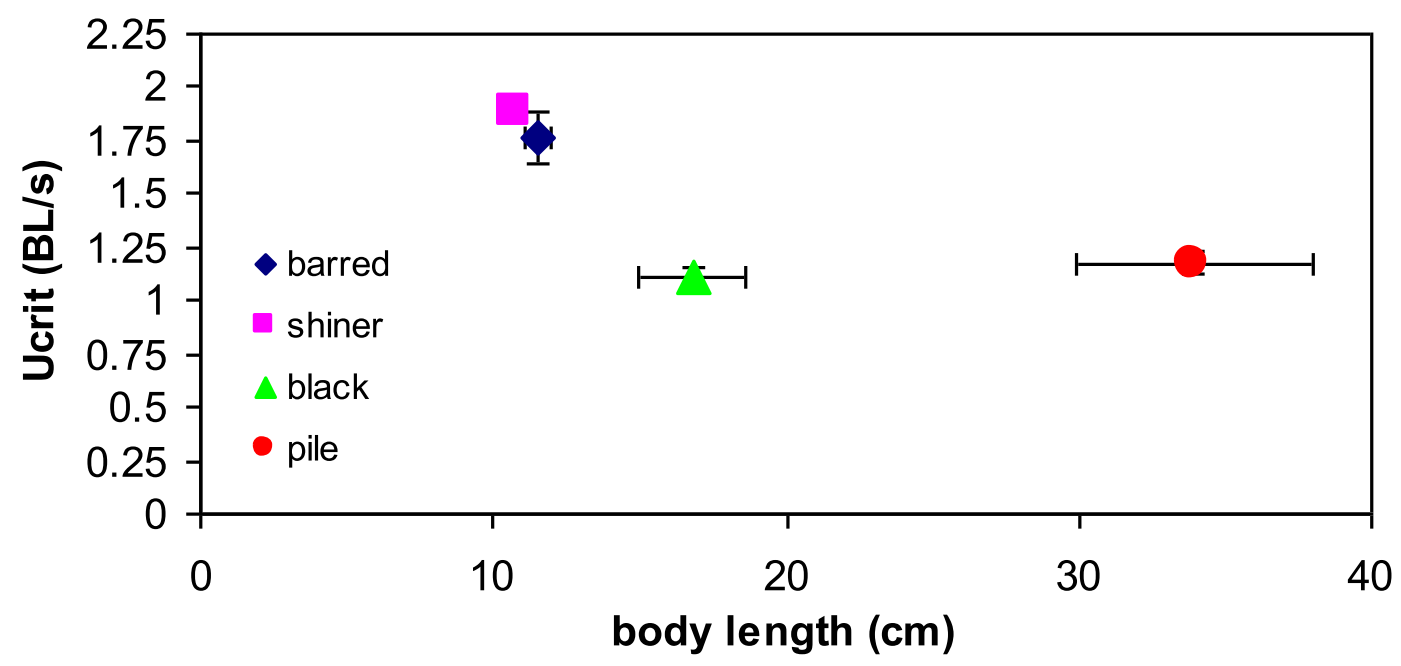

Figure 2.4. Standardized critical swimming speed $\left(U_{\text {crit }}\right)$ of four species of surfperches versus total body length $(\mathrm{cm})$. ANOVA revealed a difference in swimming speeds among the four surfperches $(p<0.0001)$. LSD post hoc tests revealed that barred and shiner surfperches were not different from one another $(p=0.23)$, yet both were different from black and pile surfperches. 


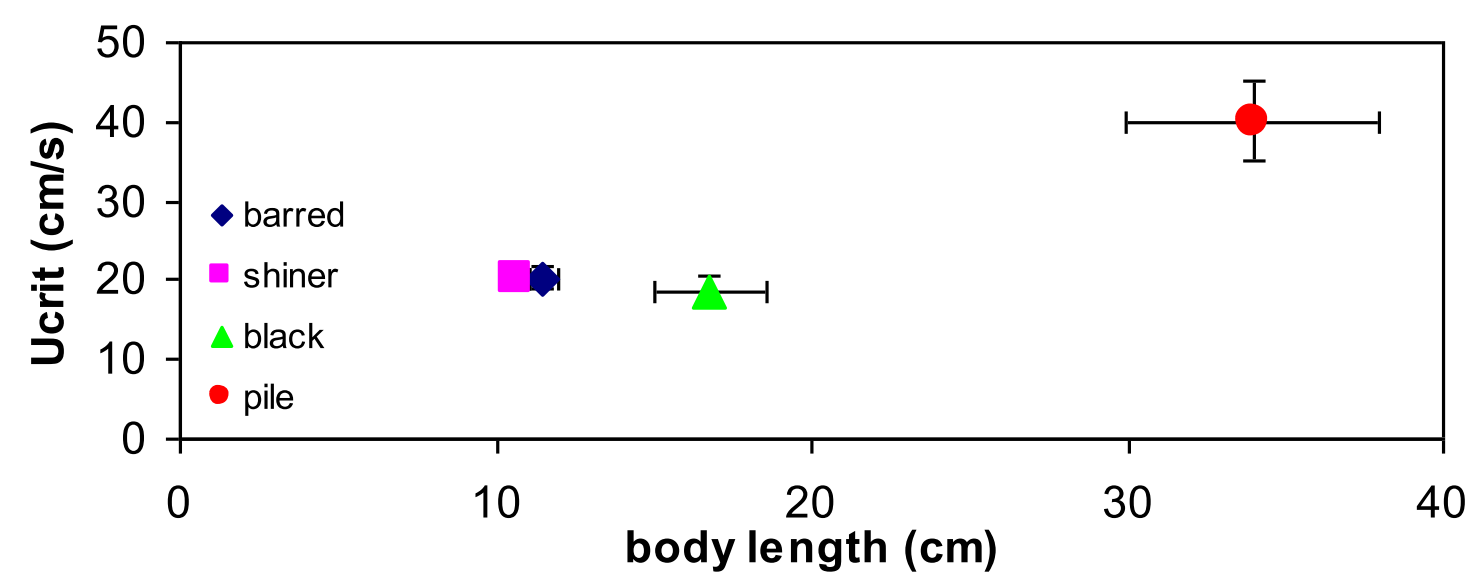

Figure 2.5. Absolute data of critical swimming speed $\left(U_{c r i t}\right)$ of four different species of surfperches. ANOVA revealed that piles achieved the fastest $U_{\text {crit }}(p<0.0001)$, which had the longest body length. LSD post hoc revealed that barred, shiner, and black surfperches were not different from one another $(p \geq 0.693)$.

Fin morphology in surfperches led to some very interesting trends with respect to the critical swimming speed. The four species were organized along a gradient of the pectoral fin angle to detect if this morphological variable would reveal any biologically and/or ecologically notable trends; no statistics were conducted. Fishes with the lower fin angle achieved the fastest $U_{\text {crit }}$, whereas fishes with the higher fin angle achieved the slowest $\mathrm{U}_{\text {crit }}\left(\mathrm{BL} / \mathrm{sec}\right.$; Figure 2.6). In terms of absolute $\mathrm{U}_{\text {crit, }}$, the barred, shiner, and black surfperches all appeared to achieve similar levels of swimming performance. Pile surfperch, with the highest fin angle, achieved the fastest absolute $U_{\text {crit }}$ (Figure 2.7). 


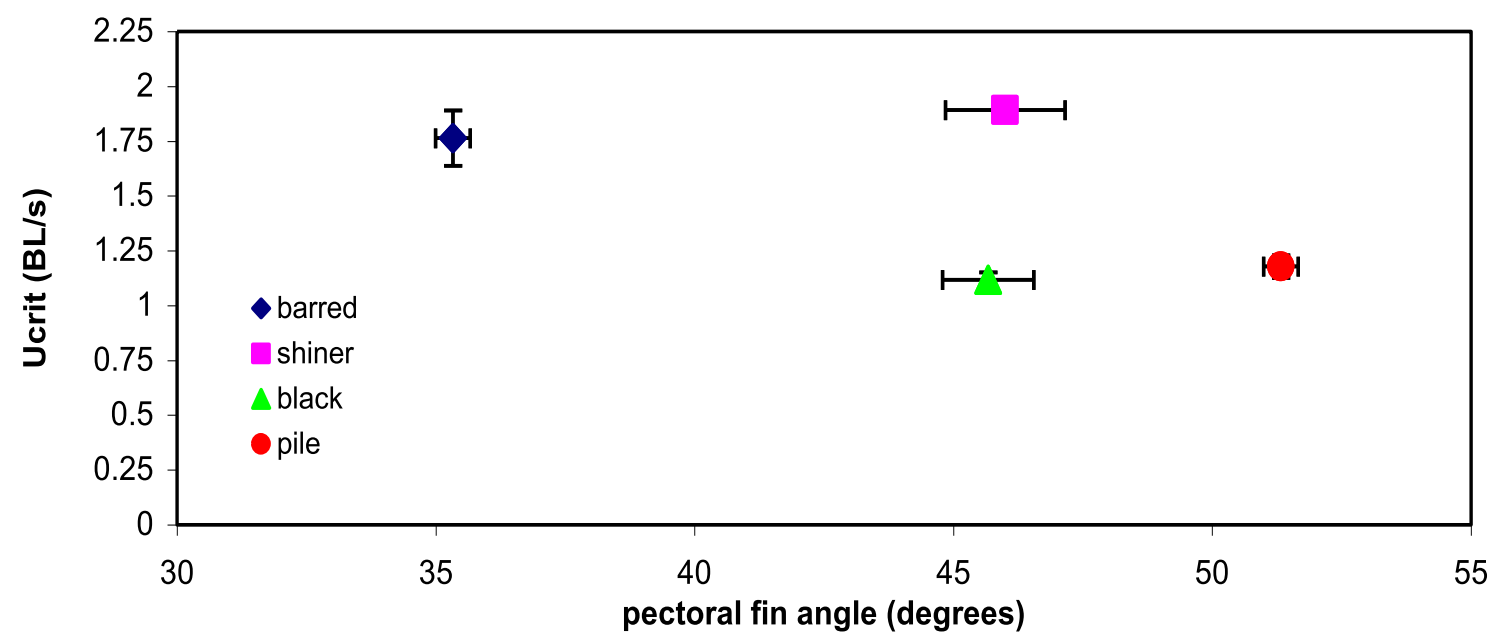

Figure 2.6. Standardized $U_{\text {crit }}$ versus pectoral fin angle. Barred and shiner surfperches achieved the fastest swimming speed and had the lowest fin angles. The slowest swimming speeds were achieved by the black and pile surfperches, which had the highest angles of insertion of the pectoral fin.

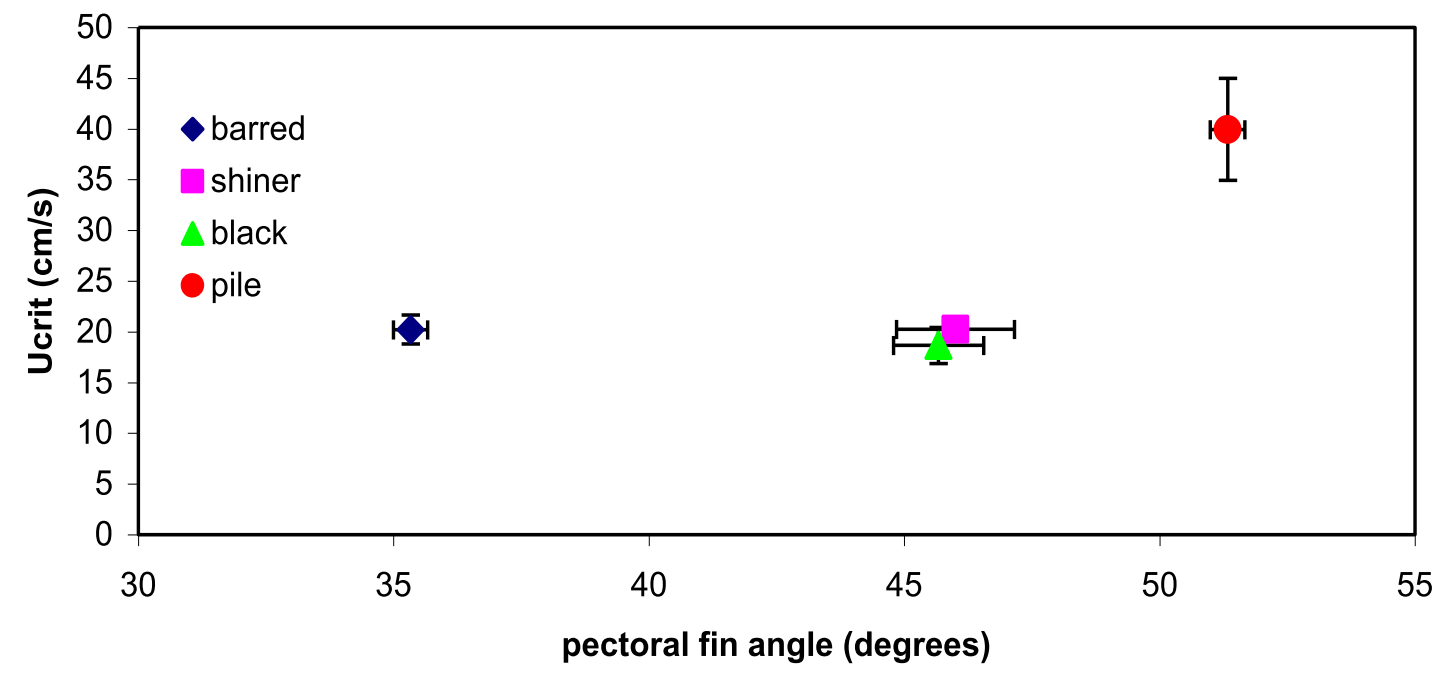

Figure 2.7. Absolute $U_{\text {crit }}$ versus pectoral fin angle. Pile surfperches achieved the fastest swimming speed and had the highest fin angle. There was no difference in swimming speed for the barred, shiner, and black surfperches, even with a difference in fin angle.

The aspect ratio of the pectoral fin was revealed to be a very important indicator of labriform swimming performance of coral reef fishes (Wainwright et al., 2002; Fulton et al., 2005). When the four species of surfperches were organized from lowest to highest 
AR of the pectoral fin, there was a negative slope in standardized $U_{\text {crit }}$ (Figure 2.8).

Shiner surfperch swam the fastest with the lowest AR, while piles had the highest AR and swam the slowest. Pile surfperch achieved the fastest swimming speed, whereas there appeared to be no difference among the barred, shiner, and black surfperches in absolute $\mathrm{U}_{\text {crit }}$ (Figure 2.9).

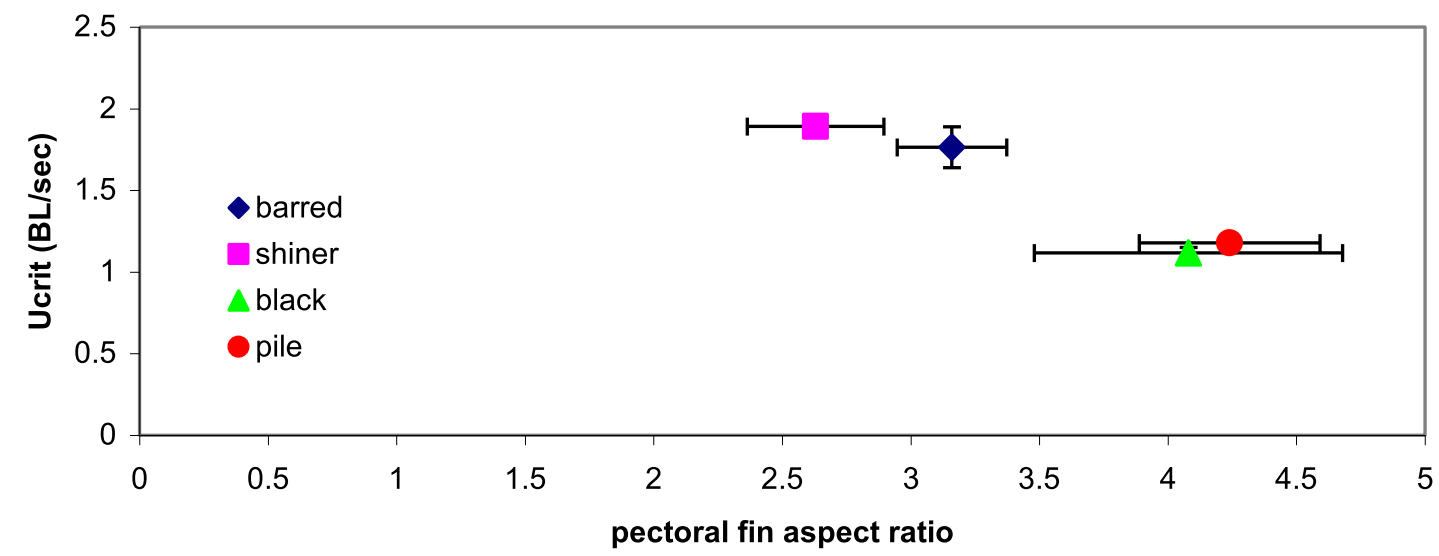

Figure 2.8. Standardized $U_{\text {crit }}$ versus pectoral fin aspect ratio. There was a trend of faster swimming performance in surfperches that had a lower aspect ratio of the pectoral fin.

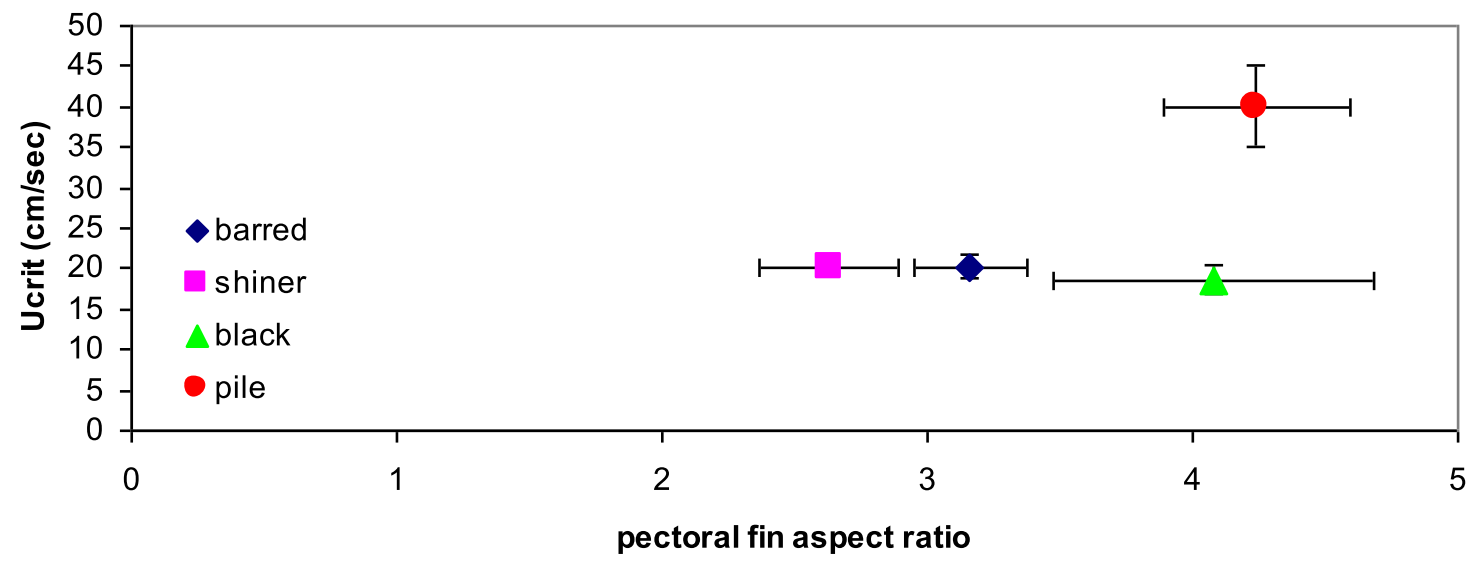

Figure 2.9. Absolute $U_{\text {crit }}$ versus pectoral fin aspect ratio. Pile surfperches achieved the fastest swimming speed and had the highest aspect ratio of the pectoral fin. 
Fin beat frequency increased throughout the $\mathrm{U}_{\text {crit }}$ experiment. Barred surfperches reached the highest fin beat frequency, followed by shiners, blacks, and then piles with the lowest fin beat frequency (Figure 2.10). ANCOVA revealed that there were differences among the four species $(\mathrm{p}<0.0001)$ along with differences during the velocity increments $(\mathrm{p}<0.0001)$. The interaction term between species and velocity increment (the covariate) was not significant $(\mathrm{p}=0.107)$. No interaction meant that all of the slopes were not different from each other. Interestingly, surfperches with a lower angle of insertion of the pectoral fin reached a higher fin beat frequency, whereas surfperches that had a higher pectoral fin angle reached a lower fin beat frequency. The trend was not as clear with respect to pectoral fin AR. Barred surfperches, with an intermediate AR value, reached the highest fin beat frequency. Shiners had the lowest AR and reached an intermediate frequency among the four species. Blacks had the second highest AR and the third lowest fin beat frequency, with piles having the highest $\mathrm{AR}$ and the lowest fin beat frequency. 


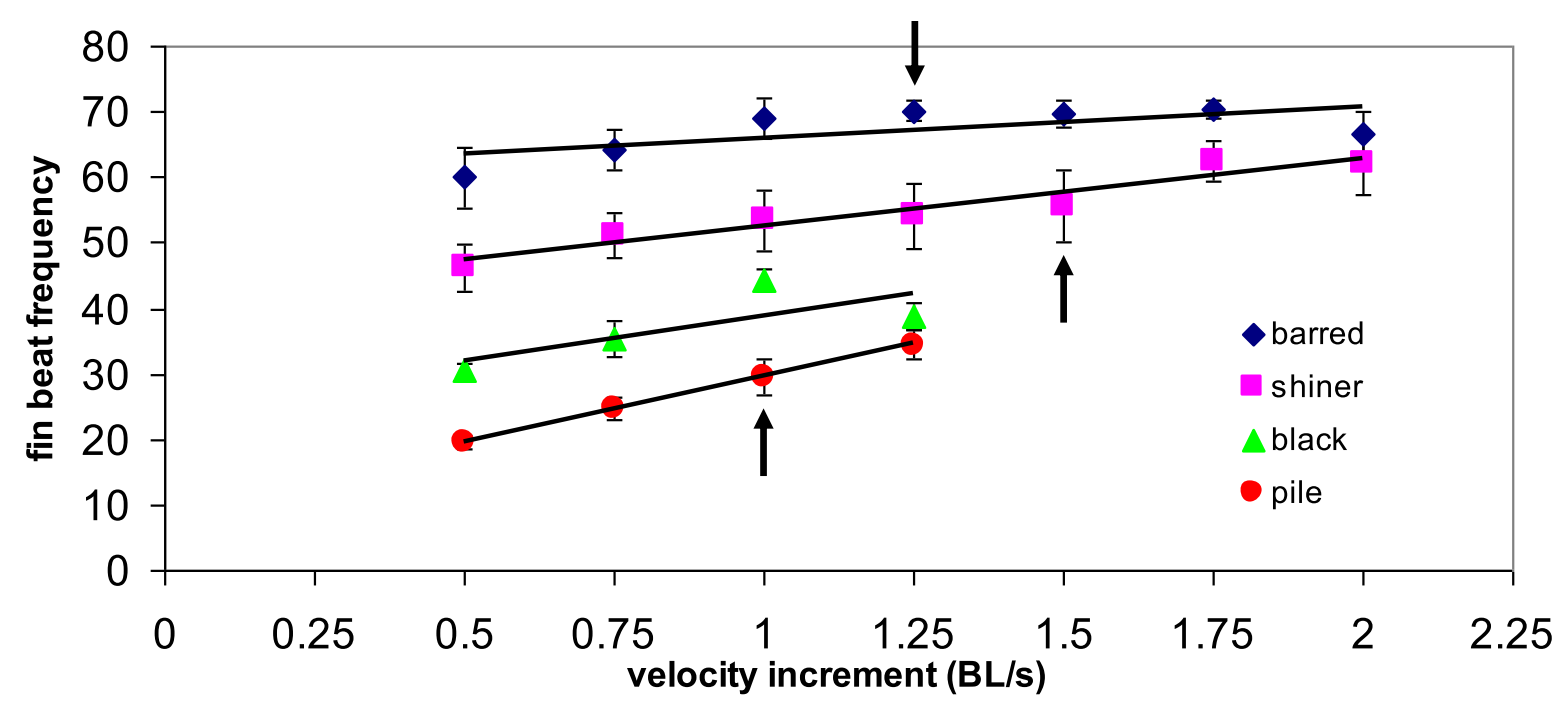

Figure 2.10. Fin beat frequency at different stages of velocity increments. Fin beats were counted until each fish reached $U_{\text {crit }}$. Barred surfperches had the highest fin beat frequency, with pile surfperches having the lowest fin beat frequency. Arrows represent the time at the pectoral-caudal fin gait transition $\left(U_{\mathrm{p}-\mathrm{c}}\right)$. Shiners reached $U_{\mathrm{p}-\mathrm{c}}$ at $1.5 \mathrm{BL} / \mathrm{sec}$, barred surfperches at $1.25 \mathrm{BL} / \mathrm{sec}$, with blacks and piles transitioning at $1.0 \mathrm{BL} / \mathrm{sec}$.

The mean time at gait transition $\left(\mathrm{U}_{\mathrm{p}-\mathrm{c}}\right)$ varied among the four species. Shiner and barred surfperches, which reached the fastest $\mathrm{U}_{\text {crit }}(\mathrm{BL} / \mathrm{sec})$, transitioned from exclusive pectoral fin swimming to recruitment of the caudal fin for additional thrust at faster flow velocities than black and pile surfperches (Figure 2.10). Barred surfperches reached $\mathrm{U}_{\mathrm{p}-\mathrm{c}}$ at the midpoint of their critical swimming speed, whereas shiners reached $U_{p-c}$ at two velocity increments prior to $\mathrm{U}_{\text {crit }}$, on average. Both black and pile surfperches underwent $\mathrm{U}_{\mathrm{p}-\mathrm{c}}$ at $1.0 \mathrm{BL} / \mathrm{sec}$, one velocity increment prior to $\mathrm{U}_{\text {crit. }}$.

\section{Body bending performance}

ANOVA revealed that there was a significant difference in body bending among the four species of surfperches $(\mathrm{df}=3, \mathrm{~F}=5.579, \mathrm{p}=0.008)$. Barred surfperches were much more flexible than the other three species (Figure 2.11). LSD post hoc tests 
revealed the main difference in body bending occurred between barred and pile surfperches $(p=0.002)$. Shiners, blacks, and piles were not different from each another $(\mathrm{p}>0.508)$

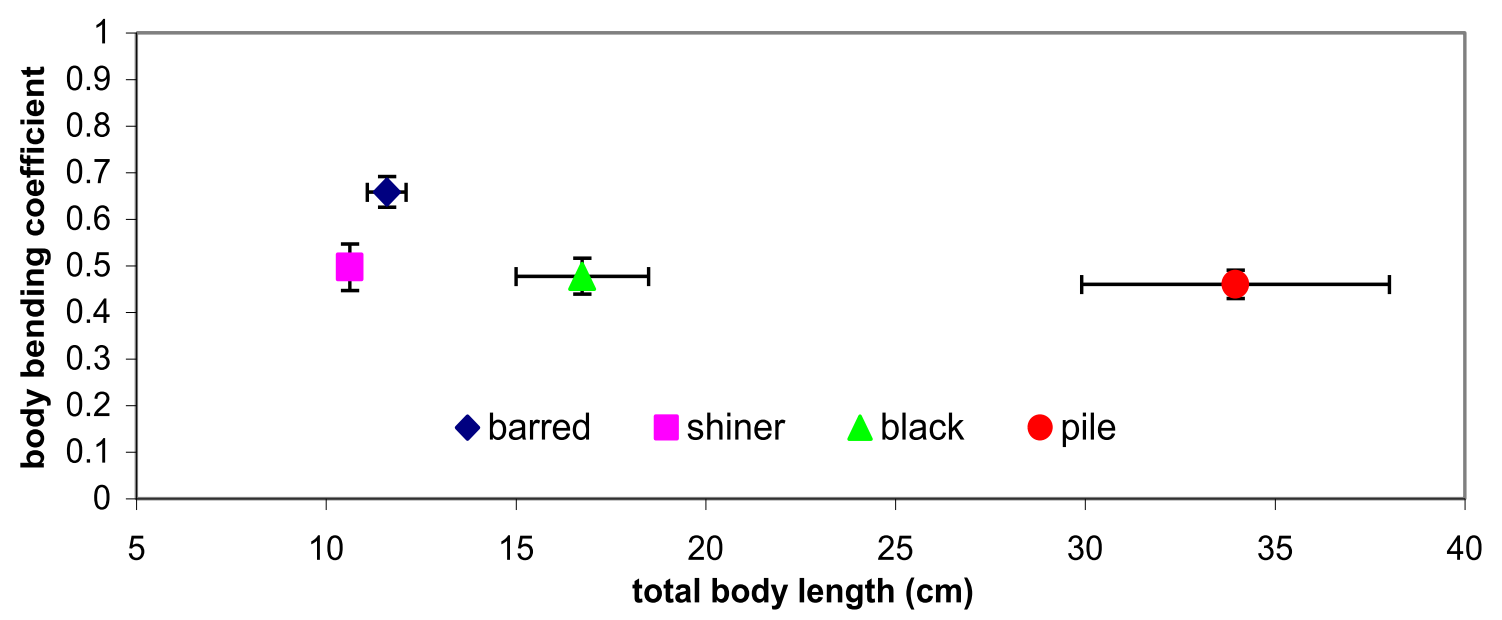

Figure 2.11. Body bending coefficient versus mean total length (cm). Barred surfperches had the greatest bending, with shiners, blacks, and piles not being statistically different from one another.

Angle of insertion and AR of the pectoral fin were each treated as the independent variable to elucidate any potential trends with body bending that may have ecological relevance with the four species. No statistics were conducted. When organized with pectoral fin angle as the $\mathrm{x}$-axis, there was a slight negative trend among the four species (Figure 2.12). Species with a lower fin angle had a greater BC, whereas species with a higher fin angle had a lower BC. There appeared to be no trend in the $\mathrm{BC}$ when dependent upon the AR of the pectoral fin (Figure 2.13). 


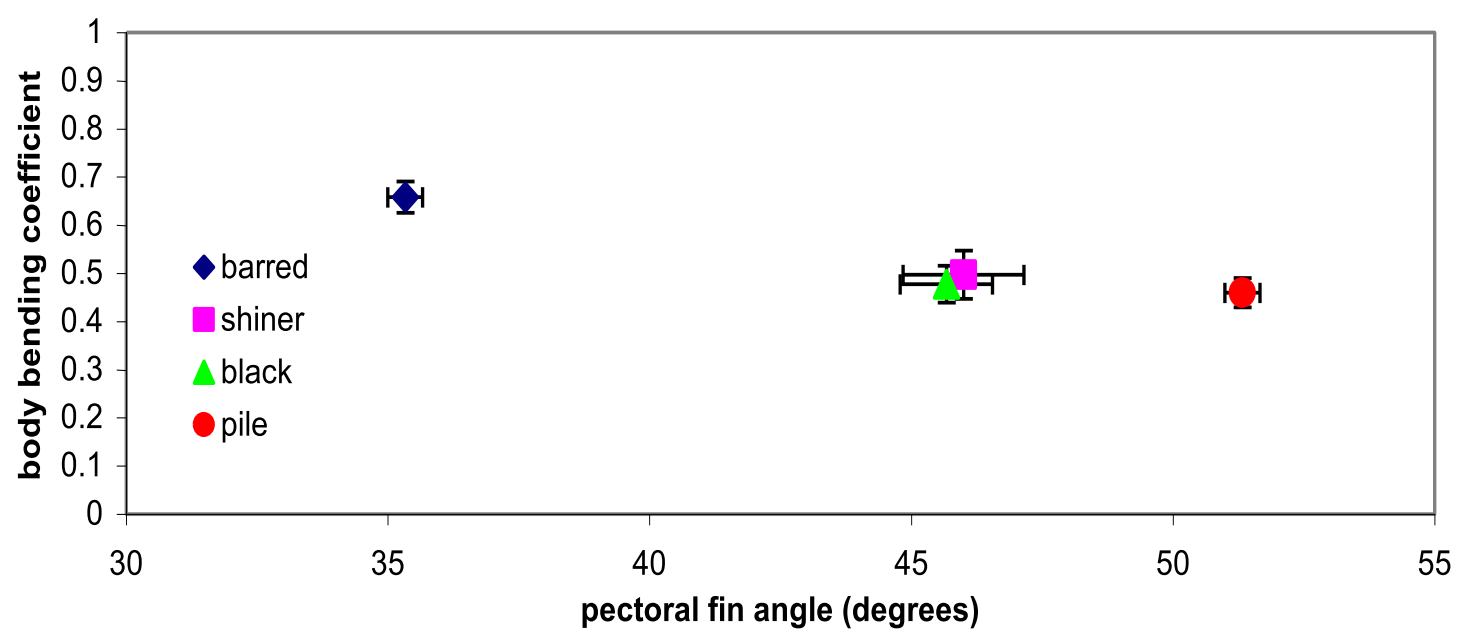

Figure 2.12. Body bending coefficient versus pectoral fin angle. Ordered in this manner, barred surfperches with the lower fin angle achieved the most amount of body bending, whereas pile surfperches with the highest fin angle had the least amount of body bending.

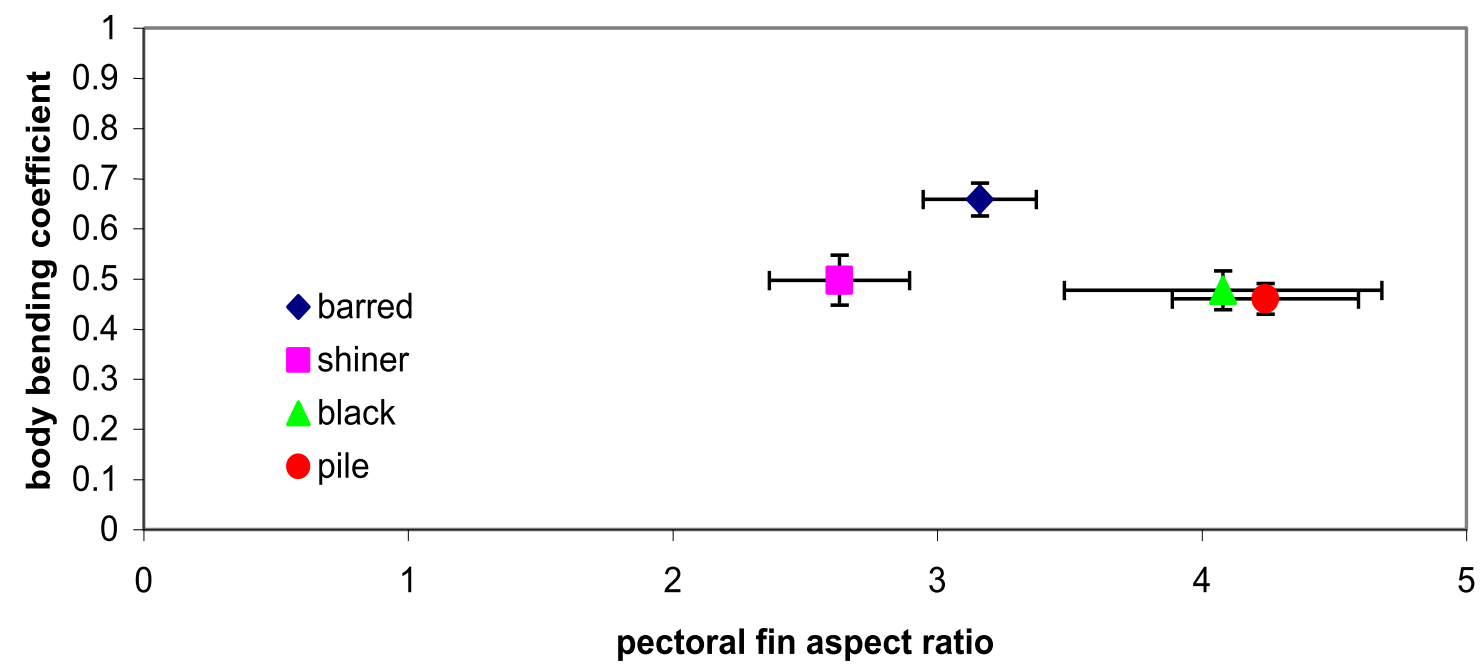

Figure 2.13. Body bending coefficient versus pectoral fin aspect ratio. There was no difference in bending with respect to aspect ratio of the pectoral fin for shiners, blacks, and piles. Barred surfperches, which had an intermediate value of AR, achieved the most bending.

Temperature and oxygen measurements are reported in Appendix B. Fluctuations of temperature $\left({ }^{\circ} \mathrm{C}\right)$ in the holding tanks were greater than in the flume (Figures B.1 and B.2). Dissolved oxygen levels $(\mathrm{mg} / \mathrm{L})$ had greater fluctuation in the holding tanks than in the flume (Figures B.3 and B.4). 


\section{DISCUSSION}

Tradeoffs in swimming performance, as indicated by $\mathrm{U}_{\text {crit }}(\mathrm{BL} / \mathrm{sec})$ and Stage 1 of the C-start escape response, were not observed in these four species of surfperches. Thus, as the physiological and morphological expectations of these labriform swimmers did not fit the ecomorphological paradigm.

Barred surfperches, which achieved the fastest $\mathrm{U}_{\text {crit }}(\mathrm{BL} / \mathrm{sec})$, also had the greatest body bending. This species occupies the surf zone, which is an extremely high energy environment (Allen et al., 2006). With waves breaking overhead and nearly constant surge-type conditions, barred surfperches must have a high aerobic capacity in order to survive in this location. The surf zone experiences more wave-swept conditions, on average, compared to the other habitats that surfperches occupy (Allen et al., 2006). Ecologically, having a greater body bending coefficient than the other three species seems to suggest that barred surfperches are the "jack of all trades," being able to swim the fastest and tightly maneuver in the surf zone.

In a prominent study on coral reef fishes that exhibit a labriform swimming mode, higher values of the pectoral fin AR were correlated with fishes that achieved faster swimming performances (Fulton et al., 2005). With a long and tapered fin, they found that fishes are able to swim faster than those with a much wider pectoral fin. In this study, the opposite effect was observed. Surfperches with a lower AR achieved a faster $\mathrm{U}_{\text {crit }}(\mathrm{BL} / \mathrm{s})$ than species with a higher AR fin. This seems counterintuitive to all other studies where researchers investigated the morphology of the pectoral fin in relation to 
swimming performance (Drucker and Jensen, 1996a; Wainwright et al., 2002; Fulton et al., 2005).

The unorthodox result of the fastest swimming surfperches having lower ARs of the pectoral fin may be explained by fin beat frequency. Barred and shiner surfperches had the highest $f$ during every step of the $\mathrm{U}_{\text {crit }}(\mathrm{BL} / \mathrm{s})$ experiments along with swimming the fastest, even though their ARs were the intermediate and highest values among the four species, respectively. Their physiology appeared to allow them to consistently beat their fins at a higher rate and for a longer amount of time until $U_{\text {crit }}(B L / s)$ was reached. Black and pile surfperches tend to occupy habitats with calmer hydrodynamic conditions compared to barred and shiner surfperches (Allen et al., 2006). Their physiological ability seems to be less aerobically fit.

Mussi et al. (2002) brought up a meaningful point about the pharyngeal jaw musculature of pile surfperches. Piles tend to crush their food items with forceful bites due to their extensive jaw muscles, which are very different from the rest of the Embiotocidae (DeMartini, 1969). To make room for their powerful jaw muscles, they may have sacrificed their capacity for aerobic activity. Both their study and mine revealed piles to swim the slowest. It would be interesting to explore the jaw muscles in relation to the rest of the muscle types to see if indeed piles are trading off jaw performance versus aerobic swimming performance.

Also in the Mussi et al. (2002) study was a claim that a physiological 'breaking point' occurred at $U_{p-c}$. There are two things to make note of here. The first is that I did not observe any 'breaking point' among the four species in this study. There was not a 
decrease in mean $f$ from the time at the gait transition through to $\mathrm{U}_{\text {crit }}(\mathrm{BL} / \mathrm{s})$ for all four species, whereas Mussi et al. (2002) observed a drop in $f$ post $\mathrm{U}_{\mathrm{p}-\mathrm{c}}$ for shiners. The four species in this study continued to swim steadily beyond $U_{p-c}$ and some even reached their maximum $f$ post $\mathrm{U}_{\mathrm{p}-\mathrm{c}}$. In their study, the decrease may have been an artifact due to the interval duration. With reduced interval duration, a particular muscle group may not have had the proper amount of time to transition to recruiting different muscles (Wilson and Egginton, 1994).

The second note is that fishes in this study all swam steadily upon entering a burst and glide behavior that occurred beyond $\mathrm{U}_{\mathrm{p}-\mathrm{c}}$. This is consistent with the findings of Rome et al. (1990a) where a real 'physiological breakpoint' occurs during the 'burst and coast' behavior, switching from aerobic to anaerobic muscle recruitment. Even though Wilson and Egginton (1994) found that some fishes recruited anaerobic muscles to power their swimming before $U_{\text {crit, }}$ it was not a factor in my study due to the fact that all 20 specimens continued to swim steadily until $U_{\text {crit }}$ was achieved. Because $U_{p-c}$ occurred at very different swimming speeds (BL/s) among the four species in this study, the gait transition does not seem to be an appropriate physiological landmark for comparing swimming performance across species.

To further explore the lack of a tradeoff in swimming performance observed among these four species, investigations into potential ontogenetic effects on $U_{\text {crit }}$ $(\mathrm{BL} / \mathrm{sec})$ and stage 1 of the C-start escape response would provide much insight into the family of surfperches. 
Observations were noted about the plasticity of the pectoral fins during the $U_{\text {crit }}$ experiments. There are two distinct modes of labriform swimming: "flapping" and "rowing." Flappers move their pectoral fins in the dorso-ventral direction, generating thrust in both directions of motion. Morphologically, the pectoral fin of a "flapper" has a low angle of attachment relative to the long axis of the body. Rowers move their pectoral fins in the antero-posterior direction, generating thrust only toward the posterior end of their body. Morphologically, pectoral fins of "rowers" have high angles of attachment relative to the long axis of the body. I found surfperches to have a gradient of pectoral fin angles ranging from $26^{\circ}$ to $51^{\circ}$, exhibiting a swimming mode between that of true flappers and rowers (Table 1.2, Chapter 1). Generating thrust via flapping is more efficient because lift is also generated, whereas rowing tends to lead to increased drag and less lift generation (Walker and Westneat, 1997; Walker and Westneat, 2002; Wainwright et al., 2002). "Flappers," therefore, tend to be associated with speed, while "rowers" might be more maneuverable at slower velocities (Webb, 1984; Bellwood and Wainwright, 2001; Wainwright et al., 2002).

Lift- and drag-based propulsion and generation of forward locomotion, however, are also affected by the kinematics of the pectoral fin (Gibb et al., 1994). Some angles of attachment may classify a fish as a "rower," but a fish can also deform (change the shape) of the pectoral fin, thus allowing it to move in a "flapper" mode (personal observation). To maximize thrust generation, a fish can actively manipulate their pectoral fins to change their angle of attack to reduce drag during forward locomotion (Lauder, 2005). Fins are also extremely flexible and hydrodynamic loading on the fin surface can cause 
the fins to passively deform (Jayne et al., 1996). By measuring fin shape during steady swimming, future investigators will be able to quantify the functional angle of attack versus the morphological angle of attack, which will provide further insight into the swimming performance of surfperches.

The role that soft rays of the pectoral fins play in shaping the picture of how surfperches partition themselves in certain habitats will further enhance our understanding of their limitations to swimming performance. Expanding on research conducted by Arita (1971) and Geerlink and Videler (1986), it is important to understand the material properties of these rays in embiotocids, as they are undoubtedly influential in the bending performance achieved. This may limit the kinematics of pectoral fins, where constraints on the functional morphology of this flexibility and/or stiffness will possibly be a factor in determining how a surfperch can manipulate its fins only so far while swimming at different flow velocities, thus affecting the habitat where a particular species of surfperch lives.

\section{ACKNOWLEDGEMENTS}

I would like to thank Dr. Lara Ferry-Graham for her assistance throughout this project. Also, I would like to thank the many volunteers that participated in the fish collections throughout central California. I am also very grateful to the Monterey Bay Aquarium and Aquarium of the Bay for their field assistance and the donation of fish specimens. All work was conducted with the approval of the SJSU IACUC under protocol \# 918 and the CDFG SCP \# 10140. 


\section{LITERATURE CITED}

Allen LG, Pondella D, Horn M. 2006. The Ecology of Marine Fishes: California and Adjacent Waters. Berkeley: University of California Press. 660 p.

Arita GS. 1971. A re-examination of the functional morphology of the soft-rays in teleosts. Copeia 1971(4):691-697.

Azizi E, Landberg T. 2002. Effects of metamorphosis on the aquatic escape response of the two-lined salamander (Eurycea bislineata). The Journal of Experimental Biology 205:841-849.

Bainbridge R. 1958b. The locomotion of fish. The New Scientist 4:476-8.

Bainbridge R. 1960. Speed and Stamina in Three Fish. Journal of Experimental Biology 37:129-153.

Bellwood DR, Wainwright PC. 2001. Locomotion in labrid fishes: implications for habitat use and cross-shelf biogeography on the Great Barrier Reef. Coral Reefs 20: 139-150.

Bernardi G, Bucciarelli G. 1999. Molecular phylogeny and speciation of the surfperches (Embiotocidae, Perciformes). Molecular Phylogenetics and Evolution 13(1):77-81.

Blake RW. 2004. Fish functional design and swimming performance. Journal of Fish Biology 65:1193-1222.

Blake RW, Chatters LM, Domenici P. 1995. Turning radius of yellowfin tuna (Thunnus albacares) in unsteady swimming manoeuvres. Journal of Fish Biology 46:536-538.

Breder CM. 1926. The locomotion of fishes. Zoologica 50:159-297.

Brett JR. 1964. The Respiratory Metabolism and Swimming Performance of Young Sockeye Salmon. Journal of Fisheries Research Board of Canada 21(5):1183-1226.

Brett JR, Sutherland DB. 1965. Respiratory metabolism of pumpkinseed (Lepomis gibbosus) in relation to swimming speed. Journal of the Fisheries Research Board of Canada 22:405-409.

DeMartini EE. 1969. A correlative study of the ecology and comparative feeding mechanism morphology of the Embiotocidae as evidence of the family's adaptive radiation into available ecological niches. Wasmann J Biol 27:177-247. 
Drucker EG, Jensen JS. 1996a. Pectoral fin locomotion in the striped surfperch. I. Kinematic effects of swimming speed and body size. J Exp Biol 199:2235-2242.

Drucker EG, Jensen JS. 1996b. Pectoral fin locomotion in the striped surfperch. II. Scaling swimming kinematics and performance at a gait transition. J Exp Biol 199: $2243-2252$.

Fish F. 1999. Performance constraints on the maneuverability of flexible and rigid biological systems. In: Proceedings of the Eleventh International Symposium on Unmanned Untethered Submersible Technology. Autonomous Undersea Systems Institute. Durham, New Hampshire. p 394-406.

Fulton CJ, Bellwood DR, Wainwright, P.C. 2005. Wave energy and swimming performance shape coral reef fish assemblages. Proc R Soc B 272:827-832.

Geerlink PJ, Videler JJ. 1986. The relation between structure and bending properties of teleost fin rays. Netherlands Journal of Zoology 37(1):59-80.

Gerstner CL. 1999. Maneuverability of four species of coral-reef fish that differ in body and pectoral-fin morphology. Canadian Journal of Zoology 77:1102-1110.

Gibb A, Jayne BC, Lauder GV. 1994. Kinematics of pectoral fin locomotion in the bluegill sunfish Lepomis macrochirus. J Exp Biol 189:133-161.

Hale ME. 1996. The development of fast-start performance in fishes: escape kinematics of the Chinook salmon (Oncorhynchus tshawytcha). American Zoologist 36:695-709.

Hale ME, Long JH, McHenry MJ, Westneat MW. 2002. Evolution of behavior and neural control of the fast-start escape response. Evolution 56:993-1007.

Jayne BC, Lozada A., Lauder GV. 1996. Function of the dorsal fin in bluegill sunfish: motor patterns during four locomotor behaviors. Journal of Morphology 228:307-26.

Kendall JL, Lucey KS, Jones EA, Wang J, Ellerby DJ. 2007. Mechanical and energetic factors underlying gait transitions in bluegill sunfish (Lepomis macrochirus). Journal of Experimental Biology 210:4265-4271.

Korsmeyer KE, Steffensen JF, Herskin J. 2002. Energetics of median and paired fin swimming, body and caudal fin swimming, and gait transition in parrotfish (Scarus schlegeli) and triggerfish (Rhinecanthus aculeatus). Journal of Experimental Biology 205:1253-1263.

Lauder GV. 2005. Locomotion. In: Evans DH, Claiborne JB, editors. The Physiology of Fishes, Third Edition. Boca Raton: CRC. p 3-46. 
Liem KF. 1991. Functional morphology. In: MHA Keenleyside, editor. Cichlid fishes: behavior, ecology and evolution. New York: Chapman and Hall. p 129-150.

Miller DJ, Lea RN. 1972. Guide to the coastal marine fishes of California. California Department of Fish and Game Fish Bulletin 157:249 p.

Mussi M, Summers AP, Domenici P. 2002. Gait transition speed, pectoral fin beat frequency and amplitude in Cymatogaster aggregatta, Embiotoca lateralis, and Damalichthys vacca. Journal of Fish Biology 61:1282-1293.

Porter ME, Roque CM, Long JH. 2009. Turning maneuvers in sharks: predicting body curvature from axial morphology. Journal of Morphology 270:954-965.

Reidy SP, Kerr SR, Nelson JA. 2000. Aerobic and anaerobic swimming performance of individual Atlantic cod. The Journal of Experimental Biology 203:347-357.

Rome LC, Funke RP, Alexander RMcN. 1990a. The influence of temperature on muscle velocity and sustained performance in swimming carp. J Exp Biol 154:163-178.

Tarp FH. 1952. A revision of the family Embiotocidae (the surfperches). Calif Div Fish Game Fish Bull 88.

Wainwright PC, Bellwood DR, Westneat MW. 2002. Ecomorphology of locomotion in labrid fishes. Environ Biol Fish 65:47-62.

Walker JA. 2000. Does a rigid body limit maneuverability? Journal of Experimental Biology 203:3391-3396.

Walker JA, Westneat MW. 1997. Labriform propulsion in fishes: kinematics of flapping aquatic flight in the bird wrasse Gomphosus varius (Labridae). The Journal of Experimental Biology 200:1549-1569.

Walker JA, Westneat M. 2002. Performance limits of labriform propulsion and correlates with fin shape and motion. Journal of Experimental Biology 205:177-187.

Webb PW. 1973. Kinematics of pectoral fin propulsion in Cymatogaster aggregata. Journal of Experimental Biology 59:697-710.

Webb PW. 1978. Fast-start performance and body form in seven species of teleost fish. J exp Biol 74:211-226.

Webb PW. 1983. Speed, acceleration and maneuverability of two teleost fishes. Journal of Experimental Biology 102:115-122. 
Webb PW. 1984. Form and function in fish swimming. Scientific American 251:72-82.

Webb PW, Kostecki PT, Don Stevens E. 1984. The effect of size and swimming speed on locomotor kinematics of rainbow trout. J exp Biol 109:77-95.

Weihs D. 1973. The mechanism of rapid starting of slender fish. Biorheology 10:343350.

Wilson RW, Egginton S. 1994. Assessment of maximum sustainable swimming performance in rainbow trout (Oncorhynchus mykiss). Journal of Experimental Biology 192:299-356.

Wu G, Yang Y, Zeng L. 2007. Routine turning maneuvers of koi carp Cyprinus carpio koi: effects of turning rate on kinematics and hydrodynamics. Journal of Experimental Biology 210:4379-4389. 


\section{CHAPTER 3: THE C-START ESCAPE RESPONSE IN FOUR SPECIES OF SURFPERCHES (EMBIOTOCIDAE) FROM CENTRAL CALIFORNIA}

\section{ABSTRACT}

Surfperches exhibit a C-start escape response to avoid disturbances, such as predators. This fast-start response consists of bending their body into a " $\mathrm{C}$ " shape, immediately followed by swinging their tail in the opposite direction to propel away from a stimulus. I hypothesized that barred, shiner, black, and pile surfperches would differ in their escape response due to variations in their fin morphology. To address this hypothesis, I collected four species with varying pectoral fin angles (range: 35 to $51^{\circ}$ ) and aspect ratio (range: 2.63 to 4.24). Each fish was acclimated in a tank for 24 hours. We elicited C-starts from individual fish, recording the escape response with a highspeed digital camera at $250 \mathrm{fps}$. I measured the maximum angle of body curvature during Stage 1 and 2, duration of Stage 1 and 2, duration of the entire C-start escape response, escape trajectory angle (ETA), and peak angular velocity (degrees/sec). I conducted a PCA on the seven variables to reduce the dimensionality of the dataset. ANOVA was then performed on the principal component scores (PCs), followed by LSD post hoc tests to reveal where significant differences, if any, occurred. PC1 described duration of Stages 1 and 2, Stage 1 angle, total escape response duration, ETA, and peak angular velocity. PC2 also described Stage1 angle and duration, and ETA. PC3 described Stage 2 angle. Shiner surfperch had the fastest response with pile surfperch being the slowest and least maneuverable. Barred surfperch achieved the greatest body curvature and the second fastest response time. Morphological and physiological differences among these 
species seemed to be the reasons for the varying performances in the C-start escape response.

KEY WORDS: embiotocids; labriform; C-start escape response

\section{INTRODUCTION}

The $\mathrm{C}$-start escape response is a fast startle response in reaction to a vibrational stimulus. Predator avoidance often elicits this response, thus being important for survival. Upon reaction, the fish's body undergoes two distinct stages (Weihs, 1973). In the first stage, the fish bends tightly around its center of mass. After undergoing what is assumed to be maximum body flexion by making a "C" shape, hence the name of this type of response, the second stage consists of the fish swinging its tail fin opposite its body to propel away from the stimulus.

Mauthner neurons, a bilateral pair of cells in the brain stem that are present in all perciform fishes, are responsible for eliciting the C-start escape response (Diamond, 1971; Eaton et al., 1977). Hair cells on a fish's body are activated by a stimulus, followed by the Mauthner axons crossing the midline of the body. The axons continue to descend down the spinal cord and then synapse on the primary motoneurons that activate the trunk musculature, which is the major component of the C-start escape response (Eaton et al., 1981; Eaton and Emberley, 1991). This escape response is considered an unsteady form of swimming. Fishes accelerate extremely fast, usually in less than one second, either away from a predator or toward a prey item. Hydrodynamic interactions are another type of stimulus to elicit this escape response in fishes. 
Surfperches occupy many nearshore habitats that vary in the complexity of their physical structure. Researchers have investigated the maneuverability of fishes in coral reef habitats and how certain morphological characteristics in fishes tend to be associated with those locations (Alexander, 1967; Webb, 1984; Bellwood and Wainwright, 2001; Fulton and Bellwood, 2002; Fulton et al., 2005). Fishes that are highly maneuverable might have a minimum turning radius along with reaching the fastest burst speeds (Howland, 1974). Those two physiological components, in terms of escaping from a predator, may be crucial to the fish's survival when swimming around corals, boulders, or kelp forests.

Speed and maneuverability are measured in this escape response. Fishes that complete stage 1 (maximum body curvature) and stage 2 (propel away from predator to begin forward swimming) in a faster duration of time may be more successful than fishes that elicit a slower response. Maximum performance is assumed to occur during this response, as the fish's survival is dependent on successfully escaping from a predator (Tytell and Lauder, 2002). Exploring the C-start escape response in a family of adult fishes will provide necessary insight into how their physiological fitness, be it speed or maneuverability, is attuned to their environment. I hypothesized that the four selected surfperches, which differ in their fin and body morphology as noted in Chapter 1, would differ in their body flexibility and reaction time.

\section{MATERIALS AND METHODS}

To test the hypothesis that there are differences in the C-start escape response, four species of adult surfperches were startled to elicit a C-start escape response (Table 
3.1). Barred surfperch were caught via beach seine at Del Monte beach, Monterey, California in October 2008. Shiner surfperch were caught in Elkhorn Slough, Moss Landing, California, also via beach seine in May 2009. Black surfperch were captured in Stillwater Cove, Carmel Bay, California using a beach seine in December 2008, and pile surfperch were caught via hook-and-line in the Monterey harbor, Monterey, California in November 2009. All fishes were immediately transported to Moss Landing Marine Laboratories and placed into aquaria with a flow-through seawater system. A minimum of a one week acclimation period was given for all fishes. Fishes were monitored on a daily basis following IACUC protocol (SJSU \# 918) and fed anchovies (Engraulis mordax) and krill (Euphausia pacifica) twice per week. Tanks were of the following dimensions: $45 \mathrm{~cm}$ long x $35 \mathrm{~cm}$ wide with a minimum water height at $30 \mathrm{~cm}$. A plastic grid matrix was placed at the bottom of the tank with grid cells at $1.5 \mathrm{~cm}$ long $\left(2.25 \mathrm{~cm}^{2}\right)$.

One to two fish of the same species were placed into the tank arena and given 24 hours to acclimate. Feeding was held off for at least a 24 time period to standardize specific metabolism (Brett, 1964). Temperature was recorded before and after the experiments, ranging from $11^{\circ} \mathrm{C}$ to $13.5^{\circ} \mathrm{C}$. To elicit the startle response, a stick (windshield wiper handle) was hit against the side of the tank while the fish was at rest. Dorsal views of the C-start events were recorded with a high-speed digital sports camera (Fastec) at 250 frames per second. A mirror was placed over the tank oriented at $45^{\circ}$ with the camera being set up laterally to record the dorsal view. A 650-watt tungsten halogen lamp was used for illumination. The lamp was approximately one meter above the tank. 
Table 3.1. Species and morphological variables. The four selected species were chosen based on differences in their pectoral fin morphology. Both the pectoral fin angle, relative to the long axis of the body, and the aspect ratio (AR) of the pectoral fin has implications on the maximum swimming performance.

\begin{tabular}{|ccccc|}
\hline Species & $\mathbf{n}$ & TL $(\mathbf{c m})$ & pectoral fin angle (deg) & pectoral fin AR \\
\hline \hline barred & 5 & $10.0-13.0$ & $35.0-36.0$ & $2.92-3.59$ \\
shiner & 5 & $10.0-11.6$ & $44.0-48.0$ & $2.12-2.98$ \\
black & 5 & $13.5-23.5$ & $44.0-47.0$ & $2.62-6.74$ \\
pile & 5 & $17.8-39.0$ & $51.0-52.0$ & $3.75-4.93$ \\
\hline
\end{tabular}

The following well-defined stages from Eaton and Emberley (1991) were recorded to capture the C-start escape response: time of applied stimulus, latency of the response, stage 1 (C-start), and stage 2 (Figure 3.1). The latency of response was the time at the initiation of the applied stimulus (time zero) to the beginning of the C-start (Weihs, 1973; Hale, 2000). After that step, the C-start escape response occured in two stages (Eaton and Emberley, 1991; Tytell and Lauder, 2002). Stage 1 was when a fish reached the maximum angle of body curvature with a "fast-body-bend" or " $\mathrm{C}$ " body shape (Eaton et al., 1977; Eaton and Emberley, 1991). After the C-start, a fish swung the posterior end of its body away from the stimulus to propel itself away from a potential predator to escape; this was referred to as stage 2 (Eaton and Emberley, 1991). The maximum angle of body curvature was measured from the body position at rest to the end of stage 2, which was the escape trajectory angle (Figure 3.2; Eaton and Emberley, 1991). Average angular velocity (degrees per second) was the maximum angle of body curvature divided by the duration of the escape response. For this study, the maximum angle always occurred in Stage 1. Therefore, average angular velocity was defined as the angle of Stage 1 divided by Stage 1 duration. This variable was most often called "peak" 
angular velocity in other studies, as it was referred to here for the remainder of this chapter.

Videos were analyzed using ImageJ software. At least four videos were recorded for each specimen $(n=5)$, with five specimens per species $(n=4)$, for a minimum of 80 videos. Duration of the time components for the entire C-start escape response was recorded by going through each video frame-by-frame (Figure 3.1). Stage 1 angle was measured by drawing a line parallel with the fish's body at rest to the point of maximum body bending, which is at the end of Stage 1 (Figures 3.1, 3.2). The line was drawn from the tip of the snout to the back of the head, being at least $1 / 3$ of the total length. Stage 2 angle was measured from the line at the end of Stage 1 to the angle drawn at the orientation of the head at the end of the escape response (when forward locomotion ensued after the fish propelled away from the stimulus with its tail fin).

Principal components analysis (PCA) was conducted on the values of each fish for seven components of the $\mathrm{C}$-start escape response. Duration of the latent response (ms) was the same for all four species; therefore it was not included in the PCA. The PCA included the following variables: stage 1 (C-start; ms), angle at stage 1 measured from the body orientation at the time of the applied stimulus (C-start; degrees), stage 2 (ms), angle at stage 2 (degrees), the entire C-start escape response (ms), escape trajectory angle (ETA; degrees), and peak angular velocity (degrees/sec). Single-factor ANOVA was performed on the principal components of the $\mathrm{C}$-start escape response variables to test for differences among the four species. LSD post hoc test were then conducted to determine where significant differences, if any, occurred. 


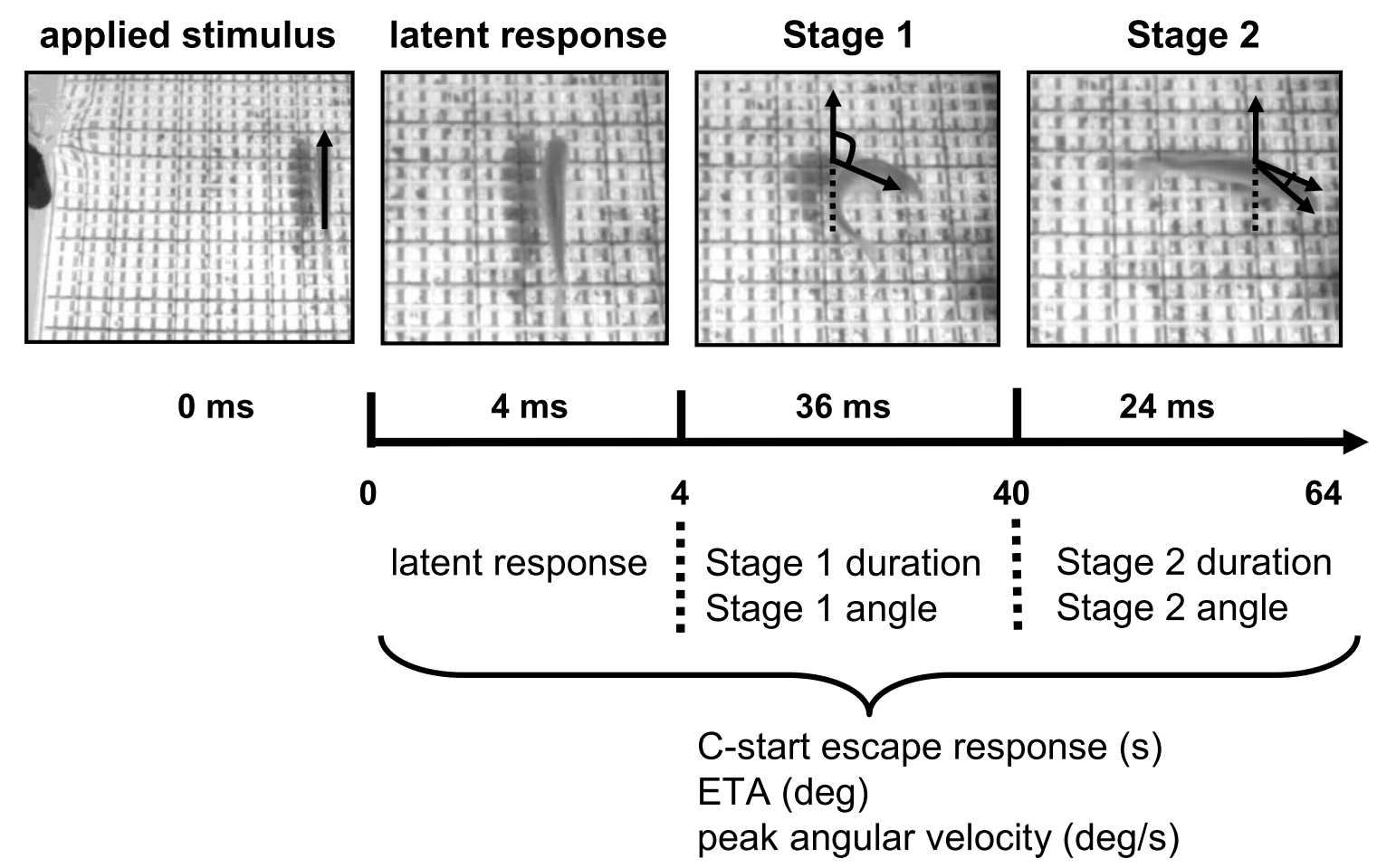

Figure 3.1. Series of a startle and escape response of a barred surfperch (Amphistichus argenteus). An external stimulus (stick) was applied to the side of a tank to elicit a C-start escape response ( 0 ms; stick at left side of tank in first cell). The latent response is the time the fish first reacts to the stimulus (here at $4 \mathrm{~ms}$ ). Maximum body curvature was achieved in $36 \mathrm{~ms}$ from the onset of the latent response (Stage 1). Forward thrust generated via the tail fin sweeping out of the "C" shape allows the fish to escape (Stage 2; this took $24 \mathrm{~ms}$ to occur). The total escape response time was $64 \mathrm{~ms}$. Each box in the matrix on the bottom of the tank is $1.5 \mathrm{~cm}$ long $\left(2.25 \mathrm{~cm}^{2}\right)$. Frames were taken from a high-speed video camera filmed at 250 frames per second. 
A

applied stimulus (start)
B

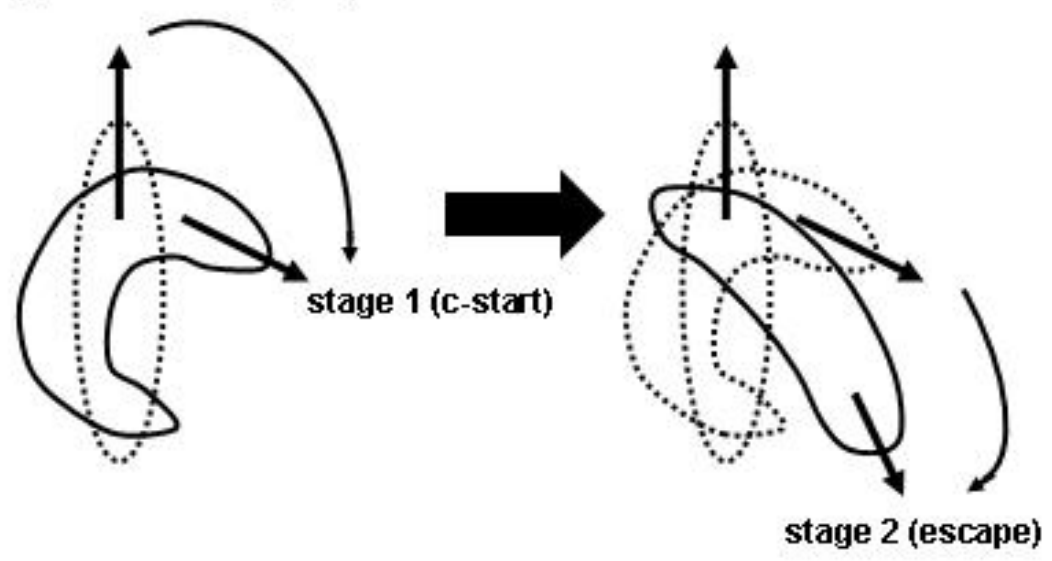

Figure 3.2. C-start escape response, as modified from Eaton and Emberley (1991). A: The dotted black line is the body shape of the fish before an applied stimulus. Arrow indicates head position. Once a stimulus is applied, the fish becomes startled and curves its body into a " $C$ " shape (stage 1 ; solid black line). The angle of stage 1 is measured from the initial body position to the position of the head angle at the end of the C-start. B: The angle of stage 2 is measured from the body position at the end of stage 1 ("C" dotted line) to the body angle when the tail fin whips away from the applied stimulus and is in line with the rest of the body (solid black line).

One important factor to note was that all four of the selected species had different body sizes. The effect of body size on swimming performance was a confounding factor that could not be ignored. The maximum total lengths of adult shiner surfperch were less than half the size of the maximum length that adult pile surfperch are capable of reaching (Miller and Lea, 1972). Comparing adult shiner surfperch to pile surfperch of the same size were not credible, as piles that small might not be adults, and possible ontogenetic effects were an added confounding factor.

\section{RESULTS}

There was variation observed among the four species of surfperches for all components in the $\mathrm{C}$-start escape response (please refer to Appendix $\mathrm{C}$ for all figures 
depicting each escape response variable versus the species and other morphological characteristics of the pectoral fin; species means were arranged via the above categories to reveal trends in the data, yet no statistics were conducted). Shiner surfperch completed the C-start escape response in the fastest amount of time, while pile surfperch reacted the slowest (Table 3.2). Barred and black surfperches were intermediate responders. The fastest C-start (Stage $1[\mathrm{~ms}]$ ) was completed by the shiner surfperch, while pile surfperch again reacted the slowest (Table 3.2). Barred surfperch had the greatest amount of body curvature for Stage 1 and the ETA, where pile surfperch had the least body bending. Stage 2 duration was completed in the fastest amount of time by the shiner surfperch, which also had the greatest body curvature for this propulsion stage. Pile surfperch were the slowest at completing Stage 2 of the escape response, where black surfperch had the least body bending for this stage. The barred surfperch had the fastest peak angular velocity, being more than double the value of pile surfperch, which were the slowest. The peak angular velocity was achieved in Stage 1 for all four species.

In the principal components analysis, six of the seven variables loaded on PCs 1 and 2, which accounted for $83 \%$ of the variability (Table 3.3). PC3 accounted for $15 \%$ of the variability with only one variable loading heavily (Stage 2 angle). Variable loadings (eigenvalues) of $0.5 \mathrm{and} /$ or greater were considered to be important for data analysis. Loadings under 0.5 were not analyzed in this study. PC1 described a positive loading of Stage 1 and 2 duration (ms), and the entire duration of the C-start escape response (ms). PC1 described a negative loading of Stage 1 angle $\left({ }^{\circ}\right)$, ETA $\left(^{\circ}\right)$, and peak angular velocity $\left({ }^{\circ} \mathrm{s}^{-1}\right)$. ANOVA performed on PC1 revealed that there was a species effect $(\mathrm{df}=3$, 
$\mathrm{F}=30.212, \mathrm{p}<0.0001)$. LSD post hoc tests revealed that barred and shiner surfperches were not different from one another $(\mathrm{p}=0.476)$, yet barred surfperch were different from black surfperch $(\mathrm{p}=0.043)$ and pile surfperch $(\mathrm{p}<0.0001)$. Black and shiner surfperches were not different from each other $(p=0.161)$, yet black surfperch were different from barred and pile surfperches. Pile surfperch were different from all three of the other species.

Along the PC1 axis, all of the timing variables loaded positively and the angular variables loading negatively (Figures 3.3A, 3.3B). Pile surfperch took the longest amount of time to complete the C-start escape response. Barred and shiner surfperches reacted in the fastest amount of time, while black surfperch were in between the other three species. Barred and shiner surfperches achieved the greatest amount of body bending for Stage 1 and the ETA, along with the fastest peak angular velocities.

PC2 described Stage 1 duration (ms) and angle $\left(^{\circ}\right)$, and ETA $\left(^{\circ}\right)$, all of which loaded positively (Table 3.3). PC2 contained the remaining variation from PC1, yet the variables were redundant. Therefore, PCs 1 and 3 were chosen to plot (Figures 3.3A, 3.3B). PC3 described Stage 2 angle, which loaded negatively (Table 3.3). ANOVA performed on PC3 revealed that this variable did not differ among the four species of surfperches $(\mathrm{df}=3, \mathrm{~F}=1.467, \mathrm{p}=0.261)$. 
Table 3.2. Mean \pm SE raw data for all variables during the $\mathrm{C}$-start escape response.

\begin{tabular}{|lcccc|}
\hline \multicolumn{1}{|c}{ Variables } & barred & shiner & black & pile \\
\hline \hline latency of response (s) & 0.004 & 0.004 & 0.004 & 0.004 \\
Stage 1 duration (s) & 0.0378 & 0.0291 & 0.0344 & 0.0477 \\
Stage 1 angle $\left(^{\circ}\right)$ & 128.9464 & 90.8495 & 94.9467 & 73.82 \\
Stage 2 duration (s) & 0.0338 & 0.0281 & 0.0365 & 0.0781 \\
Stage 2 angle $\left(^{\circ}\right)$ & 22.1417 & 30.6067 & 19.9333 & 27.5 \\
total escape response $(\mathbf{s})$ & 0.0755 & 0.0612 & 0.0749 & 0.1298 \\
ETA $\left({ }^{\circ}\right)$ & 151.0881 & 121.4562 & 114.88 & 101.32 \\
peak angular velocity $\left({ }^{\circ} \mathbf{s}^{-1}\right)$ & 3443.351 & 3234.4409 & 2769.328 & 1574.108 \\
\hline
\end{tabular}

Table 3.3. PCA results. Numbers in bold represent loadings (eigenvalues) that are important for analysis in this study.

\begin{tabular}{|lccc|}
\hline \multicolumn{1}{|c}{ Principal components } & $\mathbf{1}$ & $\mathbf{2}$ & $\mathbf{3}$ \\
\hline Variation explained (\%) & $\mathbf{6 3 . 5 8 8}$ & $\mathbf{1 9 . 7 0 8}$ & $\mathbf{1 5 . 0 0 7}$ \\
\hline Stage 1 duration (s) & $\mathbf{0 . 7 6}$ & $\mathbf{0 . 6 3}$ & 0.051 \\
Stage 1 angle ( ${ }^{\circ}$ ) & $-\mathbf{0 . 7 6 8}$ & $\mathbf{0 . 6 3 5}$ & 0.072 \\
Stage 2 duration (s) & $\mathbf{0 . 9 5 5}$ & 0.236 & 0.006 \\
Stage 2 angle ( ${ }^{\circ}$ ) & 0.165 & -0.083 & $-\mathbf{0 . 9 8 3}$ \\
C-start escape response (s) & $\mathbf{0 . 9 3 1}$ & 0.35 & 0.019 \\
escape trajectory angle $\left({ }^{\circ}\right)$ & $-\mathbf{0 . 7 3 1}$ & $\mathbf{0 . 6 2 4}$ & -0.273 \\
peak angular velocity $\left({ }^{\circ} \mathbf{s}^{-1}\right)$ & $-\mathbf{0 . 9 7 1}$ & 0.076 & 0.046 \\
\hline
\end{tabular}

In terms of body size, surfperches that were smaller had a faster C-start escape response, whereas larger surfperches had a slower response time (Figure 3.4). 


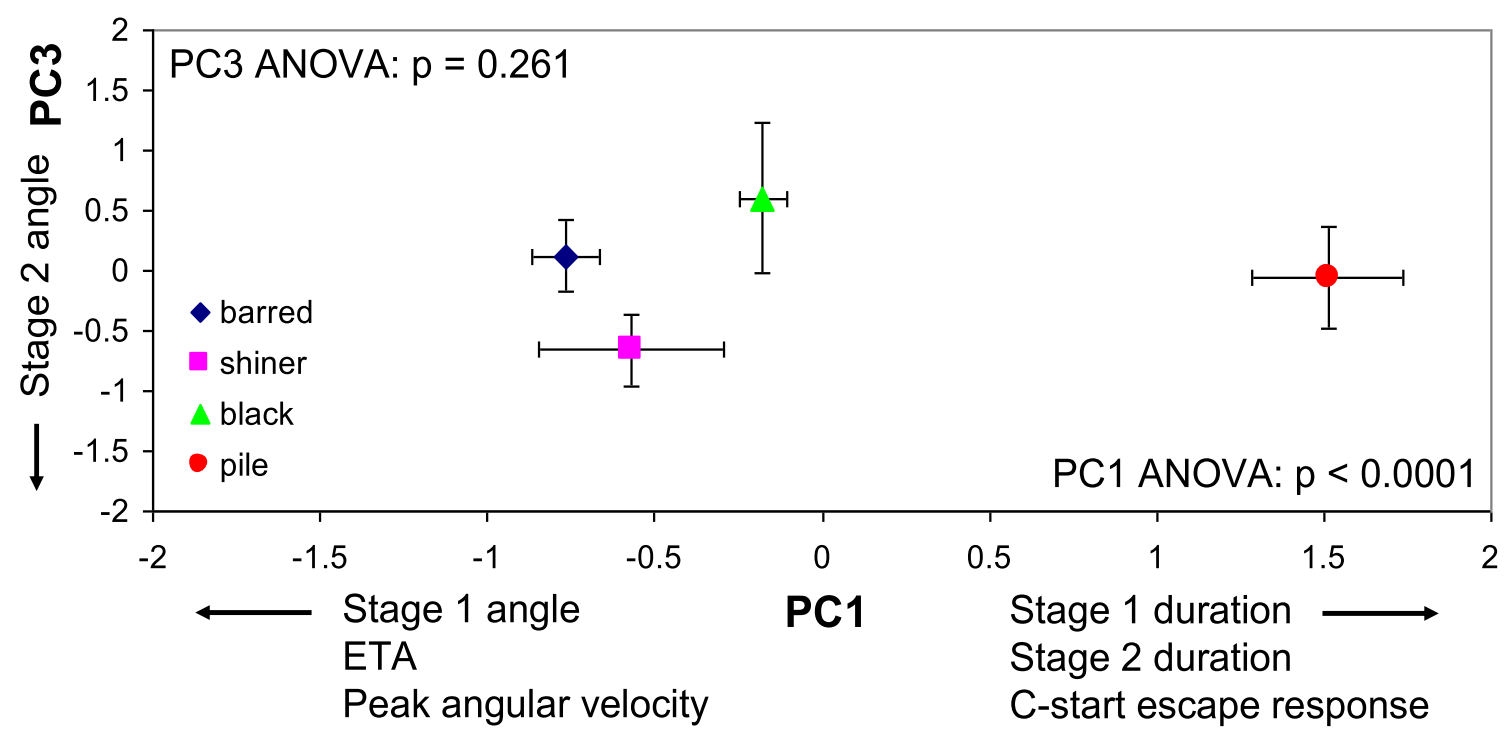

Figure 3.3A. Means \pm SE for $\mathrm{C}$-start escape response effects with $\mathrm{PC} 1$ along the $\mathrm{x}$ axis and PC3 along the y-axis. There were differences in the seven C-start escape response variables among the four species of surfperches. The four points are the means for each species. Arrows denote increasing values of the seven variables. Pile surfperch took the longest amount of time to complete the $\mathrm{C}$-start escape response, whereas shiner and barred surfperches reacted the fastest. Black surfperch achieved intermediate speeds. There was no statistical difference among the four species in terms of Stage 2 angle.

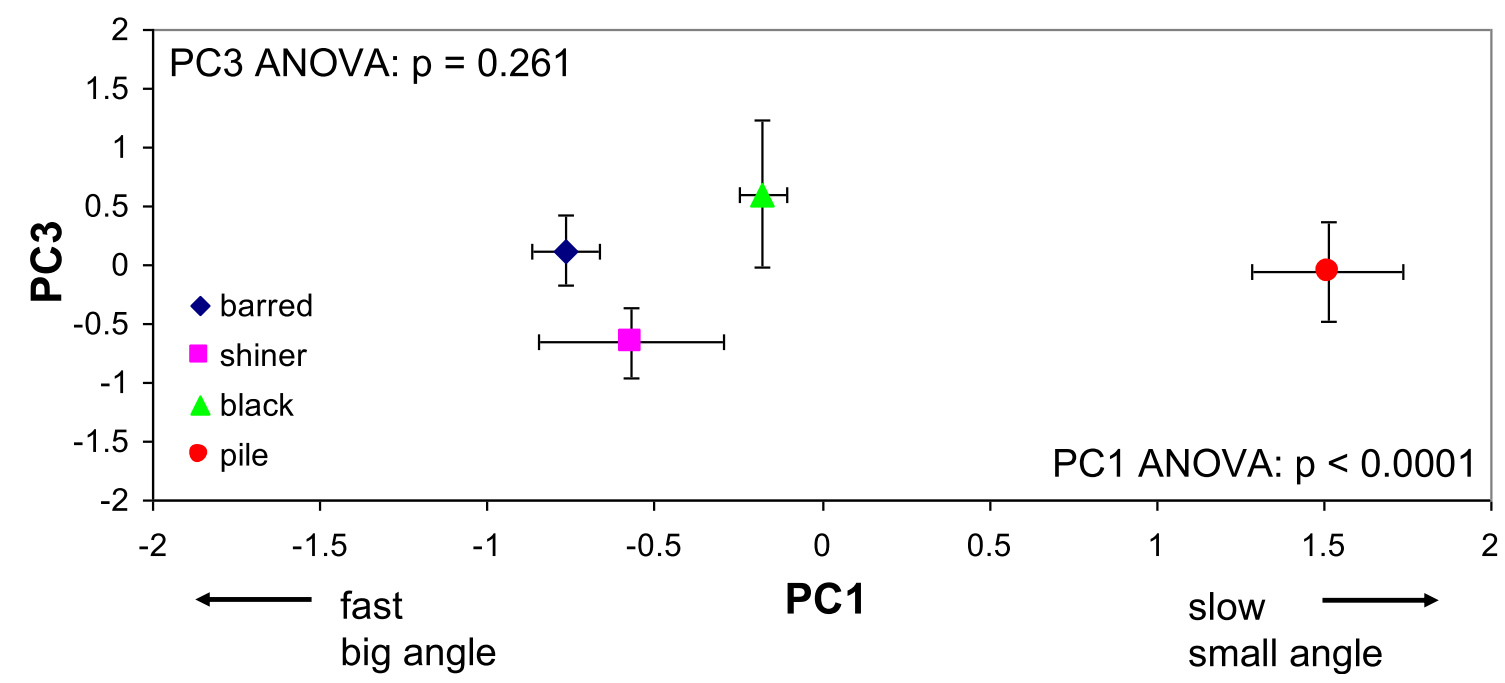

Figure 3.3B. Interpreted axes following Figure 3.3A. Along the $x$-axis, fishes toward the right swam the slowest and had a small angle of body curvature. Fishes toward the left swam the fastest and generated a larger body angle. Along the $y$ axis, there was no difference among the four species in angle of body curvature for Stage $2(\alpha=0.05)$. 


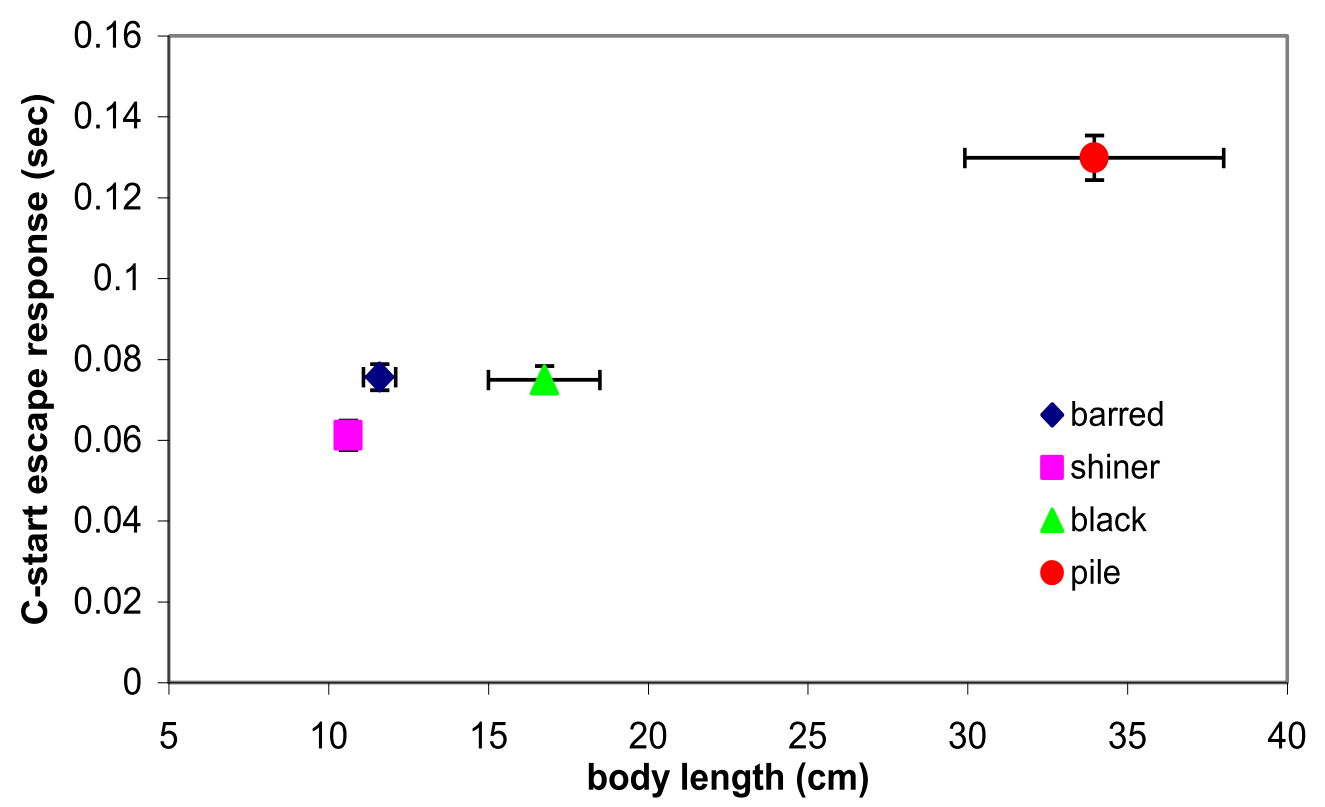

Figure 3.4. Mean \pm SE C-start escape response (sec) versus body length (cm). Larger surfperches completed the entire escape response in a slower amount of time compared to surfperches of smaller body size.

\section{DISCUSSION}

The most striking observation in this study was how different the pile surfperch performed in relation to the barred, shiner, and black surfperches. Pile surfperch were overwhelmingly slower than the other three species along with having the least body bending. Pile surfperch were also the largest of the four species, thus confounding the results. When comparing them to other fishes of large body size, they also escaped in the slowest amount of time (Table 3.4). In order to make sound comparisons, smaller adult piles would need to be selected.

The barred surfperch achieved the greatest body curvature for Stage 1 and the ETA, along with the fastest peak angular velocity. Barred surfperch live in the surf zone, where they are almost constantly experiencing vibrational stimuli from every direction. 
They must be extremely flexible at maneuvering through their habitat in order to prevent being swept away from their food source.

Black surfperch were the intermediate species in terms of body bending and reaction time. Thinking about their ecology and feeding behaviors, this species winnows their food items (DeMartini, 1969). They scoop up material along hard substrates in kelp forests and other rocky habitats and separate the non-nutritive debris from the food via their pharyngeal jaw apparatus, keeping only prey items (Tarp, 1952; DeMartini, 1969). Those habitats tend to experience, on average, moderate hydrodynamic conditions compared to the surf zone (Allen et al., 2006). Thus, black surfperch are not put to the same physiological challenges as are the barred and shiner surfperches.

Overall, shiner surfperch completed the C-start escape response in the fastest amount of time. Even so, they did not achieve as much body bending as did the barred surfperch and were second to them in terms of angular velocity. Shiners were the smallest among the four species, whereby their maximum body size only reaches about $50 \%$ of the total length of the maximum reported sizes of the other three species (Love et al., 2005). Shiner surfperch also tend to feed in the water column, consuming amphipods, fish eggs, and crustacean larvae.

Few researchers have investigated fast start and escape behaviors of marine adult fishes in comparison to the plethora of similar studies on larval fishes, many of which explored ontogenetic shifts in performance (Kimmel et al., 1980; Batty and Blaxter, 1992; Williams and Brown, 1992; Hale, 1996; Williams et al., 1996). This study was intended to add to our understanding how adult fishes in a nearshore coastal environment 
are able to respond to stimuli. In Table 3.4, the C-start escape response of the four selected surfperches was compared to other adult fishes. Pile surfperch had the slowest peak angular velocity $\left({ }^{\circ} \mathrm{s}^{-1}\right)$ among all species. The bluegill sunfish (Lepomis macrochirus), a closely related freshwater species that is also a labriform swimmer, had a peak angular velocity that was intermediate to that of the four selected surfperches. Shiner surfperch, which were similar in size for both experiments, had relatively close peak angular velocities. When observing the entire escape response, bluegills reacted the fastest, with shiner surfperch being the second fastest, about $10 \mathrm{~ms}$ slower. The bowfin (Amia calva), another freshwater fish, had one of the slowest escape responses. Both the bowfin and the pile surfperch were the longest fishes (TL), each having the slowest escape responses. This suggests that size may be a factor in the escape response. Interestingly, the bowfin had a peak angular velocity that was more than double the speed of the pile surfperch. Bowfins are long-bodied fish that undulate when they swim, whereas pile surfperch are deep-bodied and maintain steady swimming via flapping their pectoral fins. Variations in these body morphologies may be the reason for the extreme differences observed in the peak angular velocity during Stage 1 of the $\mathrm{C}$-start escape response. The bichir (Polypterus senegalus), another long-bodied fish that inhabits mostly freshwater, also had a faster peak angular velocity than all four of the selected surfperches. Barred surfperch had the fastest peak angular velocity among the four species in my study; their body morphology was much more streamlined than the bowfin and bichir, yet still slower during Stage 1. No pattern seemed to emerge regarding body 
morphology and escape response for all of the surfperches in my study. Surfperches have a broad range of escape responses in comparison to those fishes, being true generalists. Predator avoidance and prey capture are essential to the survival of a species. Further exploration is needed to understand the complexities of fast start and escape responses of marine teleost fishes with different morphological characteristics that live in different habitats. Investigating the effect of body size both intra- and interspecifically on the $\mathrm{C}$-start escape response is crucial to understanding their physiological abilities. 
Table 3.4. C-start escape response comparisons among different adult fishes. Species are categorized according to increasing total length (TL). Species observed in my study are in bold. Peak angular velocity was for Stage 1 only. Total duration of the C-start escape response included the latent response, Stage 1 duration, and Stage 2 duration. ETA included Stage 1 and 2 angles. All values are mean \pm standard error (SE), unless noted otherwise as standard deviation (SD).

\begin{tabular}{|c|c|c|c|c|c|}
\hline Species & TL (cm) & Peak ang. vel. $\left({ }^{\circ} \mathrm{s}^{-1}\right)$ & C-start esc. res. (ms) & ETA $\left(^{\circ}\right)$ & Literature cited \\
\hline guppy @ $20^{\circ} \mathrm{C}$ & $2.0 \pm 0.2$ & 10,250 & - & - & Johnson et al. (1998) \\
\hline goldfish @ $5^{\circ} \mathrm{C}$ & $7.7 \pm 0.3$ & 4250 & - & - & Johnson et al. (1998) \\
\hline goldfish @20 $20^{\circ} \mathrm{C}$ & $7.7 \pm 0.3$ & 6500 & - & - & Johnson et al. (1998) \\
\hline shiner & $10.6 \pm 0.3$ & $3234.4 \pm 393.8$ & $61.2 \pm 3.7$ & $121.5 \pm 6.9$ & present study \\
\hline goldfish & $10-13(S L)$ & 2289.6 & - & 55.1 & Eaton et al. (1988) \\
\hline bluegill sunfish* & $11.0 \pm 0.4$ & $3150 \pm 20$ & $52 \pm 0.4$ & $104 \pm 1$ & Tytell and Lauder (2008) \\
\hline barred & $11.6 \pm 0.5$ & $3443.4 \pm 59.8$ & $75.5 \pm 3.2$ & $151.1 \pm 6.9$ & present study \\
\hline bichir & $16.6 \pm 0.3$ & $3611.5 \pm 2$ & - & $130 \pm 7$ & Tytell and Lauder (2002) \\
\hline black & $16.75 \pm 1.7$ & $2769.3 \pm 95.8$ & $74.9 \pm 3.3$ & $114.9 \pm 7.5$ & present study \\
\hline bowfin** & $17.8-22.0$ & $3500 \pm 390(S D)$ & $117 \pm 26(\mathrm{SD})$ & $138.7 \pm 41.7$ & Hale et al. (2002) \\
\hline pile & $34.0 \pm 4.1$ & $1574.1 \pm 142.1$ & $129.8 \pm 5.5$ & $101.3 \pm 9.0$ & present study \\
\hline
\end{tabular}

* The bluegill sunfish was a juvenile. ** The C-start escape response for the bowfin (Amia calva) included Stage 1 and 2 duration only. 


\section{ACKNOWLEDGEMENTS}

I would like to thank Dr. Lara Ferry-Graham for her assistance with this project.

Also, I want to thank the many volunteers that helped me in the field collecting the fishes and the countless hours in the lab. All work was conducted with the approval of the SJSU IACUC under protocol \# 918 and the CDFG SCP \# 10140. Support was provided by NSF grant CAA-0641286 to LFG.

\section{LITERATURE CITED}

Alexander RMcN. 1967. Functional design in fishes. Hutchinson. London.

Allen LG, Pondella D, Horn M. 2006. The Ecology of Marine Fishes: California and Adjacent Waters. Berkeley: University of California Press. 660 p.

Batty RS, Blaxter JHS. 1992. The effect of temperature on the burst swimming performance of fish larvae. J exp Biol 170:187-201.

Bellwood DR, Wainwright PC. 2001. Locomotion in labrid fishes: implications for habitat use and cross-shelf biogeography on the Great Barrier Reef. Coral Reefs 20: 139-150.

Brett JR. 1964. The Respiratory Metabolism and Swimming Performance of Young Sockeye Salmon. Journal of Fisheries Research Board of Canada 21(5):1183-1226.

DeMartini EE. 1969. A correlative study of the ecology and comparative feeding mechanism morphology of the Embiotocidae as evidence of the family's adaptive radiation into available ecological niches. Wasmann J Biol 27:177-247.

Diamond J. 1971. The Mauthner cell. In: Hoar WS, Randall DJ, editors. Fish Physiology vol V. New York: Academic Press. p 265-346.

Eaton RC, Bombardieri RA, Meyer DL. 1977. The Mauthner-initiated startle response in teleost fish. Journal of Experimental Biology 66:65-81.

Eaton RC, Lavender WA, Wieland CM. 1981. Identification of Mauthner-initiated response patterns in goldfish: evidence from simultaneous cinematography and electrophysiology. J Comp Physiol 144:521-531. 
Eaton RC, DiDomenico R, Nissanov J. 1988. Flexible body dynamics of the goldfish Cstart: implications for reticulospinal command mechanisms. The Journal of Neuroscience 8(8):2758-2768.

Eaton RC, Emberley DS. 1991. How stimulus direction determines the trajectory of the Mauthner-initiated escape response in a teleost fish. Journal of Experimental Biology 161:469-487.

Fulton CJ, Bellwood DR. 2001. Ontogenetic habitat use in labrid fishes: an ecomorphological perspective. Marine Ecology Progress Series 236:255-262.

Fulton CJ, Bellwood DR, Wainwright PC. 2005. Wave energy and swimming performance shape coral reef fish assemblages. Proc R Soc B 272:827-832.

Gerstner CL. 1999. Maneuverability of four species of coral-reef fish that differ in body and pectoral-fin morphology. Canadian Journal of Zoology 77:1102-1110.

Hale ME. 1996. The development of fast-start performance in fishes: escape kinematics of the Chinook salmon (Oncorhynchus tshawytcha). American Zoologist 36:695-709.

Hale ME. 2000. Startle responses of fish without Mauthner neurons: escape behavior of the lumpfish (Cyclopterus lumpus). Biol Bull 199:180-182.

Hale ME, Long JH, McHenry MJ, Westneat MW. 2002. Evolution of behavior and neural control of the fast-start escape response. Evolution 56:993-1007.

Howland HC. 1974. Optimal strategies for predator avoidance: the relative importance of speed and manoeuverability. J Theor Biol 47:333-350.

Johnson TP, Cullum AJ, Bennett AF. 1998. Partitioning the effects of temperature and kinematic viscosity on the C-start performance of adult fishes. The Journal of Experimental Biology 201:2045-2051.

Kimmel CB, Eaton RC, Powell SL. 1980. Decreased fast-start performance of zebrafish larvae lacking Mauthner neurons. J Comp Physiol 140:343-350.

Love MS, Mecklenburg CW, Mecklenburg TA, Thorsteinson LK. 2005. Resource Inventory of Marine and Estuarine Fishes of the West Coast and Alaska: A Checklist of North Pacific and Arctic Ocean Species from Baja California to the Alaska-Yukon Border. U.S. Department of the Interior, U.S. Geological Survey, Biological Resources Division, Seattle, Washington, 98104, OCS Study MMS 2005030 and USGS/NBII 2005-001. 
Miller DJ, Lea RN. 1972. Guide to the coastal marine fishes of California. California Department of Fish and Game Fish Bulletin 157:249 p.

Tarp FH. 1952. A revision of the family Embiotocidae (the surfperches). Calif Div Fish Game Fish Bull 88.

Tytell ED, Lauder GV. 2002. The C-start escape response of Polypterus senegalus: bilateral muscle activity and variation during stage 1 and 2. The Journal of Experimental Biology 205:2591-2603.

Tytell ED, Lauder GV. 2008. Hydrodynamics of the escape response in bluegill sunfish, Lepomis macrochirus. The Journal of Experimental Biology 211:3359-3369.

Webb PW. 1984. Body form, locomotion and foraging in aquatic vertebrates. Am Zool 24:107-120.

Weihs D. 1973. The mechanism of rapid starting of slender fish. Biorheology 10:343350.

Williams PJ, Brown JA. 1992. Development changes in the escape response of larval winter flounder Pleuronectes americanus from hatch through metamorphosis. Marine Ecology Progress Series 88:185-193.

Williams PJ, Brown JA, Gotceitas V, Pepin P. 1996. Developmental changes in escape response performance of five species of marine larval fish. Can J Fish Aquat Sci 53: 1246-1253. 


\section{CONCLUSION}

Interestingly, no potential tradeoffs in swimming performance were observed among the four species of surfperches selected for this study. Barred surfperch achieved the greatest body bending and reached the fastest velocities; they had the lowest angle of attachment of the pectoral fin. It would be incorrect to claim that the ecomorphological paradigm was "busted," yet form did not seem to fit the function observed among these four species.

Barred surfperch occupy the surf zone, a high-energy habitat that constantly has waves propagating through the area. In order to maintain their position in the water column, barred surfperch must have a high metabolic rate to withstand the constant pounding of the surf. With waves sloshing back and forth, it seems intuitive that barred surfperch would be highly maneuverable. Also, with high metabolic rates, as observed in the $U_{\text {crit }}$ experiments, they reached the fastest speeds. With these high levels of swimming performance, it is very interesting that the aspect ratio of their pectoral fin was not the highest, but third of the four species. Their pectoral fin morphology did not conform to that as observed in similar studies, where labriform fishes with the highest aspect ratio of the pectoral fin reached the fastest swimming velocities (Fulton et al., 2001; Wainwright et al., 2002; Walker and Westneat, 2002; Fulton et al., 2005). The opposite trend was observed in the present study.

There are much needed investigations into the flexibility, stiffness, resilience, and other material properties of soft rays of the pectoral fin. Studying these biomechanical properties of the pectoral fin will allow us to better understand the limitations to their 
kinematics. Determining maximum bending before structural failure of the soft rays will allow us to understand the physical limits of fin rotation.

Knowing that the pectoral fin is flexible and highly maneuverable, we must investigate how the fin shape deforms during power and recovery strokes. The potential change in the functional angle of attack may be the reason for the differences in the swimming ability observed among the four species of surfperches. It will be important to analyze fin beat frequency to determine how the pectoral fin deforms its shape to reduce drag and increase thrust during the power stroke, which may be telling in how surfperches with higher angles of attachment of the pectoral fin may reach fast speeds.

Another important study to conduct would be to measure the metabolic conditions at the onset of burst-and-glide behavior. To this date, no researchers have investigated whether it is a combination of the pectoral girdle and caudal fin muscle complexes that have gone anaerobic, or just on at the time of this behavior. Fiber-typing these muscle complexes would prove to be important in order to better understand how and when labriform fishes transition from aerobic to anaerobic swimming.

Knowing the percentage of the pectoral girdle musculature in relation to total body musculature is important to understand possible limitations to swimming performance. Pile surfperch have a highly specialized pharyngeal jaw apparatus in order to crunch hard prey items. The evolution of musculature used for that feeding ability may have allowed for a reduced amount of space for muscles used for labriform swimming. 
An ongoing study includes researchers investigating potential size effects on swimming performance of black surfperch (Perlman and Basilio in prep). Because the four adult species selected for this study were of different body sizes both intra- and interspecifically, a more detailed analysis of size effects on an intraspecific level is important to understand if swimming performance varies. Ontogenetic experiments were also included to determine if different life history stages affect swimming performance, as indicated by $\mathrm{U}_{\text {crit }}$.

As for the C-start escape response, we now have a solid baseline dataset at known temperature values. With fluctuating ocean temperatures, the metabolic rates of surfperches, which are temperate fishes, will certainly be affected. Rises in ocean temperatures will affect their physiological performance, thus altering their escape responses. Predator-prey interactions and feeding strategies of predators may change as fast-start responses are influenced by temperature. Studying escape responses and fast starts on adult marine fishes along a temperature gradient will provide insight into how predator-prey interactions may be altered due to climatic changes.

There is much to be gained from the family of surfperches. As a small commercial fishery and popular recreational sport fish, demand on these fishes will only increase with the exponential growth of human populations. Learning as much as we can about their morphology, physiology, ecology, and evolutionary history will help us to best understand the Embiotocidae and how they fit into the greater lineage of fishes. 


\section{LITERATURE CITED (FOR CONCLUSION)}

Fulton CJ, Bellwood DR, Wainwright PC. 2001. The relationship between swimming ability and habitat use in wrasses (Labridae). Marine Biology 139:25-33.

Fulton CJ, Bellwood DR, Wainwright PC. 2005. Wave energy and swimming performance shape coral reef fish assemblages. Proc R Soc B 272:827-832.

Wainwright PC, Bellwood DR, Westneat MW. 2002. Ecomorphology of locomotion in labrid fishes. Environ Biol Fish 65:47-62.

Walker JA, Westneat M. 2002. Performance limits of labriform propulsion and correlates with fin shape and motion. Journal of Experimental Biology 205:177-187. 


\section{Appendix A}

Table A.1. Preserved specimens from the collections in the Department of Ichthyology, California Academy of Sciences, San Francisco, California.

\begin{tabular}{|c|c|c|c|c|c|}
\hline Genus & species & Group & Category \# & Location caught & Date \\
\hline Cymatogaster & aggregata & 193 & CAS 225281 & inner harbor at Estuary Park, Oakland (San Francisco Bay) & $6 / 4 / 2007$ \\
\hline Cymatogaster & aggregata & C 54 & 25528 & Millerton Gulch (NE side of Tomales Bay, Marin County) & 9/19/1948 \\
\hline Cymatogaster & aggregata & -- & 17882 & Crown Point, Mission Bay (San Diego County) & $2 / 25 / 1945$ \\
\hline Amphistichus & argenteus & 193 & SU & sandy beach inland from point, Punta Banda, Baja CA & $9 / 8 / 1949$ \\
\hline Amphistichus & argenteus & 193 & CAS 14241 & beach seine $28^{\circ} 56.2 \mathrm{~N}, 144^{\circ} 31.7 \mathrm{~W}$, Baja CA & $10 / 3 / 1970$ \\
\hline Amphistichus & argenteus & 193 & CAS 14241 & beach seine $28^{\circ} 56.2 \mathrm{~N}, 144^{\circ} 31.7 \mathrm{~W}$, Baja CA & $10 / 3 / 1970$ \\
\hline Brachyistius & frenatus & -- & 11378 & off of Summerland, CA & $12 / 8 / 1943$ \\
\hline Brachyistius & frenatus & -- & W49-406 & $\sim 1$ mile N of Portuguese Bend Pier (L.A. County) & 1949 \\
\hline Brachyistius & frenatus & -- & W49-406 & $\sim 1$ mile N of Portuguese Bend Pier (L.A. County) & 1949 \\
\hline Damalichthys & vacca & C 54 & 26142 & Tomales Bay, CA & $7 / 1 / 1955$ \\
\hline Damalichthys & vacca & C 54 & 26142 & Tomales Bay, CA & $7 / 1 / 1955$ \\
\hline Damalichthys & vacca & C 54 & 23590 & Duxbury Reef (Marin County) & $5 / 16 / 1964$ \\
\hline Embiotoca & jacksoni & 193 & -- & Monterey breakwater (Monterey County) & 6/2/1971 \\
\hline Embiotoca & jacksoni & 193 & CAS 225260 & Fort Point Pier, San Francisco Bay & $2 / 18 / 2007$ \\
\hline Embiotoca & jacksoni & 193 & CAS 213614 & near Fort Point, San Francisco Bay & $12 / 25 / 1957$ \\
\hline Embiotoca & lateralis & 193 & CAS 17774 & Shell beach $\sim 5.5$ miles N of Bodega Bay (tidepools) & $1 / 21 / 1964$ \\
\hline Embiotoca & lateralis & 193 & CAS 29571 & 1st reef point N of Mendocino, S of Jack Peters Creek mouth & $8 / 1 / 1965$ \\
\hline Embiotoca & lateralis & 193 & CAS 29777 & 2nd major reef projection, N of Shelter Cove (Humboldt Co.) & $8 / 26 / 1965$ \\
\hline Hypsurus & caryi & 193 & -- & Drakes Bay, CA & 2/6/1963 \\
\hline Hypsurus & caryi & C 54 & 25003 & Santa Barbara, CA & 1946 \\
\hline Hypsurus & caryi & 193 & -- & near Fort Point, San Francisco Bay & $12 / 25 / 1957$ \\
\hline Hyperprosopon & ellipticum & 193 & CAS 212455 & San Pedro, CA (on seiners) & Jan-47 \\
\hline Hyperprosopon & ellipticum & 193 & CAS 212455 & San Pedro, CA (on seiners) & Jan-47 \\
\hline Hyperprosopon & ellipticum & 193 & CAS 212454 & -- & 1972 \\
\hline Hyperprosopon & argenteum & 193 & CAS 225258 & Fort Point Pier, San Francisco Bay & 2/18/2007 \\
\hline Hyperprosopon & argenteum & C 54 & 25235 & Sunset Cliffs, CA & $6 / 18 / 1947$ \\
\hline Hyperprosopon & argenteum & C 54 & 25235 & Sunset Cliffs, CA & $6 / 18 / 1947$ \\
\hline
\end{tabular}

Continued on the next page... 
Table A.1. (Continued).

\begin{tabular}{|c|c|c|c|c|c|}
\hline Micrometrus & aurora & -- & 19547 & 0.8 miles $\mathrm{N}$ of Punta Descanso, Baja CA & $11 / 21 / 1945$ \\
\hline Micrometrus & aurora & -- & 19547 & 0.8 miles N of Punta Descanso, Baja CA & $11 / 21 / 1945$ \\
\hline Micrometrus & aurora & 193 & CAS 212355 & Williams Cove, Santa Cruz Island, Channel Islands, CA & $3 / 11 / 1950$ \\
\hline Hysterocarpus & traski & 193 & CAS 45490 & Clear Lake, CA (Lake County) & 6/6/1962 \\
\hline Hysterocarpus & traski & 193 & CAS 212527 & San Joaquin River (Italian Slough 6 miles NW of Tracy, CA) & $6 / 21 / 1969$ \\
\hline Hysterocarpus & traski & 193 & CAS 212527 & San Joaquin River (Italian Slough 6 miles NW of Tracy, CA) & $6 / 21 / 1969$ \\
\hline Zalembius & rosaceus & C 54 & 26590 & off of Santa Monica, CA & $6 / 21 / 1953$ \\
\hline Zalembius & rosaceus & -- & EI-1833-1846 & $\sim 3$ miles NW of Tomales Point, Bodega Bay, CA & $8 / 20 / 1971$ \\
\hline Zalembius & rosaceus & -- & EI-1833-1846 & $\sim 3$ miles NW of Tomales Point, Bodega Bay, CA & $8 / 20 / 1971$ \\
\hline Micrometrus & minimus & 193 & CAS 225288 & Half Moon Bay harbor pier and rock jetty, CA & $6 / 17 / 2007$ \\
\hline Micrometrus & minimus & 193 & CAS 212372 & Whites Point 100 yards N of Main Point (L.A. County) & $6 / 2 / 1949$ \\
\hline Micrometrus & minimus & 193 & CAS 212372 & Whites Point 100 yards N of Main Point (L.A. County) & $6 / 2 / 1949$ \\
\hline Rhacochilus & toxotes & C 54 & 26143 & Tomales Bay, CA & $7 / 1 / 1955$ \\
\hline Rhacochilus & toxotes & C 54 & 26143 & Tomales Bay, CA & $7 / 1 / 1955$ \\
\hline Rhacochilus & toxotes & 54 & 48883 & just beyond PG\&E intake by Morro Bay rock (SLO County) & $10 / 30 / 1955$ \\
\hline Phanerodon & atripes & 193 & SU 68876 & San Francisco Bay & $2 / 28 / 1916$ \\
\hline Phanerodon & atripes & 193 & CAS 51283 & 2 miles off of Redondo beach at $100 \mathrm{ft}$ depth & 9/23/1935 \\
\hline Phanerodon & atripes & 193 & CAS 51283 & 2 miles off of Redondo beach at $100 \mathrm{ft}$ depth & 9/23/1935 \\
\hline Phanerodon & furcatus & 193 & 38748 & Monterey Bay (depth 20-40 meters via $26 \mathrm{ft}$ otter trawl) & Dec-75 \\
\hline Phanerodon & furcatus & 193 & CAS 31829 & Gulf of the Farallones (3 miles offshore) & Oct-73 \\
\hline Phanerodon & furcatus & 193 & CAS 31829 & Gulf of the Farallones (3 miles offshore) & Oct-73 \\
\hline Hyperprosopon & anale & 193 & 38747 & Monterey Bay (depth 20-40 meters via $26 \mathrm{ft}$ otter trawl) & Dec-75 \\
\hline Hyperprosopon & anale & 193 & CAS 31828 & Gulf of the Farallones (3 miles offshore) & Oct-73 \\
\hline Hyperprosopon & anale & 193 & CAS 31828 & Gulf of the Farallones (3 miles offshore) & Oct-73 \\
\hline Amphistichus & rhodoterus & -- & -- & Monterey Bay & $3 / 15 / 1946$ \\
\hline Amphistichus & rhodoterus & -- & -- & Monterey Bay & $3 / 15 / 1946$ \\
\hline Amphistichus & rhodoterus & -- & -- & Monterey Bay & $3 / 15 / 1946$ \\
\hline Amphistichus & koelzi & -- & F 51-7 & Muir beach, CA & 1951 \\
\hline Amphistichus & koelzi & -- & F 51-7 & Muir beach, CA & 1951 \\
\hline Amphistichus & koelzi & 193 & CAS 82491 & Beechers Bay, Santa Rosa Island, Channel Islands, CA & $3 / 8 / 1950$ \\
\hline
\end{tabular}


Appendix B

\section{Tank temperature fluctuations}

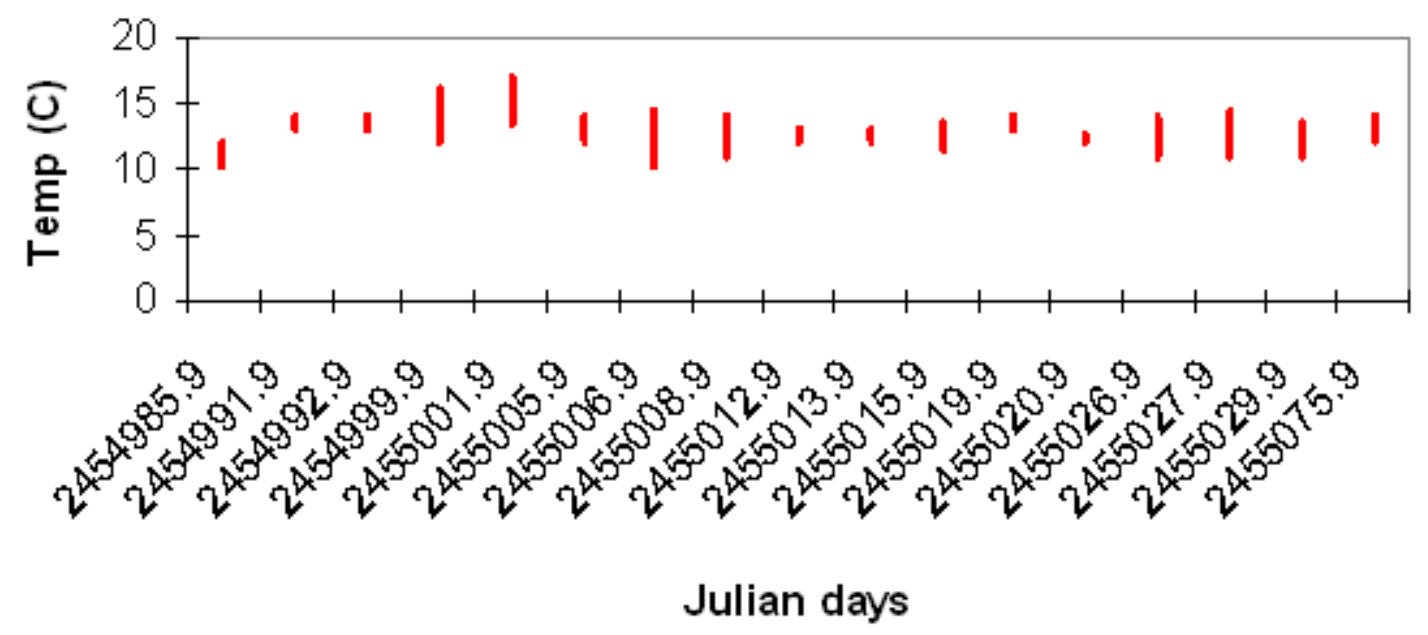

Figure B.1. Temperature fluctuations in holding tanks.

Flume temperature fluctuations

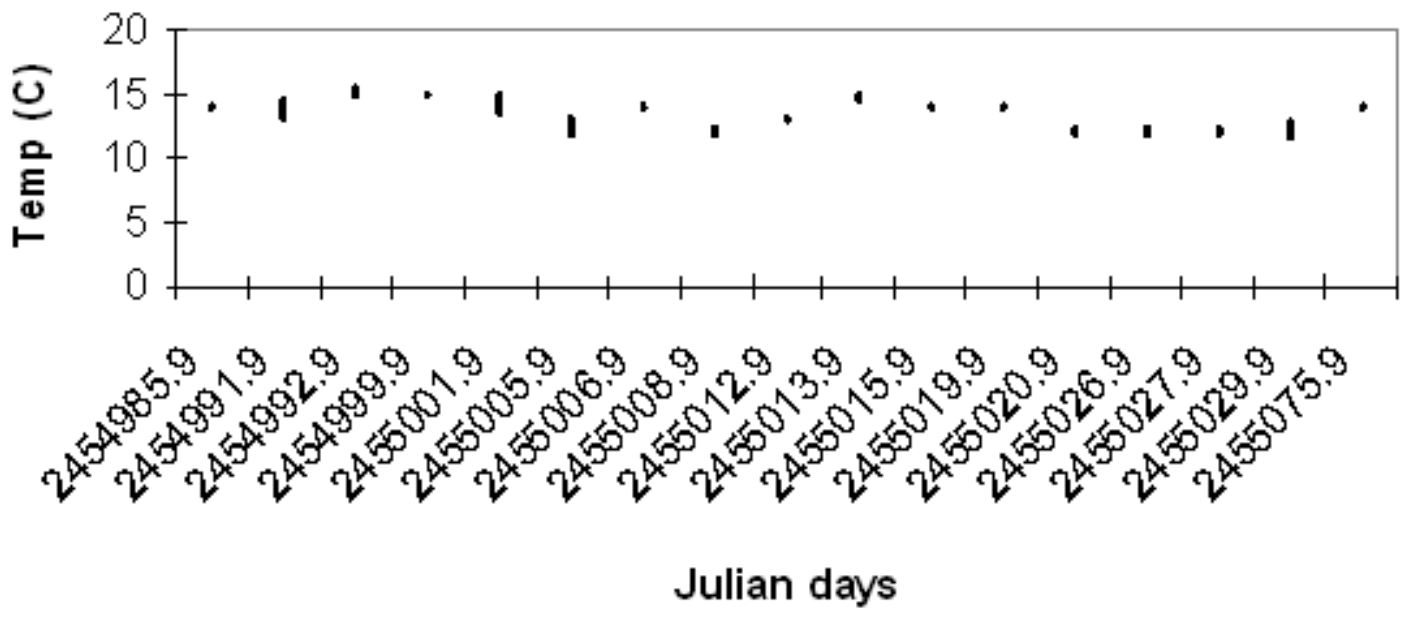

Figure B.2. Temperature fluctuations in the flume. 
Dis s olve d oxygen ( $\mathrm{mg} / \mathrm{L}$ ) fluctuations in tanks

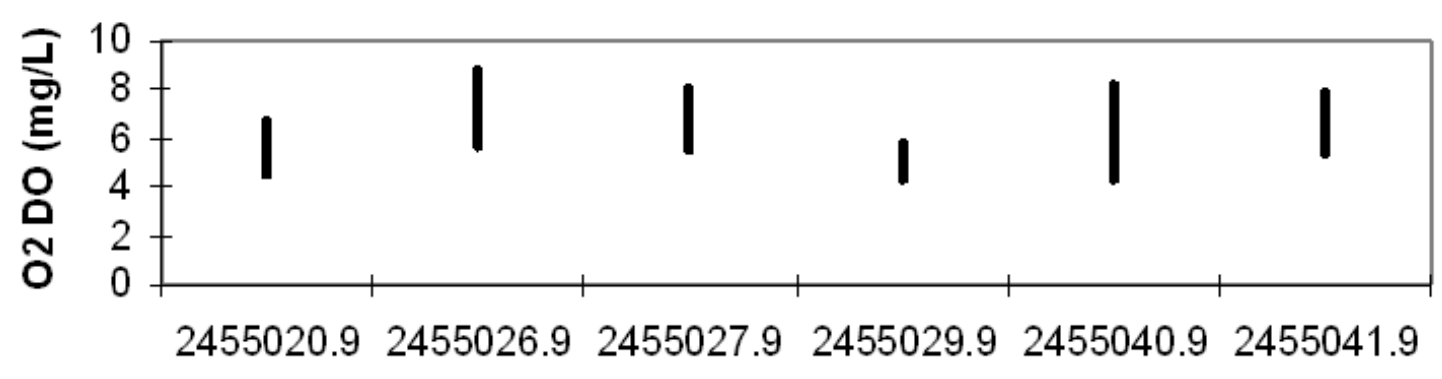

Julian days

Figure B.3. Fluctuation of dissolved oxygen $(\mathrm{mg} / \mathrm{L})$ in the holding tanks.

Diss olved oxygen ( $\mathrm{mg} / \mathrm{L}$ ) fluctuations in flume

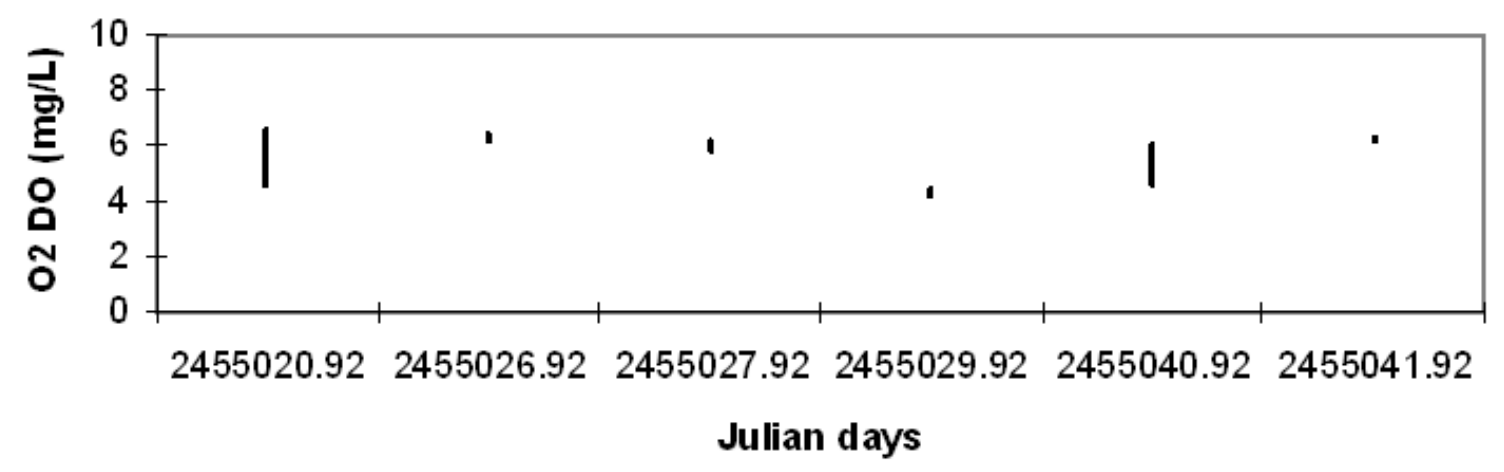

Figure B.4. Fluctuation of dissolved oxygen $(\mathrm{mg} / \mathrm{L})$ in the flume. 
Appendix C

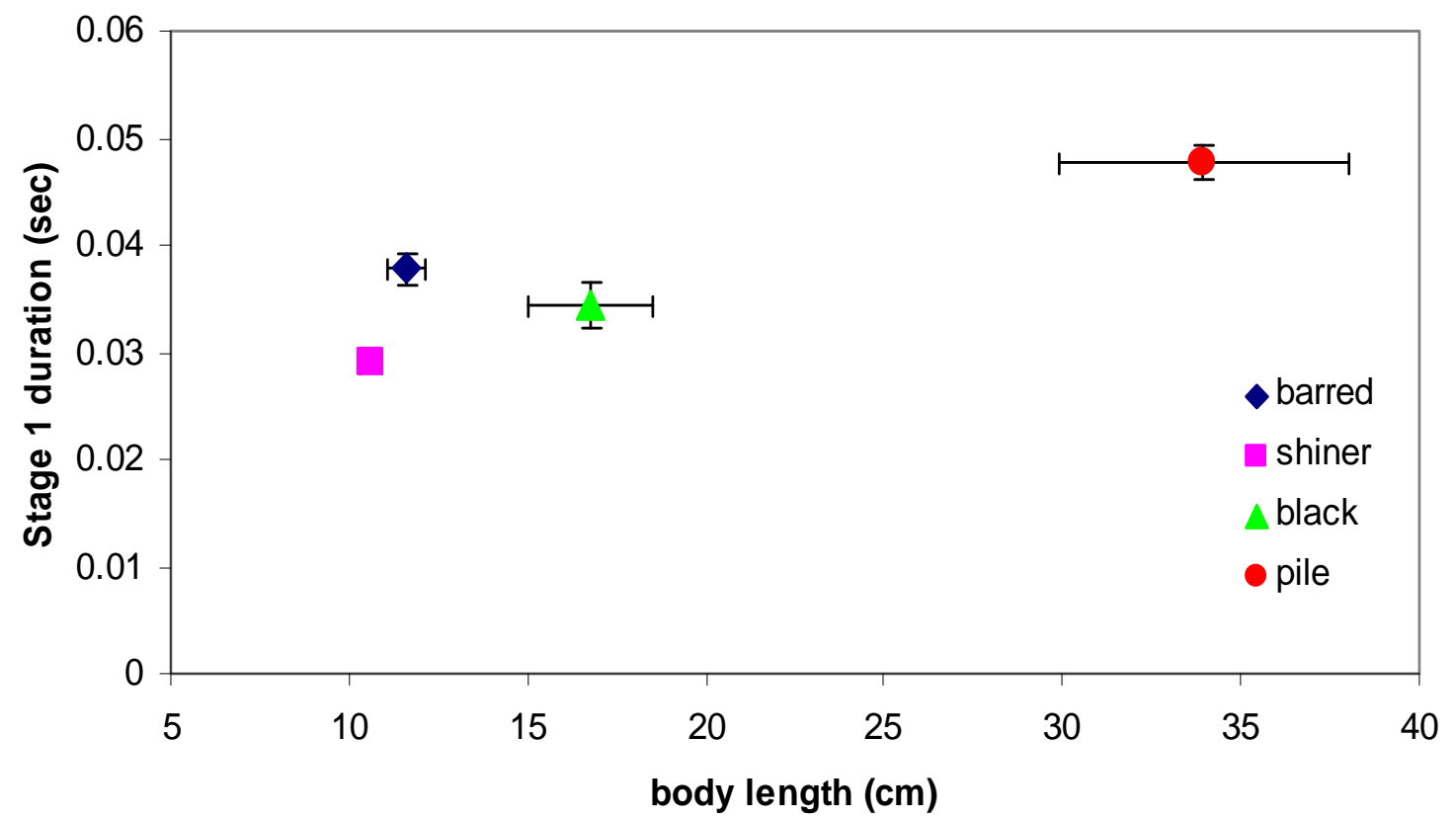

Figure C.1. Mean \pm SE stage 1 duration (sec) versus body length $(\mathrm{cm})$. Pile surfperch surfperches took the longest amount of time to complete stage 1 , whereas shiner surfperch reacted the fastest. Barred and black surfperches were not different from one another, with both achieving intermediate speeds during stage 1.

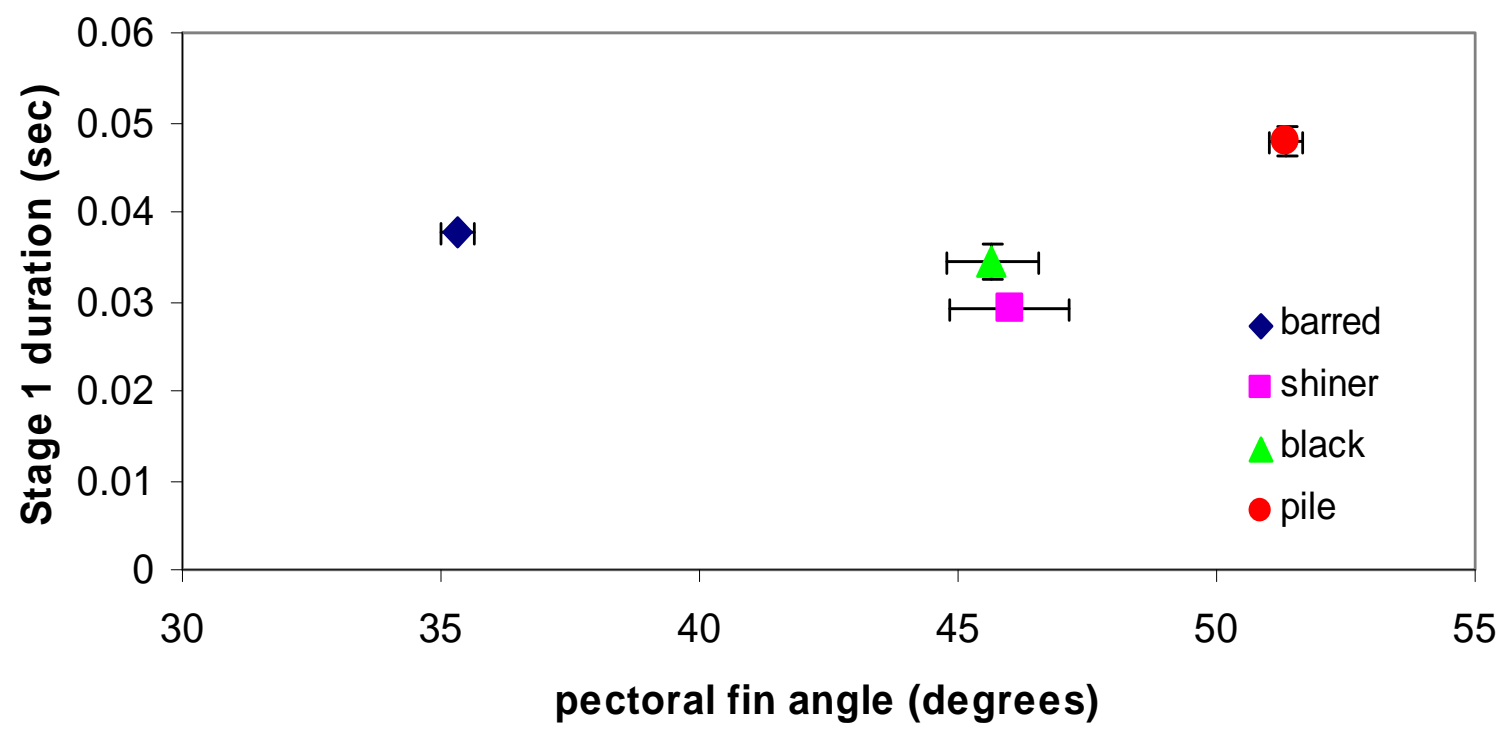

Figure C.2. Mean \pm SE stage 1 duration (sec) versus pectoral fin angle (degrees). Piles took the longest amount of time to complete stage 1, with shiners escaping in the fastest amount of time. 


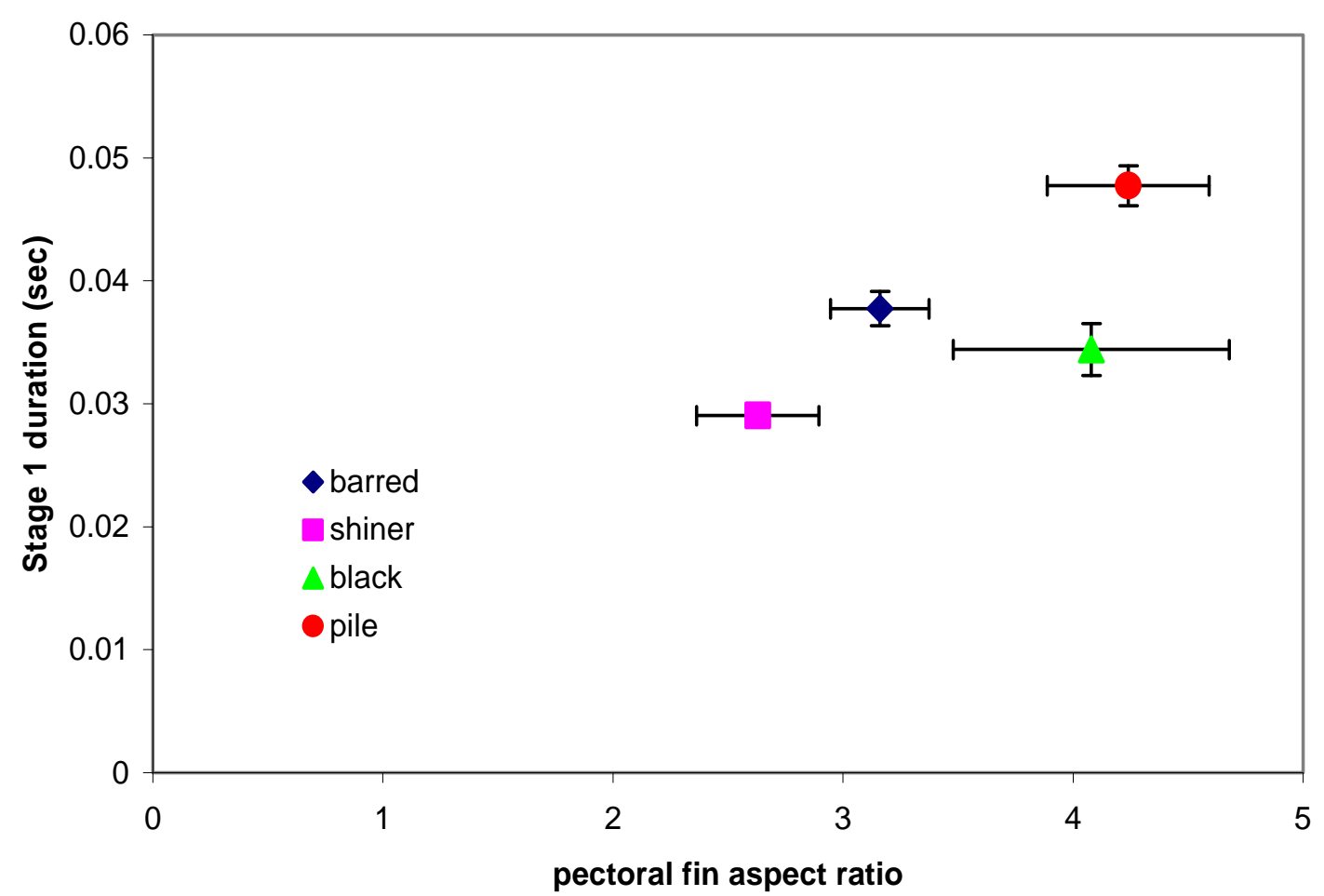

Figure C.3. Mean \pm SE stage 1 duration (sec) versus pectoral fin aspect ratio. Piles, which had the highest AR, took the longest amount of time to complete stage 1. Shiners completed stage 1 the fastest, having the lowest AR.

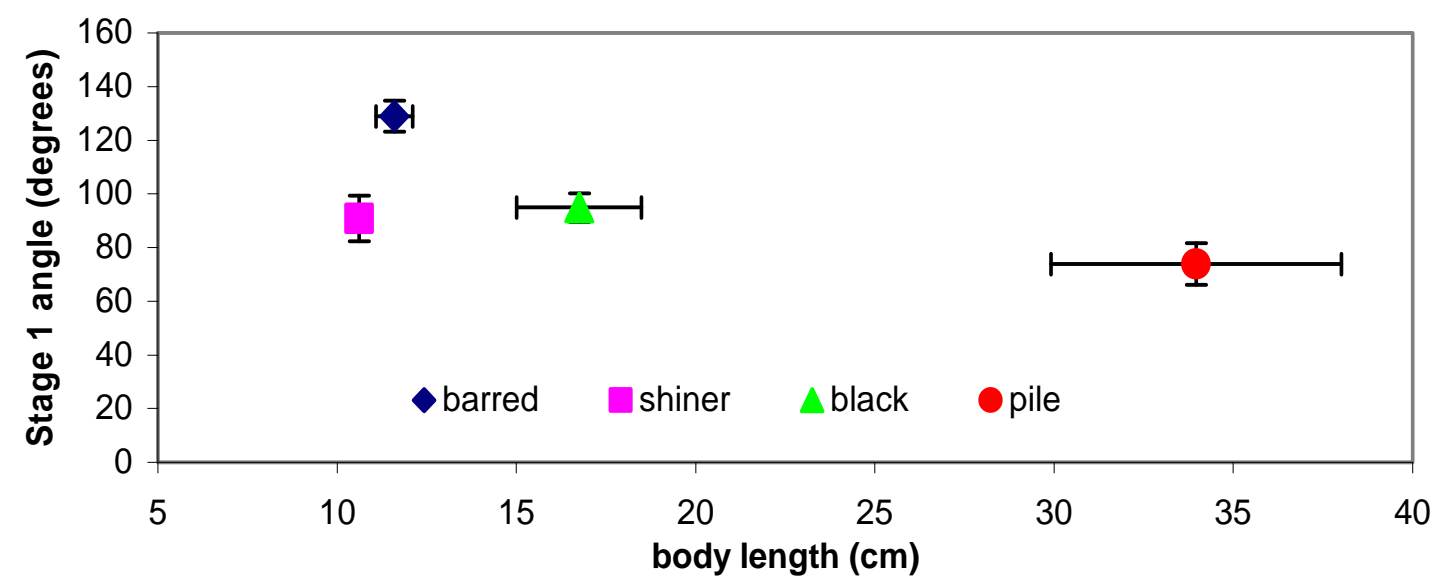

Figure C.4. Mean \pm SE stage 1 angle (degrees) versus body length $(\mathrm{cm})$. Barred surfperches had the greatest angle of body curvature, with shiners, blacks, and piles all bending at the same angle. 


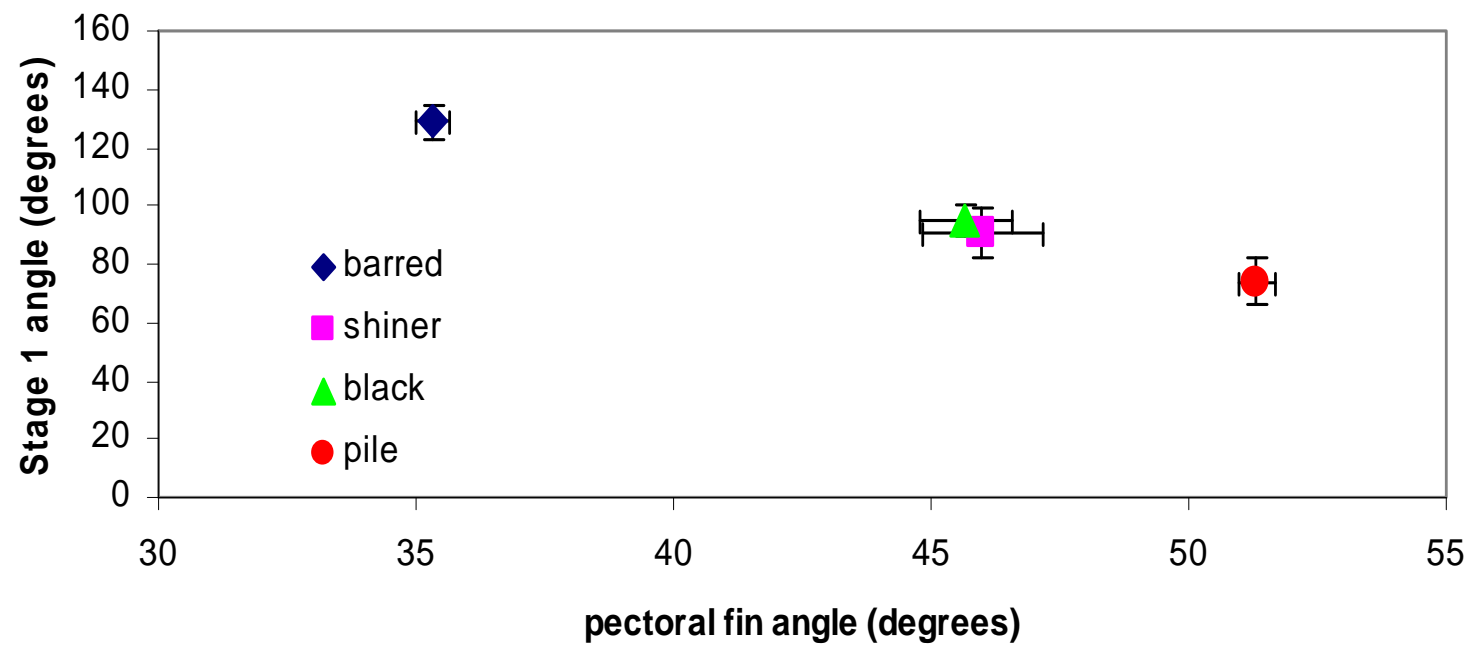

Figure C.5. Mean \pm SE stage 1 angle (degrees) versus pectoral fin angle (degrees). When organized along this gradient of fin angle, surfperches that had a lower fin angle had a greater amount of body bending, whereas surfperches with higher fin angles achieved a lower angle of bending.

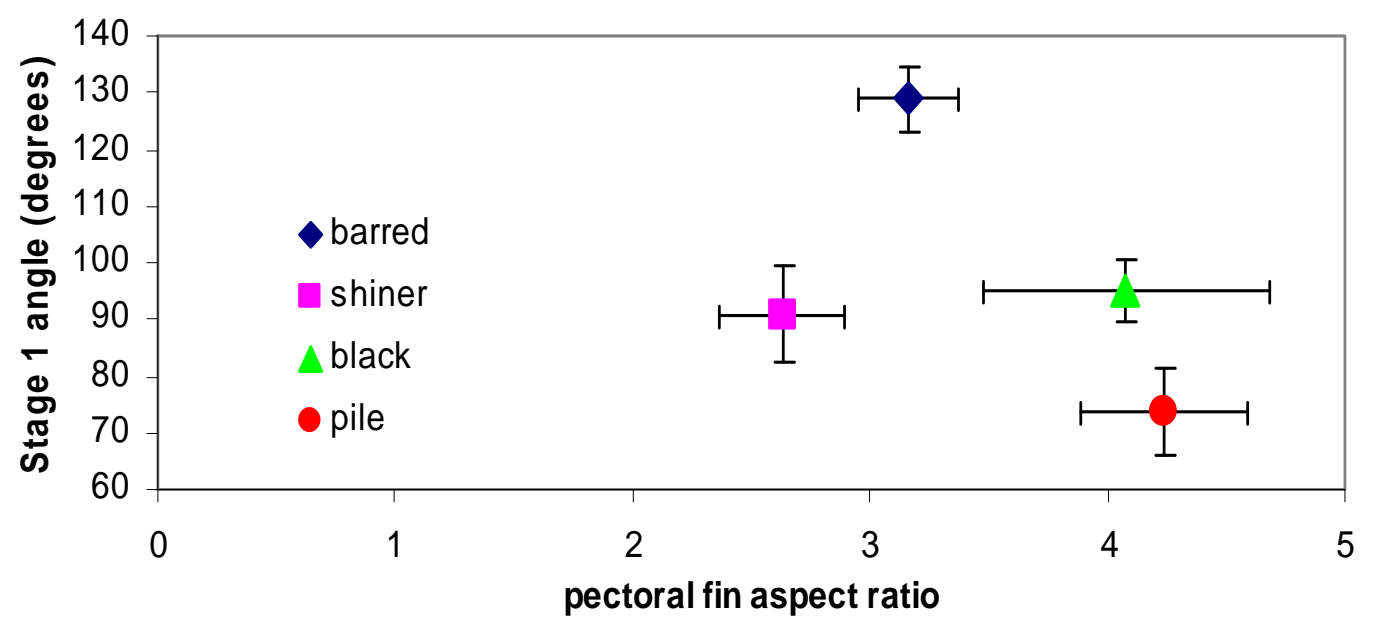

Figure C.6. Mean \pm SE stage 1 angle (degrees) versus pectoral fin aspect ratio. Piles, which had the highest AR, achieved the least amount of bending. Barred surfperches had an intermediate $A R$ and the greatest bending. 


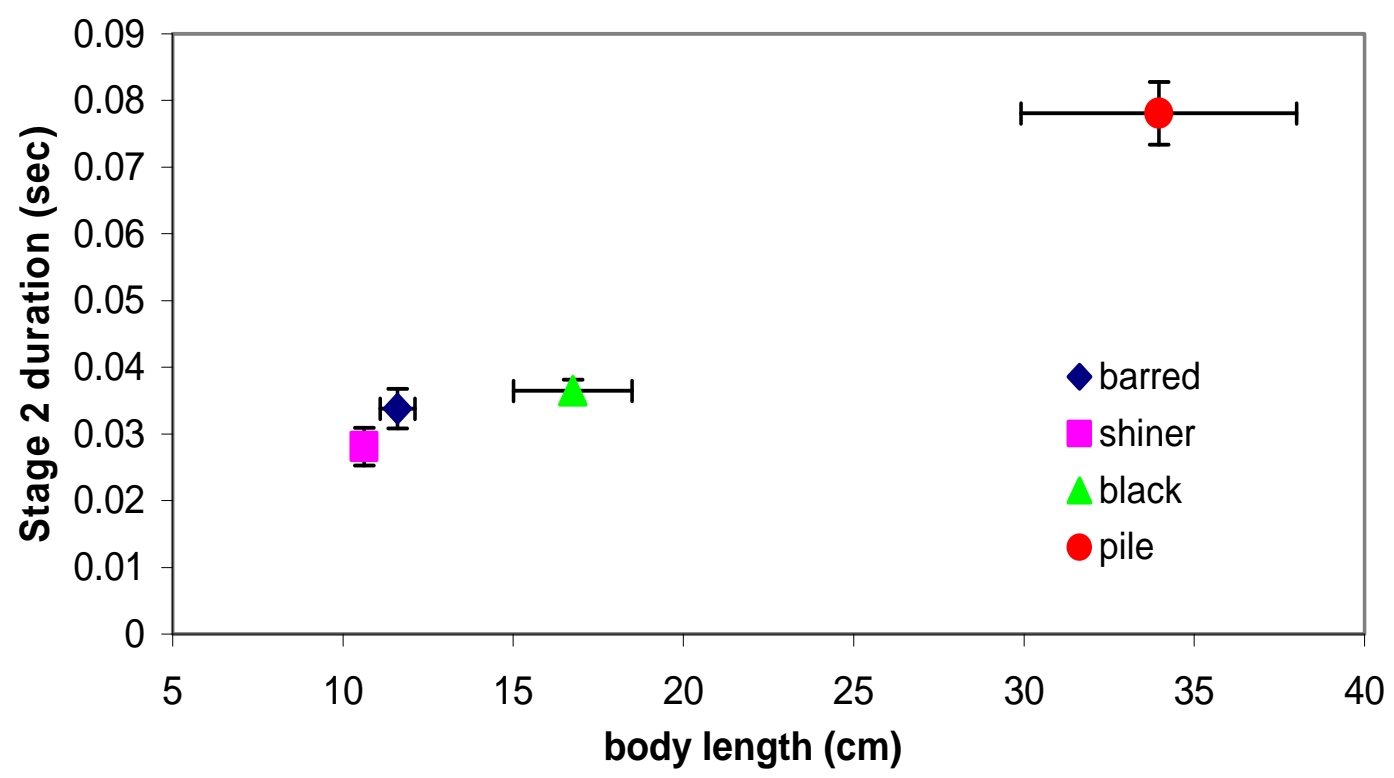

Figure C.7. Mean \pm SE stage 2 duration (sec) versus body length $(\mathrm{cm})$. The larger surfperches took a longer amount of time to complete stage 2 than the smaller surfperches.

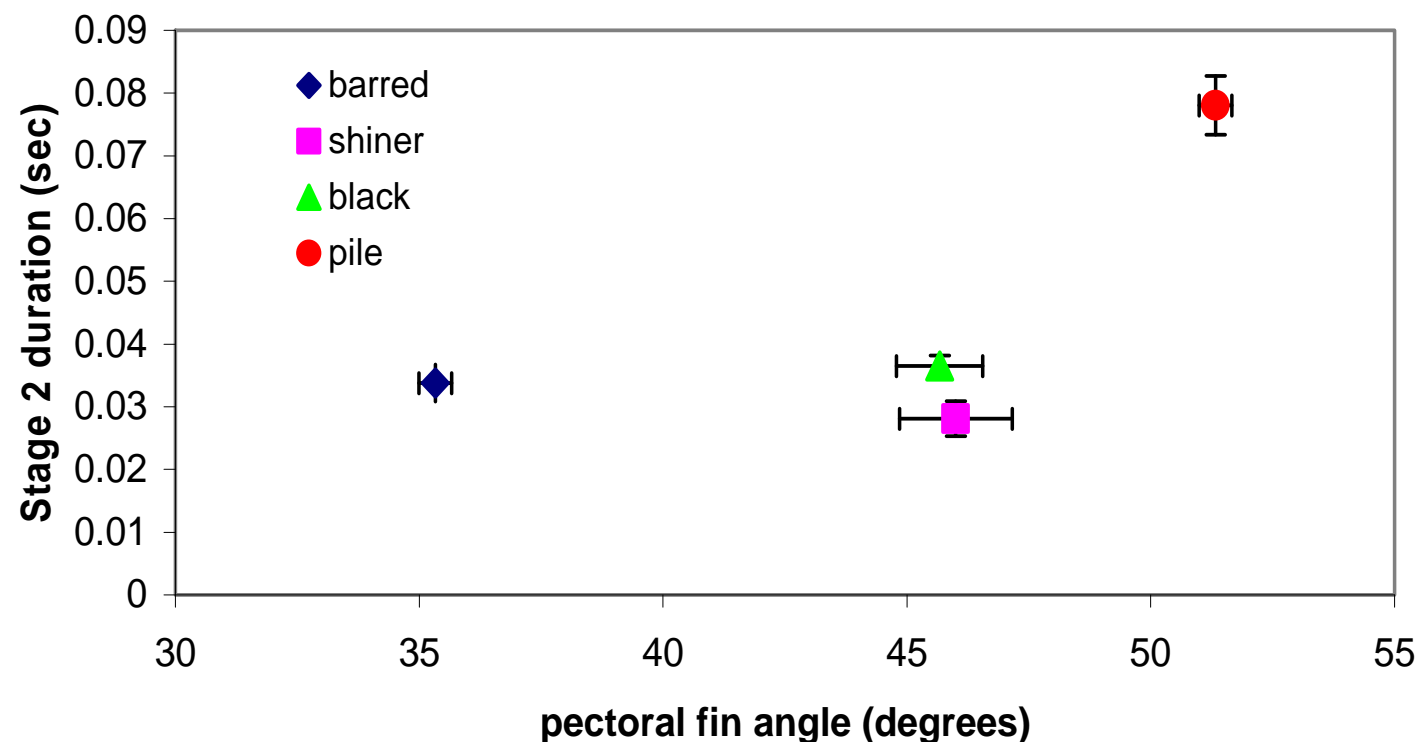

Figure C.8. Mean \pm SE stage 2 duration (sec) versus pectoral fin angle (degrees). Piles took the longest amount of time to complete stage 2, with barred, shiner, and black surfperches all taking relatively the same amount of time. 


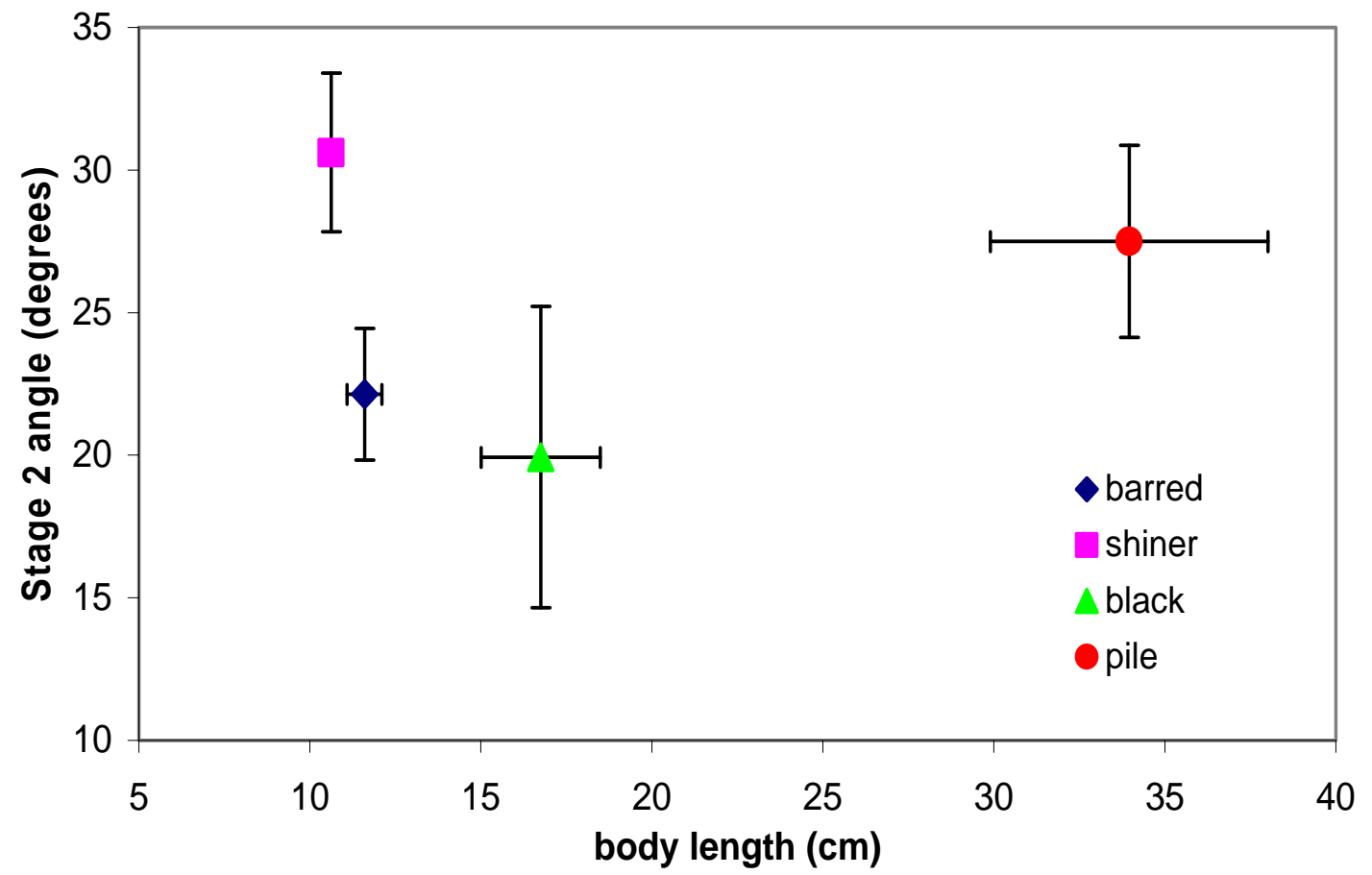

Figure C.9. Mean \pm SE stage 2 angle (degrees) versus body length $(\mathrm{cm})$. There was no trend among the four species in terms of body size and bending in stage 2. 


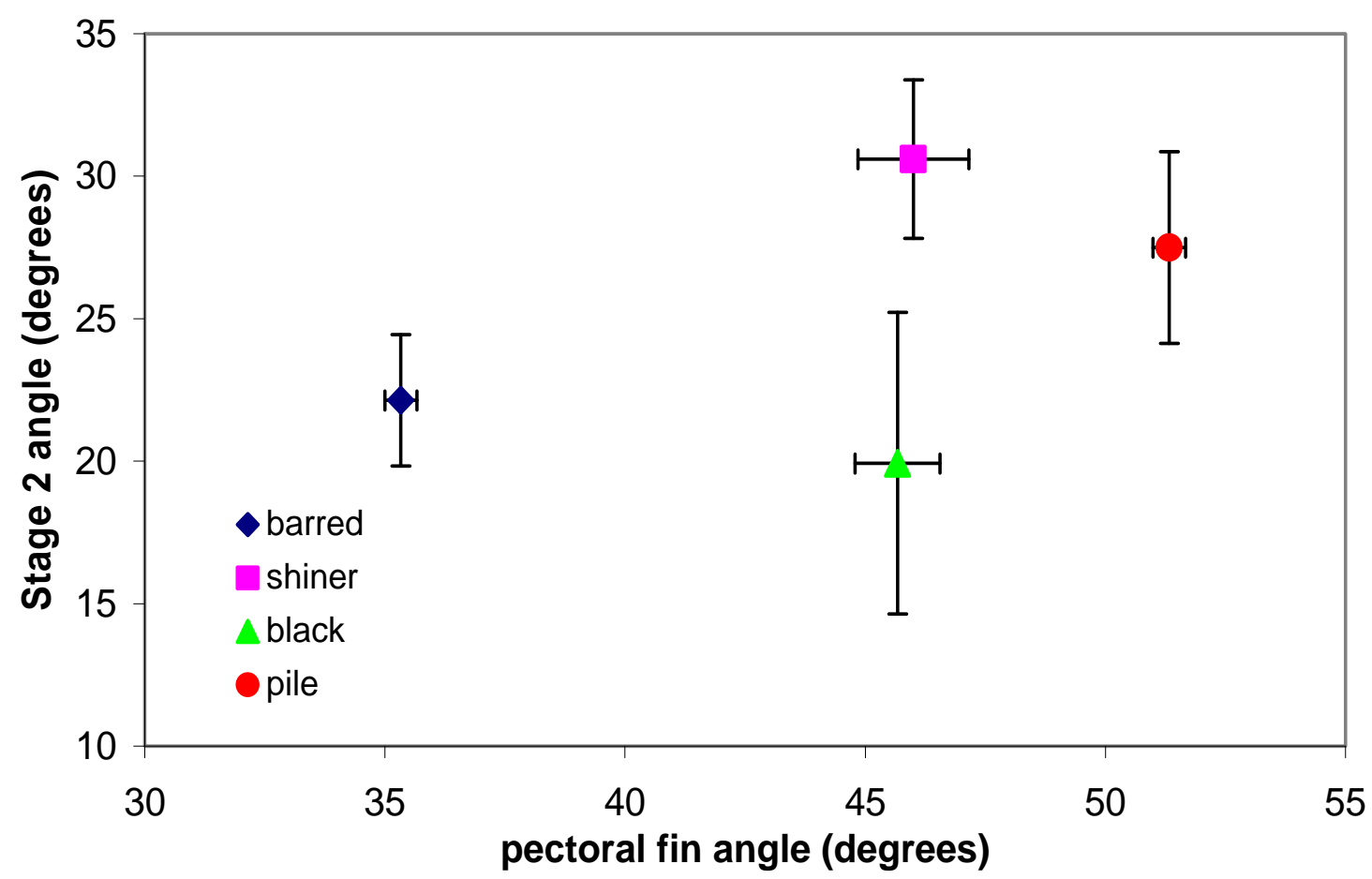

Figure C.10. Mean \pm SE stage 2 angle (degrees) versus pectoral fin angle (degrees). There is no obvious trend in body bending in stage 2 with respect to species with different angles of insertion of the pectoral fin. 


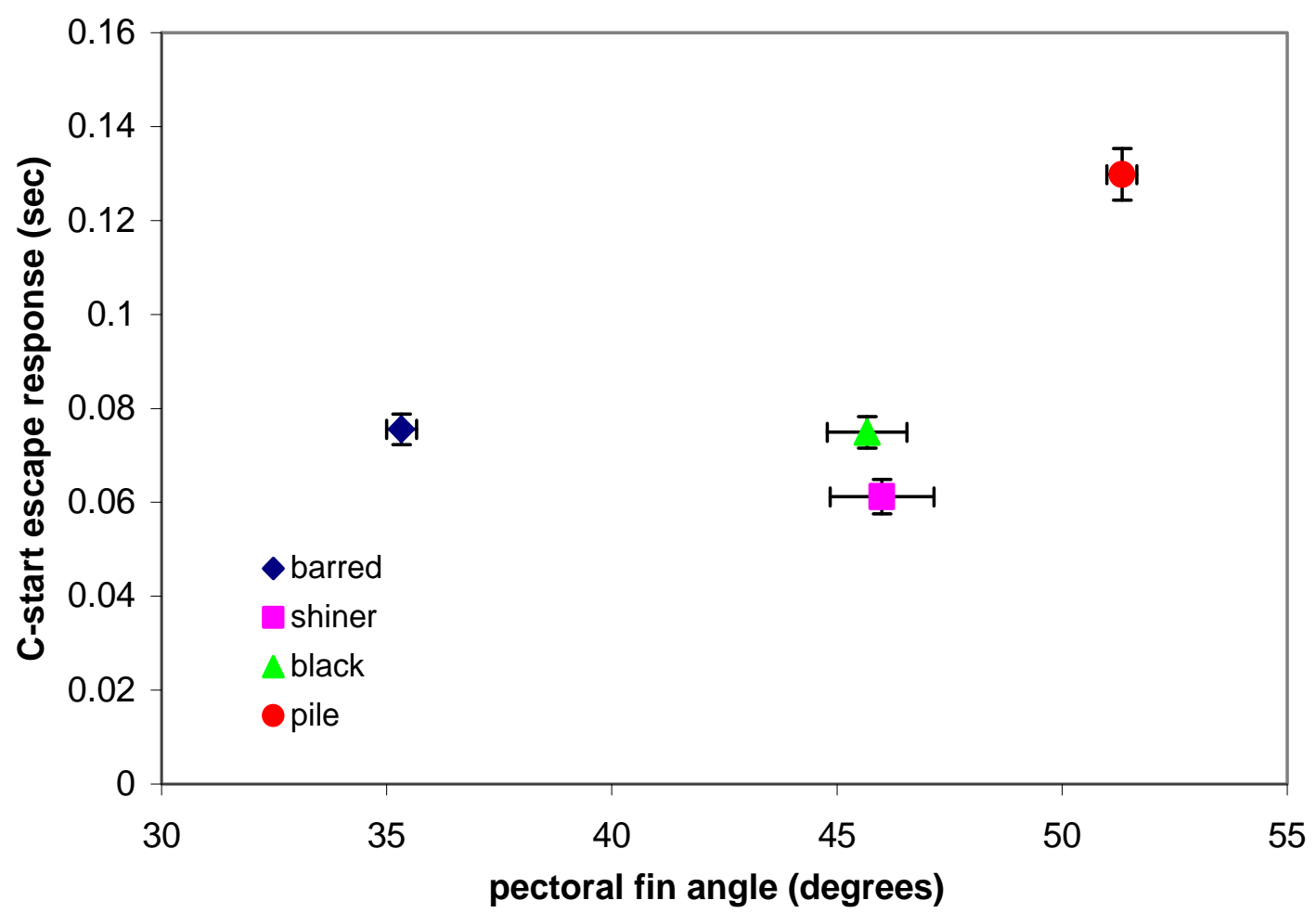

Figure C.11. Mean \pm SE C-start escape response (sec) versus pectoral fin angle (degrees). Pile surfperches, with the highest fin angle, were the slowest to escape. No difference in escape response duration occurred with barred and black surfperches. Shiners escaped in the shortest amount of time, having an intermediate angle of the pectoral fin. 


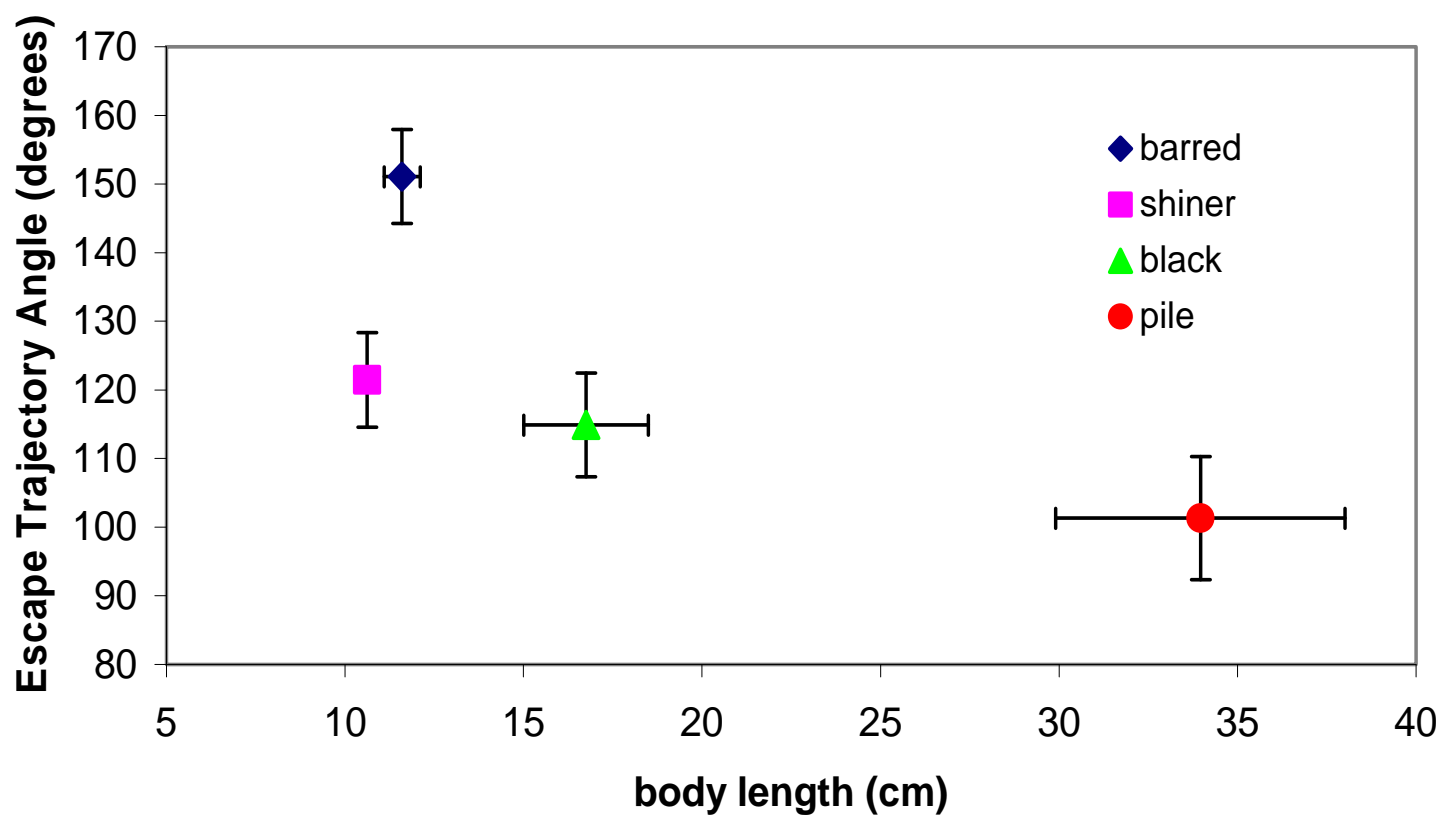

Figure C.12. Mean \pm SE Escape trajectory angle (degrees) versus body length $(\mathrm{cm})$. Barred surfperches had the greatest ETA, with shiners, blacks, and piles having the least bending during the escape response.

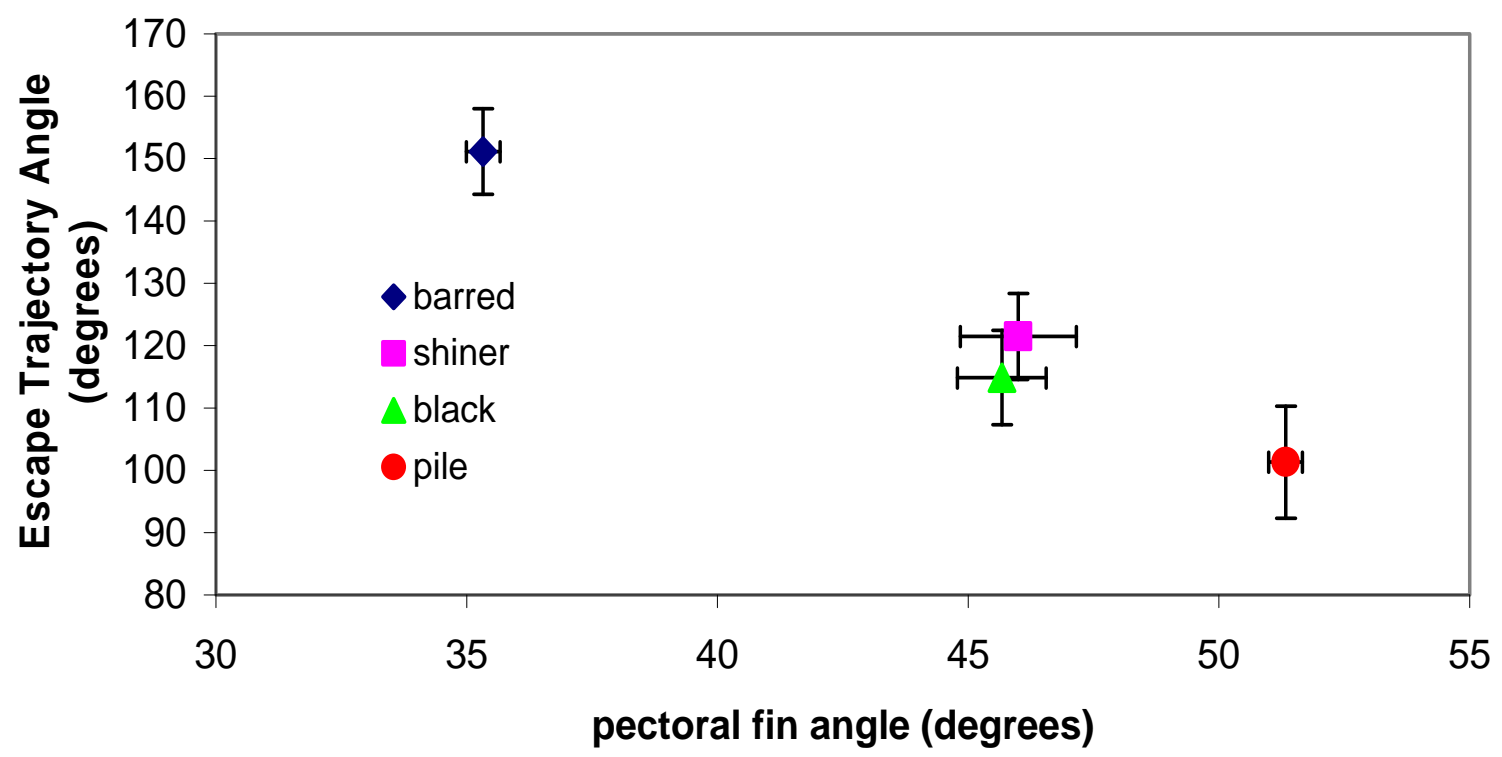

Figure C.13. Mean \pm SE Escape trajectory angle (degrees) versus pectoral fin angle (degrees). Barred surfperches, which had the lowest fin angle, achieved the greatest amount of body curvature. Piles, with the highest fin angle of insertion, had the least body curvature during the escape response. 


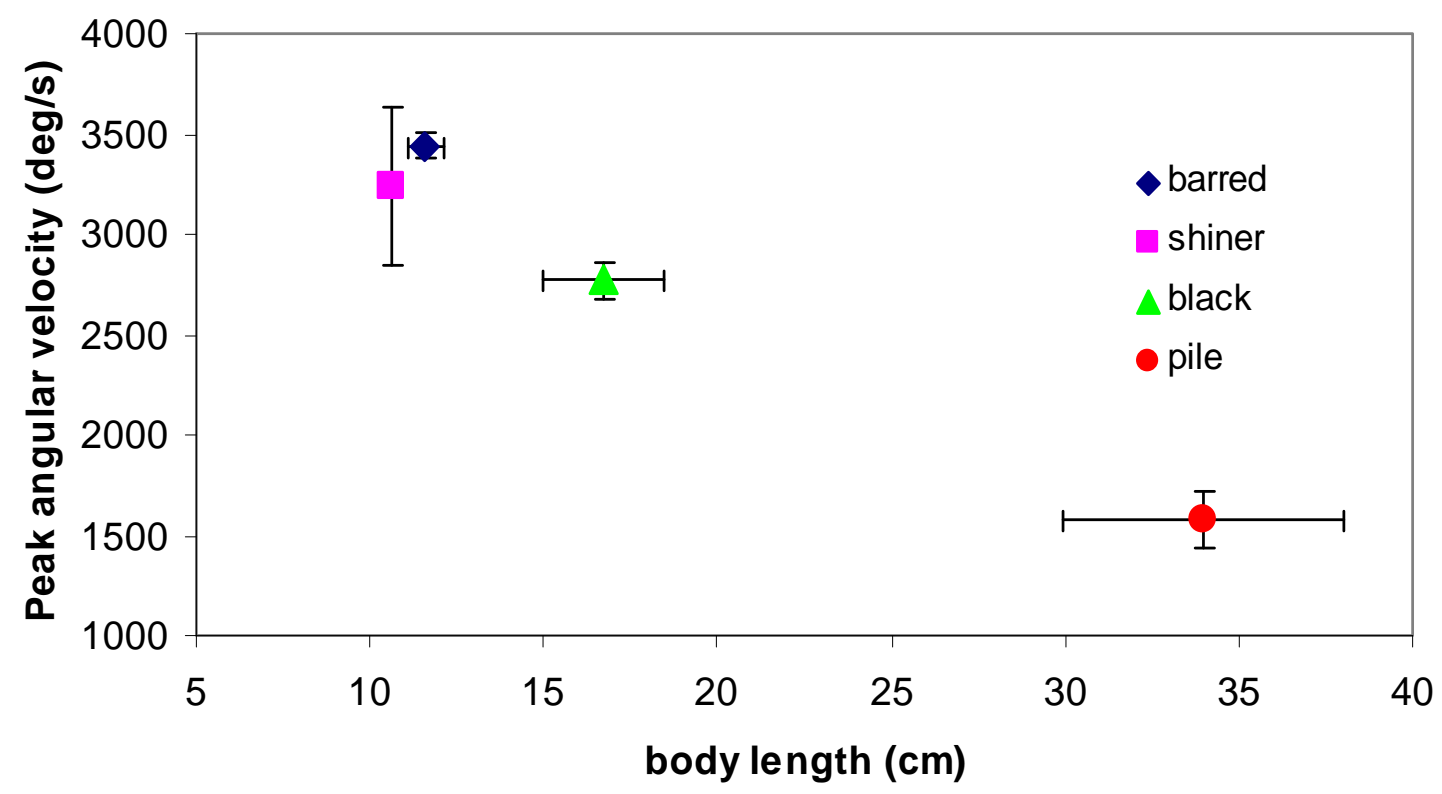

Figure C.14. Mean \pm SE peak angular velocity $(\mathrm{deg} / \mathrm{s})$ versus body length $(\mathrm{cm})$. Barred and shiner surfperches achieved the fastest peak angular velocity, followed by blacks, and then piles.

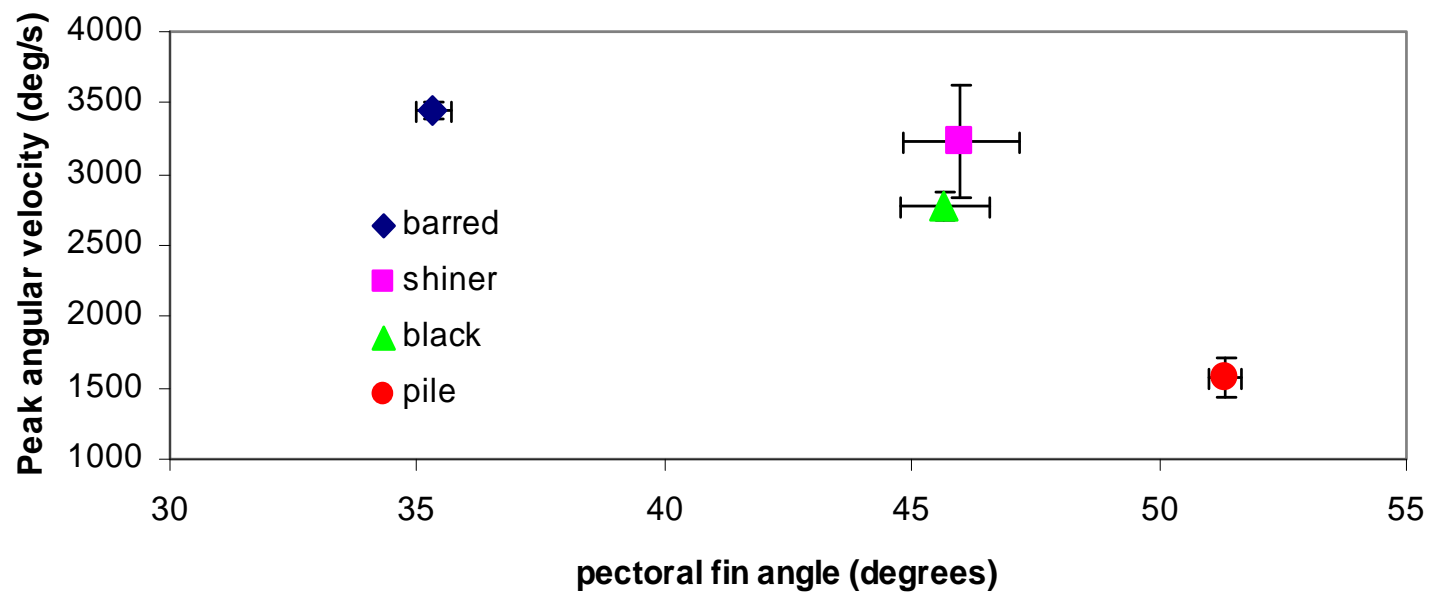

Figure C.15. Mean \pm SE peak angular velocity (deg/s) versus pectoral fin angle (degrees). Barred surfperch, with the lowest fin angle, reached the fastest peak angular velocity. Pile surfperch, with the highest fin angle, had the slowest peak angular velocity. 